Irenice de Fátima Carboni

Avaliação de qualidade e controle de defeitos de um software para registro eletrônico de dados clínicos da Unidade de Genética do Instituto da Criança da Faculdade de Medicina na Universidade de São Paulo

Tese apresentada à Faculdade de Medicina da Universidade de São Paulo para obtenção do título de doutor em Ciências

Programa Patologia

Orientador: Prof. Dr. Marcelo Nascimento Burattini

(Versão corrigida. Resolução CoPGr 6018/11, de 13 de outubro de 2011. A versão original está disponível na Biblioteca da FMUSP)

São Paulo

2019 

Irenice de Fátima Carboni

\title{
Avaliação de qualidade e controle de defeitos de um software para registro eletrônico de dados clínicos da Unidade de Genética do Instituto da Criança da Faculdade de Medicina na Universidade de São Paulo
}

Tese apresentada à Faculdade de Medicina da Universidade de São Paulo para obtenção do título de doutor em Ciências

Programa Patologia

Orientador: Prof. Dr. Marcelo Nascimento Burattini

(Versão corrigida. Resolução CoPGr 6018/11, de 13 de outubro de 2011. A versão original está disponível na Biblioteca da FMUSP)

\author{
São Paulo
}

2019 
Dados Internacionais de Catalogação na Publicação (CIP)

Preparada pela Biblioteca da

Faculdade de Medicina da Universidade de São Paulo

C)reprodução autorizada pelo autor

Carboni, Irenice de Fátima

Avaliação de qualidade e controle de defeitos de um software para registro eletrônico de dados

clínicos da Unidade de Genética do Instituto da

Criança da Faculdade de Medicina na Universidade de

são Paulo / Irenice de Fátima Carboni. -- São

Paulo, 2019.

Tese (doutorado) --Faculdade de Medicina da

Universidade de são Paulo.

Programa de Patologia.

Orientador: Marcelo Nascimento Burattini.

Descritores: 1.Registros eletrônicos de saúde 2. Análise de dados 3. Controle de qualidade 4. Confiabilidade dos dados 5.Validação de programas de computador

$\mathrm{USP} / \mathrm{FM} / \mathrm{DBD}-352 / 19$

Responsável: Erinalva da Conceição Batista, CRB-8 6755 


\section{Agradecimentos}

Agradeço ao Prof. Dr. Marcelo Nascimento Burattini, pela paciência e persistência na orientação, durante o decorrer desses anos.

Agradeço a Dra. Chong Ae Kim e equipe da Genética, sendo que, sem a ajuda deles, tanto o PEG-software, como este trabalho não seriam possíveis.

Agradeço a Francisco Costa Neto e equipe do TIS pela colaboração e possibilidade do desenvolvimento do PEG-software.

Agradeço a minha família como um todo, nos momentos em que não estive presente e pelo incentivo para o término deste.

Agradeço a Deus Pai, ao Filho e ao Espírito Santo, que me fortalecem todos os dias, para seguir em frente. 



\section{Lista de abreviaturas e siglas}

ABNT - Associação Brasileira de Normas Técnicas

ATS - Avaliação de Tecnologias em Saúde

CAPPesq - Comissão de Ética para Análise de Projetos de Pesquisa

CCTI - Conselho de Ciência, Tecnologia e Inovação em Saúde do Ministério da

Saúde

CFM - Conselho Federal de Medicina

CID10 - Código Internacional de Doença

CNS - Conselho Nacional de Saúde

DECIT - Departamento de Ciência e Tecnologia

DT - Número de defeitos válidos relatados em um período de tempo

ENSP Escola Nacional de Saúde Pública Arouca

FIOCRUZ - Fundação Oswaldo Cruz

FMEA - Failure Mode and Effect Analysis

FMUSP - Faculdade de Medicina da Universidade de São Paulo

GB - Gigabyte

$\mathrm{GHz}$ - GigaHertz

HITECH - Health Information Technology for Economic and Clinical Health

IBM - International Business Machines

$\mathrm{ICr}$ - Instituto da Criança

ICr-HCFMUSP - Instituto da Criança do Hospital das Clínicas da Faculdade de Medicina da Universidade de São Paulo

IEC - International Electrotechnical Commission

IS - Indicador de Satisfação

ISO - International Organization for Standardization

KSLoC - Kilo Source Line of Code

MB - Megabyte 
MS - Ministério da Saúde

NBR - Norma Brasileira

NLoc - Número de linhas de código

ODC - Orthogonal Defect Classification

ONC - Office of the National Coordinator for Health Information Technology

PEG-software - Prontuário Eletrônico da Genética

RAM - Random Access Memory

REBRATS - Rede Brasileira de Avaliação de Tecnologias em Saúde

REFORSUS - Reforço à Reorganização do sistema Único de Saúde

RES - Registro Eletrônico de Saúde

RG - Registro Geral

SAME - Serviço de Atendimento Médico e Estatística

SBIS - Sociedade Brasileira de Informática em Saúde.

SCTIE - Secretaria de Ciência, Tecnologia e Insumos Estratégicos

SIGMA - eDoc - Evolução médica e multiprofissional

SIGMA - Sistema Integrado de Gestão Médico Hospitalar

SQuaRe - Software Quality Requiriments and Evaluation

ST - Número de respostas satisfatórias por período de tempo

SUS - Sistema Único de Saúde

TD - Taxa de Defeitos

TIC - Tecnologias da Informação e Comunicação

TIS - Tecnologia da Informação em Saúde

TT - Total de respostas durante o período de tempo

TR - Relatório Técnico

TS - Technical specification

UCINE - Unidade de Cuidados Intensivos Neonatal

UERJ - Universidade Estadual do Rio de Janeiro

UFBA - Universidade Federal da Bahia

UFRGS - Universidade Federal do Rio Grande do Sul

UG - Unidade de Genética do ICr-HCFMUSP 
UNIFESP - Universidade Federal de São Paulo

USP - Universidade de São Paulo

UT - Usuários em um determinado intervalo de tempo

UTI - Unidade de Terapia Intensiva 


\section{Lista de figuras}

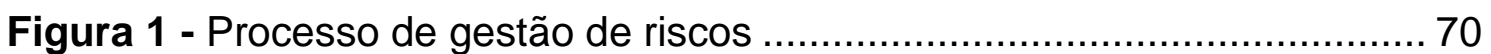




\section{Lista de quadros}

Quadro 1 - Relação de Sistemas do ICr-HCFMUSP - Externos e Internos posição em 2013

Quadro 2 - Relacionamento entre as séries ISO/IEC 9126 e ISO/IEC 14598 e a série de normas SQuaRe

Quadro 3 - Atividade de remoção de defeitos, gatilhos e impacto na abertura do defeito.

Quadro 4 - Definição de características e subcaracterísticas com as respectivas questões para avaliação

Quadro 5 - Gatilhos da Orthogonal Defect Classification (ODC)

Quadro 6 - Classificação dos Defeitos do PEG-software quanto à Severidade

Quadro 7 - Classificação dos Defeitos quanto à Probabilidade de Ocorrência 93

Quadro 8 - Matriz de Risco - Severidade e Probabilidade de Ocorrência 94 


\section{Lista de tabelas}

Tabela 1 - Caracterização dos usuários do PEG-software nas Fases 1 a 6 .... 97

Tabela 2 - Distribuição das frequências absolutas e relativas [N (\%)] das avaliações dos usuários do PEG-software para cada uma das características avaliadas, nas Fases 1 a 6 99

Tabela 3 - Distribuição dos índice de satisfação [ST/TT(\%)] das variáveis explicativas da qualidade para cada uma das características avaliadas, do PEG-software, nas Fases 1 a 6 100

Tabela 4 - Número de defeitos apontados (do PEG-software e Externos que afetam o PEG-software), Total de Defeitos Válidos, Não Defeitos, Alterações e/ou Novos Requisitos marcados como defeitos e Sugestões de Melhoria nas Fases 1 a 6 . 102

Tabela 5 - Total de Defeitos Válidos, Total de Linhas de Código e Indicador de defeitos KSLoc das Fases 1 a 6 102

Tabela 6 - Número de Usuários, Classificação dos defeitos do PEG-software e Externos que afetam o PEG-software, nível de severidade, Total de Defeitos, KSLoc e TD nas fases 1 a 6 103

Tabela 7 - Densidade de Defeitos, incidência ODC, incidência de Riscos dos Defeitos nas Fases 1 a 6 104 


\section{Resumo}

Carboni IF. Avaliação de qualidade e controle de defeitos de um software para registro eletrônico de dados clínicos da Unidade de Genética do Instituto da Criança da Faculdade de Medicina na Universidade de São Paulo [tese]. São Paulo: Faculdade de Medicina, Universidade de São Paulo; 2019.

Objetivos: Descrever a avaliação de RES em uma clínica genética, para sistematizar e melhorar o serviço, aperfeiçoar a recuperação de informações, satisfazer as necessidades de pesquisas científicas, atender às expectativas dos usuários e da qualidade organizacional, e controlar e classificar os defeitos para não comprometer o atendimento da assistência à saúde. Métodos: Os usuários responderam a um questionário avaliando funcionalidade, usabilidade, confiabilidade e qualidade do serviço prestado, além da computação em Taxa de Defeitos (DR) e KSLOC, a cada seis meses, de abril de 2015 a outubro de 2017. No mesmo período foi introduzido o método Análise de Modo e do Efeito de Falhas (FMEA) para priorizar a correção dos defeitos usando matriz de risco (crítico, elevado, moderado, leve). Resultados: DR (8,5 - 0,25 defeitos / usuário) e KSLOC (2,6 - 0,08 defeitos / 1.000 linhas de código) caíram de forma consistente. Serviço, funcionalidade e usabilidade classificados positivamente para $80 \%-90 \%, 81 \%-94 \%$ e $81 \%$ - $93 \%$ dos entrevistados, respectivamente. A positividade da confiabilidade foi menor $(21 \%-72 \%)$, mas aumentou ao longo do período de avaliação. O FMEA possibilitou a correção dos defeitos em ordem de risco, priorizando os mais urgentes. Conclusões: $O$ RES apresentou poucos defeitos, recebendo avaliações positivas de serviço, funcionalidade e usabilidade. As avaliações de confiabilidade permaneceram baixas, mas aumentaram com o tempo. A Unidade Genética de Pediatria incorporou o RES nos cuidados de rotina, onde ainda está em uso, apresentando baixas e melhorando as taxas gerais de defeitos. O uso do FMEA para controle e priorização dos defeitos se mostrou eficaz.

Descritores: Registros eletrônicos de saúde; Análise de dados; Controle de qualidade; Confiabilidade dos dados; Validação de programas de computador. 


\section{Abstract}

Carboni IF. Quality assessment and defect control of a software for electronic clinical data recording of the Genetics Unit of the Children's Institute, School of Medicine in University of São Paulo [thesis]. São Paulo: "Faculdade de Medicina, Universidade de São Paulo"; 2019.

Objectives: Describe an EHR evaluation in a genetic clinic, to systematize and improve service, optimize information retrieving, satisfy scientific research needs and meet users and organizational quality expectations and control and classify defects so as not to compromise health care delivery. Methods: Users answered a questionnaire assessing functionality, usability, reliability and quality of provided service, besides Defect Rate (DR) and KSLOC computation, every six months from April-2015 to October-2017. In the same period, the Failure Mode and Effect Analysis (FMEA) method was introduced to prioritize the correction of defects used risk matrix (critical, high, moderate, mild). Results: DR (8.5 - 0.25 defects/user) and KSLOC (2.6 - 0.08 defects/1,000 code lines) dropped consistently. Service, functionality and usability rated positively to $80 \%-90 \%, 81 \%-94 \%$ and $81 \%-93 \%$ of respondents respectively. Reliability positivity were lower $(21 \%-72 \%)$, but increased throughout the evaluation period. The FMEA enabled the correction of defects in order of risk, prioritizing the most urgent. Conclusions: EHR presented few defects, receiving positive evaluations for service, functionality and usability. Reliability evaluations remained low, but increased with time. Pediatrics Genetic Unit incorporated the EHR in routine care, where it is still in use, presenting low and improving overall defect rates. The use of FMEA for defect control and prioritization proved effective.

Descriptors: Electronic health records; Data analysis; Quality control; Data reliability; Validation of computer programs. 


\section{Sumário}

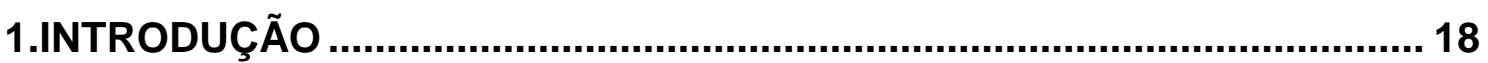

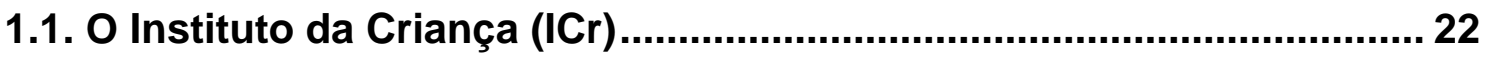

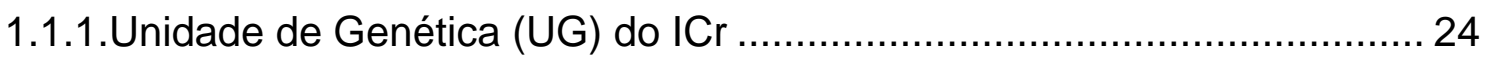

1.1.2. O Software da Unidade de Genética do ICr ......................................... 28

2. AVALIAÇÃO DE QUALIDADE DE SOFTWARE .......................................38

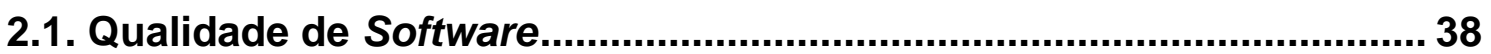

2.1.1. Padrão de Qualidade de Software - ISO/IEC ....................................... 40

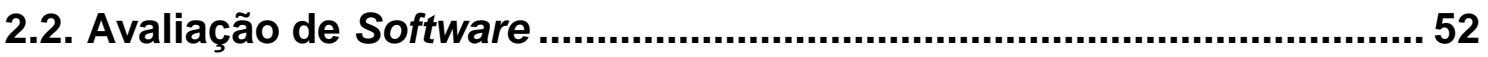

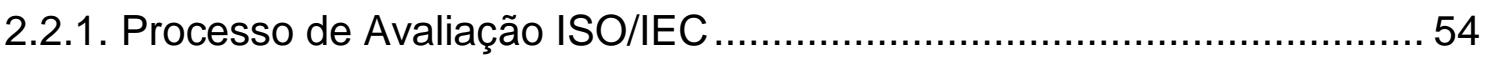

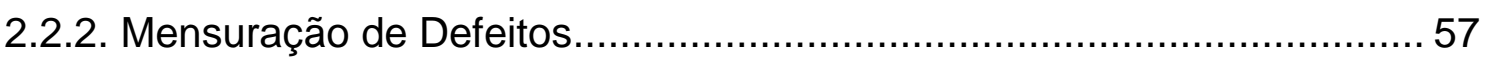

2.2.3. Avaliação de Tecnologias em Saúde (ATS) ….................................... 60

3.GESTÃO DE RISCO

3.1. Orthogonal Defect Classification (ODC) ................................................ 71

3.2. Failure Mode and Effect Analysis (FMEA) .......................................... 76

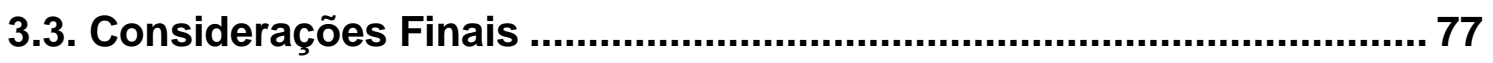

4.OBJETIVOS

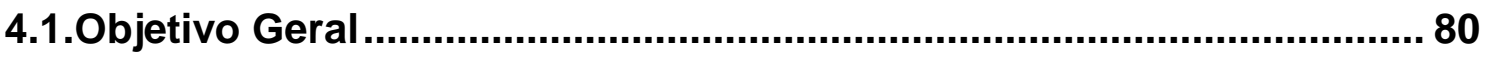


5.METODOLOGIA

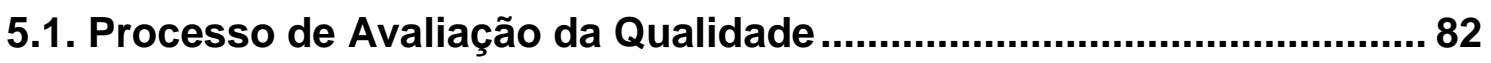

5.1.1. Avaliação ISO/IEC 25010 e suas antecessoras .................................. 83

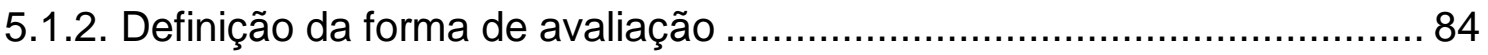

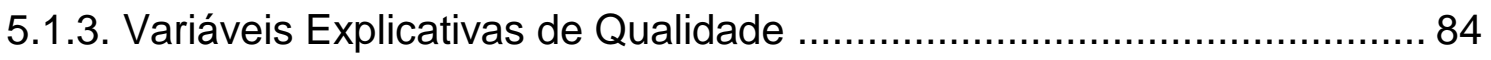

5.1.4. Definição de Indicador de Satisfação (IS) …………………….......... 87

5.2. Mensurando os Defeitos do Software ................................................. 88

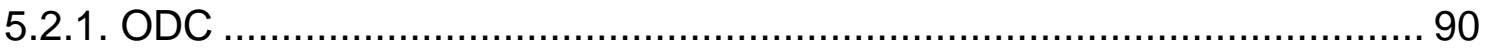

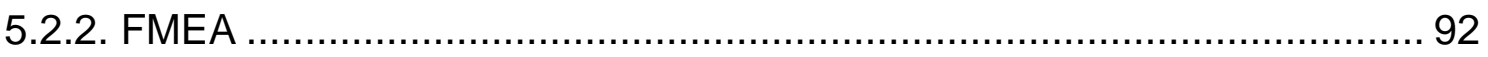

5.2.3. Classificação de Defeitos (Severidade, Ocorrência e Risco) ................. 92

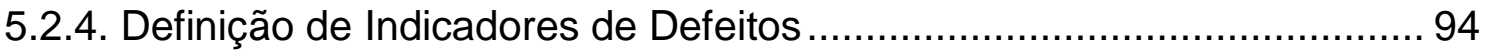

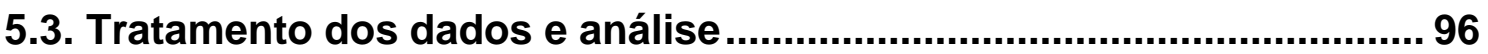

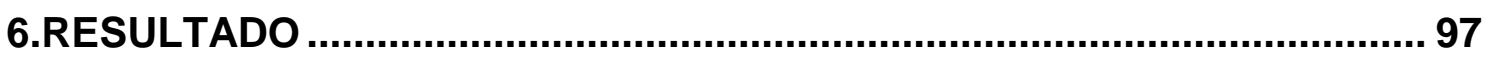

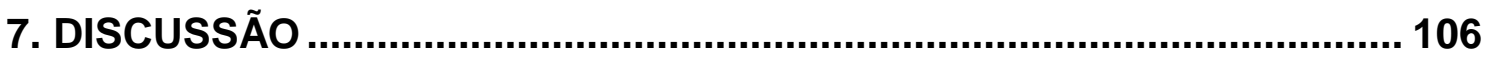

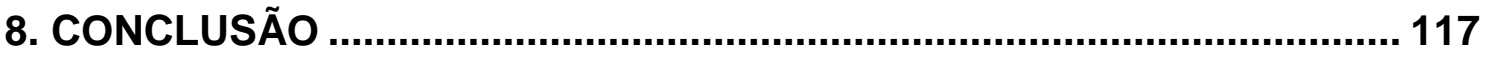

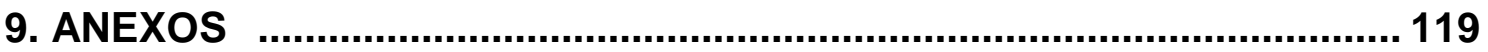

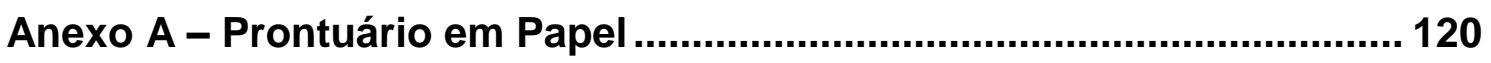

Anexo B - Requisitos Funcionais e Não Funcionais ............................... 124 
Anexo C - Imagens do PEG-software ….............................................. 130

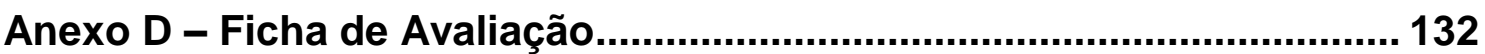

Anexo E - Ficha de Detecção de Defeitos …........................................... 135

Anexo F - FMEA - Controle de Defeitos ............................................... 138

Anexo G - Solicitação de Alterações e Melhorias.................................... 145

Anexo H - Tabelas Suplementares..................................................... 148

10. REFERÊNCIAS 


\section{INTRODUÇÃO}

A genética médica está mostrando um desenvolvimento surpreendente e permeia todo o campo da medicina. Trata de doenças cuja relevância para a saúde pública cresceu com intensidade nas últimas décadas. Além das doenças genéticas, o geneticista também atende a vários defeitos congênitos constituídos por anomalias do desenvolvimento funcional e/ou estrutural do feto (Kim et al, 2010).

O Instituto da Criança (ICr) do Hospital das Clínicas da Faculdade de Medicina da Universidade de São Paulo (ICr-HCFMUSP) é um dos maiores serviços dedicados ao atendimento de crianças e adolescentes no Brasil. Tem diferentes especialidades médicas que fornecem atendimento terciário de alta complexidade (ICr, 2017a). A Unidade de Genética do ICr-HCFMUSP (UG) atende crianças e adolescentes com diferentes doenças genéticas. Esses pacientes são referenciados não apenas de outros serviços médicos do Instituto da Criança, mas também de todo o complexo do Hospital das Clínicas, bem como de outros serviços de saúde do estado de São Paulo e de outros estados do Brasil (ICr, 2017b) .

O aumento do atendimento da genética clínica em unidades de referência estimulou o desenvolvimento de ferramentas que garantam uma maior organização e racionalização do uso de dados médicos cada vez mais 
complexos (Horovitz et al, 2006). O desenvolvimento de softwares de Registro Eletrônico de Saúde (RES) está aumentando, substituindo os registros médicos escritos à mão e contribuindo para otimizar a assistência clínica e a pesquisa. Eles ajudam a um melhor atendimento, uma maior integração operacional e uma definição mais rápida do diagnóstico final (Marin et al, 2003). Nesse sentido foi criado um software para repositório eletrônico dos dados clínicos dos pacientes para a UG do ICr-HCFMUSP, chamado Prontuário Eletrônico da Genética (PEG-software).

O objetivo primário do RES é disponibilizar um registro documentado que apoie a continuidade, eficiência e qualidade da assistência integral em saúde presente e futura. Fornecendo um meio de comunicação entre os clínicos que contribuem para a assistência ao paciente, de maneira que o registro possa ser compartilhado, mediante autorização, entre membros de uma equipe de assistência multidisciplinar (ABNT, 2008a; ABNT, 2013).

Por outro lado, o mercado de software é cada vez mais exigente em qualidade e gerenciamento de informações, a fim de garantir o alto nível de desempenho exigido na assistência à saúde (Grady, 1992; ISO/IEC 25010, 2011). Uma definição de qualidade de software pode ser sua capacidade de satisfazer requisitos explícitos e implícitos quando em uso, em condições especificadas (ABNT, 2008b). 
A qualidade do software deve ser garantida pelo uso e/ou criação de métricas, por um processo de adaptação de software, mesmo depois de seu uso ser liberado para o usuário final, além de um sistema de detecção de defeitos; para que correções e melhorias possam ser feitas continuamente (Grady, 1992; Pressman, 2011; Wazlawick, 2013). Mesmo que o software atenda aos requisitos iniciais solicitados, é importante que o usuário esteja satisfeito, pois sua opinião pode afetar o julgamento do valor e da qualidade do software desenvolvido (Sommerville, 2007; Pressman, 2011).

A medição, avaliação e modificação contínuas são ferramentas intrínsecas do processo de gestão da qualidade. Portanto, uma métrica conveniente para considerar defeitos e correções necessárias deve estar em vigor para otimizar o processo de desenvolvimento, garantindo a melhor qualidade possível. Nesse sentido, a aplicação de métodos de medição específicos permite a quantificação e categorização das propriedades de qualidade relacionadas ao software em suas características e/ou subcaracterísticas (ABNT, 2008b).

A International Organization for Standardization (ISO) - Organização Internacional de Normalização e a International Electrotechnical Commission (IEC) - Comissão Eletrotécnica Internacional formam o sistema especializado de normalização mundial, participando no desenvolvimento de normas internacionais através de comissões técnicas (ISO/IEC 25010, 2011). Com relação à qualidade de engenharia de software, a ISO/IEC emitiu várias normas 
para servir como padrões internacionais para avaliação da qualidade de software. As características de qualidade do produto de software são adequação funcional (funcionalidade), eficiência de desempenho, compatibilidade, usabilidade, confiabilidade, segurança, manutenibilidade e portabilidade. Essas características estão descritas na ISO/IEC 25010, da família de normas Software Quality Requiriments and Evaluation (SQuaRe), que substituiu a ISO/IEC 9126 e 14598 (ABNT, 2003; ABNT, 2008b; ISO/IEC 25010, 2011).

O presente estudo descreve o processo de avaliação de qualidade do PEG-software, baseado principalmente na ISO/IEC 25010 e suas antecessoras; tem o objetivo ainda de descrever o processo de levantamento e classificação de defeitos usado para o PEG-software, e após a análise de defeitos, mostrar qual foi a prioridade na resolução dos defeitos encontrados através de uma matriz de risco. Em acréscimo, a partir dos defeitos levantados, calcular dois indicadores formais de qualidade de software, a taxa de defeitos (TD) e a taxa de defeitos por mil linhas de código - Kilo Source Line Code (KSLoC), para acompanhar ao longo da avaliação a progressão da confiabilidade, fazendo assim os ajustes necessários. Justificamos o presente estudo pela necessidade de avaliar e melhorar a qualidade do PEG-software, incluindo a opinião dos usuários, garantindo um melhor desempenho no atendimento médico e pesquisas da UG. 


\subsection{O Instituto da Criança (ICr)}

O ICr-HCFMUSP é um dos maiores expoentes no cuidado de crianças e adolescentes, de 0 a 19 anos. Tem como missão "prestar assistência de alta complexidade e de excelência ao recém-nascido, criança e adolescente, por meio de atendimento humanizado e interdisciplinar, integrado ao ensino e à pesquisa". É reconhecido pelo Ministério da Saúde como "Centro de Referência Nacional de Saúde da Criança" e conta com 21 especialidades médicas, que prestam um atendimento de alta complexidade (ICr, 2017a).

Possui no Pronto-Socorro uma capacidade de 17 leitos, Unidade de Terapia Intensiva (UTI) Pediátrica com 20 leitos, Hospital-dia com 10 leitos, Especialidades II - internação com 13 apartamentos, a Unidade de Cuidados Intensivos Neonatal (UCINE) com 20 leitos e salas de endoscopia, possui ainda enfermaria de Especialidades I com 31 leitos, e a Cirurgia Infantil com 24 leitos, num total de 135 leitos. Possui ainda 31 consultórios para atendimento das especialidades e pronto-socorro das diversas especialidades. O ICr realiza mensalmente, em média, 6500 consultas, 650 internações, 180 cirurgias, 36 mil exames laboratoriais e 3800 exames radiológicos (ICr, 2017a). Conta com uma força de trabalho de 1709 profissionais, 353 são médicos assistentes, sendo que $40 \%$ do corpo clínico possui doutorado, dados de 10/2017, fornecidos pela Direção do ICr. 
Os colaboradores do ICr-HCFMUSP contam com o apoio dos profissionais da divisão de Tecnologia da Informação em Saúde (TIS) que tem a missão de "Prestar serviço de excelência, garantindo o acesso, segurança e integridade da informação, apoiando a administração, ensino, pesquisa e assistência através da tecnologia" (Equipe do TIS, 2002). No total a equipe é formada por 17 colaboradores, sendo: 3 da equipe de redes, 6 da equipe de relacionamento com o cliente, 4 da equipe de sistemas de informação, 2 recepcionistas, 1 jovem aprendiz, e 1 gestor. Sua estrutura funcional é formado por 3 áreas distintas: sistemas de informação, redes, relacionamento com 0 cliente. A equipe controla e presta assistência para 683 computadores, 74 impressoras laser, 18 servidores físicos, 20 servidores virtuais, 1 blade com 2 laminas, 4 storages, backup com fitas LTO4.

O ICr-HCFMUSP possui sistemas que não são comuns no complexo do Hospital das Clínicas. Possuem softwares desenvolvidos internamente (internos) pela equipe de sistemas de informação, e também sistemas de terceiros (externos). Ao todo são 32 sistemas (Quadro 1), sendo 18 sistemas externos, e 14 sistemas internos. Dos 18 sistemas externos, 10 estão integrados aos sistemas internos. Dos softwares internos, destacamos o Sistema Integrado de Gestão Médico Hospitalar (SIGMA) que é um portal médico da instituição, onde através de senha autorizada, o colaborador tem acesso aos dados e cadastros para realização de parte de suas atividades diárias, como segue ${ }^{1}$. 
Quadro 1 - Relação de Sistemas do ICr-HCFMUSP - Externos e Internos posição em 2013

\begin{tabular}{|c|c|}
\hline Sistemas Externos & Sistemas Internos \\
\hline $\begin{array}{l}\text { Ifractal - controle de acesso (segurança } \\
\text { patrimonial) } \\
\text { NCI - custos (Finanças) } \\
\text { Dinamus - gestão de O.S. (manutenção, } \\
\text { engenharia clínica, T.I.) } \\
\text { ForPonto - registro de frequência (RH) } \\
\text { Dynamics - gestão de estoque } \\
\text { (suprimentos) } \\
\text { Multimed - faturamento convênio } \\
\text { (faturamento) } \\
\text { SIAFISICO - compras governo (compras) } \\
\text { Net Manager - tarifação telefonia } \\
\text { (telefonia) } \\
\text { MV suprimentos - suprimentos } \\
\text { MVSE - sistema estratégico } \\
\text { Loyal - gestão documental (qualidade) } \\
\text { Brand - dietoterapia, produção cozinha } \\
\text { (nutrição) } \\
\text { HCMed - resultado de exames } \\
\text { GE-PACS - pacs (radiologia) } \\
\text { TW - prescrição eletrônica } \\
\text { E2DOC - prontuário digitalizado (SAME) } \\
\text { URO - prontuário urologia (urologia) } \\
\text { SIGH - sistema hospitalar Prodesp } \\
\text { (SAME) }\end{array}$ & $\begin{array}{l}\text { SIGMA - laudo médico } \\
\text { SIGMA - portal de serviços } \\
\text { SIGMA - portal do paciente } \\
\text { SIGMA - recepção P.S. e internação } \\
\text { SIGMA - atendimento P.S. e internação } \\
\text { SIGMA - laboratório } \\
\text { SIGMA - agendamento } \\
\text { SIGMA - ambulatório } \\
\text { SIGMA - arquivo médico } \\
\text { SIGMA - cadastro de usuários } \\
\text { SIGMA - dados para custos } \\
\text { SIGMA - relatórios } \\
\text { SIGMA - agenda cirúrgica }\end{array}$ \\
\hline
\end{tabular}

Fonte: ${ }^{1}$

\subsubsection{Unidade de Genética (UG) do ICr}

A área de genética médica alcançou um papel reconhecido como a especialidade da medicina que lida com a prevenção, diagnóstico, tratamento e aconselhamento genético de distúrbios hereditários (Mcinnes et al, 2008). A

${ }^{1}$ Dados fornecidos pelo gestor do TIS, Francisco Costa Neto, que é formado em Ciência da Computação, com especialização em Projeto e desenvolvimento de sistemas web e MBA Executivo em Saúde. Afirma que trabalha no TIS há 21 anos, sendo 10 como gestor. 
genética se ocupa de um grupo de doenças, cuja relevância na saúde pública vem crescendo sobremaneira nas últimas décadas. Além de doenças genéticas, o médico geneticista, acaba atendendo também vários defeitos congênitos, que constituem toda anomalia funcional e estrutural do desenvolvimento do feto decorrentes não apenas de fatores genéticos, mas também ambientais ou desconhecidos (Kim et al, 2010).

O aumento do atendimento em genética clínica nas unidades de referência tem suscitado de forma prioritária maior organização e racionalização dos dados, estimando-se o número de consultas ambulatoriais, em genética clínica no país em 56 mil por ano, dessas 35 mil somente no estado de São Paulo. Metade do total de consultas foi realizada em apenas nove instituições, sendo uma delas a UG (Horovitz et al, 2006).

Segundo a Organização Mundial da Saúde (OMS), a Sociedade Brasileira de Genética Clínica e a Sociedade Brasileira de Genética, aproximadamente $5 \%$ das gestações resultam no nascimento de uma criança com anomalia congênita; sendo que $15 \%$ a $25 \%$ das anomalias congênitas são a segunda causa de mortalidade infantil no Brasil (Brasil, 2009).

A Unidade de Genética do $\mathrm{ICr}$ atende crianças e adolescentes com diferentes doenças genéticas, procedentes, não apenas do ICr-HCFMUSP, mas de todo o complexo do Hospital das Clínicas e de outros estados, além do estado de São Paulo. Tem um atendimento aproximado de 1500 pacientes por 
ano. Em sua equipe de profissionais, que é variável, consiste de quatro médicos assistentes, um preceptor, seis médicos residentes e cinco médicos estagiários. Em geral, os pacientes da UG são acompanhados no ambulatório até completar 18 anos, podendo ir até 21 anos, com retorno variado.

Para o paciente se consultar com a equipe de genética, marcavam consulta no Setor de Atendimento, e através de seu Registro Geral (RG), era identificado, nas suas consultas e exames no instituto.

Para o atendimento na UG, os médicos da unidade levantavam as fichas dos pacientes agendados, para estudo antecipado à consulta, pois discutir os casos era uma rotina importante para a equipe médica, com 0 objetivo de trocar conhecimento e aprendizado.

No dia da consulta, chamavam o paciente através do sistema de Agenda do ICr-HCFMUSP, e após questionamento, preenchiam a ficha do paciente (Anexo A), contendo dados de: identificação, pré-natal e parto, achados clínicos, exames, heredograma e diagnóstico. Quando necessário eram solicitados exames específicos, tais como: cariótipo e demais testes cito genéticos e moleculares. As fotografias eram tiradas dos pacientes rotineiramente com autorização dos pais. As anotações da consulta eram transcritas na pasta de Serviço de Atendimento Médico e Estatística (SAME), que é responsável pela guarda de todas as consultas dos pacientes, nas diversas especialidades, além das fichas da UG. Toda consulta após ser 
realizada, tinha alguns dados ( $R G$, nome do paciente e diagnóstico) anotados em um livro da UG, para controle do atendimento. A equipe médica da UG, antes de fechar um diagnóstico, consultava um médico assistente para discussão de um diagnóstico final e encerramento da consulta.

Nos procedimentos relatados, a ficha do paciente (prontuário em papel), trazia algumas limitações para a equipe da UG: era ineficiente para a localização, organização e armazenamento, além de dificultar os dados para pesquisa. Conforme a Sociedade Brasileira de Informática em Saúde (SBIS) o prontuário em papel gera ainda outras desvantagens: uso da ficha somente por um profissional de cada vez; pode estar ilegível; pode ser ambíguo; pode haver duplicidade de fichas; requer local amplo e apropriado para ser armazenado e requer cuidado no manuseio, pois é de fácil deterioração (SBIS, 2014).

Além da cópia que era enviada para o SAME, os pacientes tinham suas fichas, fotos e exames arquivados na sala da UG, o que dificultava muito devido ao espaço físico da sala de $15 \mathrm{~m}^{2}$, com vários livros, além dos arquivos de pacientes de mérito ambulatorial (4800 fichas de paciente, exames e heredogramas). A sala da UG possuía, na época, dois computadores em rede. Outros computadores podiam ser utilizados nas salas de consulta dos pacientes nos dias de ambulatório, totalizando cinco computadores, com sistema operacional Windows $2000 \AA$ entre outras versões. 


\subsubsection{O Software da Unidade de Genética do ICr}

Tentando melhorar e ampliar os atendimentos, considerando a promoção, prevenção, tratamento e reabilitação; identificar os principais problemas de saúde relacionados a anomalias congênitas; definir critérios técnicos mínimos para os serviços que realizam genética clínica; qualificar a assistência e promover a educação, o Ministério da Saúde (MS), em 2009, criou a Política Nacional de Genética Clinica, através da Portaria Ministerial no. 81, considerando ainda como objetivo algumas necessidades na incorporação de tecnologias em seu Art. 2․․ Parágrafos IV, a seguir: "IV - incentivar a realização de pesquisas e projetos estratégicos destinados ao estudo do custoefetividade, eficácia e qualidade e incorporação de tecnologias na área de genética clínica;".

Nesse sentido, os responsáveis pela UG solicitaram o desenvolvimento de um software de registro eletrônico dos dados clínicos específico para a unidade, com o objetivo de substituir as fichas médicas dos pacientes, até então manuscritas, de maneira a contribuir e aperfeiçoar o atendimento médico e auxiliar em suas pesquisas. Esse enfoque permitiria um melhor atendimento, maior integração operacional e maior rapidez na efetivação do diagnóstico definitivo e com uma nova forma de manusear as informações, de forma mais eficiente (Marin et al, 2003). 
Apesar da necessidade e solicitação da UG, foi realizada uma análise de viabilidade, verificando se a criação do software era ou não viável, considerando os objetivos da organização e as leis e normas existentes, inclusive da tecnologia que seria usada.

O departamento responsável pela informática do ICr-HCFMUSP, é o TIS e através de seu gestor, Francisco Costa Neto, se mostrou favorável, mas solicitou algumas adequações, quanto a ferramenta de desenvolvimento e banco de dados (Visual Basic.net $\AA$ e Oracle $\AA$ ), cujas licenças possuía a organização. O projeto ainda recebeu parecer do Prof. Dr. Marcelo Knorich Zuffo, professor titular do Laboratório de Sistemas Integráveis, do departamento de Engenharia de Sistemas Eletrônicos da Escola Politécnica da Universidade de São Paulo (USP), que emitiu parecer favorável:

\footnotetext{
“...a proposta de informatização da Unidade de Genética é relevante e possui o mérito de ser o primeiro passo para que a unidade possa vir a realizar pesquisas mais aprofundadas em bioinformática e genética num futuro próximo". (Marcelo Knorich Zuffo)
}

Em seguida, foi submetido o projeto na Comissão de Ética para Análise de Projetos de Pesquisa (CAPPesq) e aprovado sob protocolo no. 0257/08. Esse software foi chamado de PEG-software, repositório de dados clínicos dos pacientes, específico para a área de genética clínica e para a equipe da UG. 
Uma análise detalhada dos processos antes da informatização e das necessidades dos usuários geralmente é feita. Como parte da análise, requisitos específicos de usuário são reunidos, podem incluir instruções detalhadas que explique em narrativa simples as necessidades dos usuários, do fluxo de trabalho e esperadas para o software. É importante que os usuários reais do sistema sejam consultados, bem como, aqueles que implementarão e manterão o software (Wilcox et al, 2014).

Com a aprovação do projeto pela CAPPesq, foi realizada uma entrevista com os médicos da UG, o gestor da UG e a analista de sistemas. Nessa entrevista o gestor afirmava que queria diminuir o número de fichas da unidade de genética, pois a sala era pequena e o número de fichas aumentava a cada ano, descreveram então como acontecia o atendimento ao paciente diariamente, como relatado. Além disso, a documentação foi levantada junto à equipe da UG, que alertou que haviam dados que deveriam ser preenchidos em caso de primeira consulta, e outros que deveriam ser preenchidos em todas as consultas (Anexo A). Tais documentos eram de fundamental importância, pois forneceriam subsídios para a criação da base de dados assim como para a interface do sistema.

No desenvolvimento do software, é notória a importância dos requisitos funcionais e não funcionais levantados na entrevista com os clínicos, logo o levantamento de requisitos, em comum acordo com os profissionais da UG, visou satisfazer suas necessidades no atendimento do paciente, resolvendo o 
problema da substituição do prontuário em papel pelo eletrônico, e foi uma base para a criação do software. Os Requisitos Funcionais e Não Funcionais para este projeto estão no anexo B.

Em resumo, os requisitos solicitados pela UG foram pontuados, quanto ao sistema que seria desenvolvido:

- Ser utilizado somente na rede local;

- Permitir somente acessos autorizados, com níveis de acesso;

- Permitir que o atendimento ambulatorial fosse realizado eletronicamente, assim como impressão para o SAME, para compor o prontuário do paciente;

- Permitir a inclusão de dados do atendimento ambulatorial específico para a área de genética;

- Permitir a alteração de dados dos pacientes, antes da finalização da consulta;

- Permitir a consulta de histórico e outros dados dos pacientes;

- Permitir a inclusão de consultas feitas em papel, posteriormente;

- Permitir a inclusão, alteração e consulta de cadastro de achados, diagnósticos, protocolos e exames próprios da UG;

- Permitir consultar, listar e imprimir pacientes por achados e diagnósticos;

- Permitir a inclusão, alteração e consulta de profissionais autorizados a acessar o sistema; 
- Permitir a alteração de senha padrão;

- Permitir cadastrar os protocolos das síndromes;

- Permitir cadastrar e mostrar em consulta os achados e diagnósticos próprios da área de genética clínica;

- Disponibilizar ajuda de uso.

Foi entregue um protótipo e documentação do projeto do PEG-software para o TIS em 2009, que nos orientaram que o PEG-software deveria se adequar a algumas restrições: poderia permitir a entrada de dados somente depois de serem atendidos na agenda da instituição, eles forneceriam lugar para armazenamento no banco de dados da instituição (por se tratar de dados confidenciais) além das licenças da interface o que foi aceito pelo gestor da equipe da UG. Além disso, o PEG-software receberia alguns dados provenientes do banco de dados da instituição através de views (dados de identificação do paciente e da agenda da UG) que a equipe de informática criaria para esse fim, de maneira que o software da UG recebesse os dados institucionais.

Um protótipo tem a finalidade de validar o design e identificar potenciais problemas e informações faltantes e pode ser construído, para garantir que o software desenvolvido é de alta qualidade e atende os requisitos. Com a fase de análise, é importante incluir os usuários-alvo e o pessoal das operações de tecnologia da informação nas revisões de design (Wilcox et al, 2014). 
No período que se seguiu, por medida de segurança, foram digitalizados os prontuários, e em 2013, o PEG-software começou o funcionamento, possibilitando o registro informatizado das etapas do atendimento: complemento de identificação, pré-natal e parto, história clínica, achados clínicos, diagnóstico, conduta, protocolos e imagens, específicos para a área de genética (Anexo C). Além de gravar os dados no banco de dados, os dados do atendimento passaram a ser impressos. Os médicos após impressão do relatório do atendimento e assinatura entregavam para o SAME para digitalização e arquivamento. Os dados então passaram a ficar disponíveis para consultas e pesquisas. No uso diário observou-se que novos requisitos e alterações de requisitos apareciam e deveriam ser atualizados junto ao software de uma maneira mais rápida, pois não deixou de ser usado desde então.

O projeto começou com a metodologia em cascata, este método sugere que cada parte do processo ocorra sequencialmente, mas devido à necessidade da equipe da UG ter um retorno mais rápido, foi necessário mudar para o método ágil visando adicionar novas funcionalidades através do desenvolvimento do software (iteração) em períodos curtos, de acordo com os pedidos da UG.

Os modelos mais comuns de desenvolvimento de software são o modelo cascata e suas variações e o modelo ágil. $O$ modelo de desenvolvimento de software em cascata prioriza o seguinte ciclo de 
desenvolvimento: a partir da definição dos objetivos da aplicação, são levantados os requisitos, para se proceder a codificação do sistema, com posterior implementação e testes, seguidos da manutenção da aplicação, podendo voltar ao início novamente, caso sejam necessários novos requisitos, ou para a alteração de requisitos é necessário voltar para a codificação, seguindo o fluxo para implementação e testes (Wilcox et al, 2014).

As abordagens de desenvolvimento de softwares modernos tentam fornecer maior flexibilidade, ao longo do processo de desenvolvimento do software, envolvendo o cliente. O desenvolvimento ágil evita o planejamento em longo prazo com iterações curtas que costumam durar de 1 a 4 semanas. $O$ método ágil é orientado a valores, o que significa que os clientes estabelecem prioridades no início de cada iteração com base em valor de negócios percebidos. Métodos ágeis enfatizam a comunicação rápida, expondo os problemas à medida que surgem durante o processo de desenvolvimento (Wilcox et al, 2014).

A equipe da UG reavaliou as novas versões de software ao usá-lo e novas demandas e prioridades de projetos foram comunicadas ao desenvolvedor de software e ao gestor da equipe que autoriza as alterações. A estreita cooperação entre o pessoal da UG e o desenvolvedor de software foi um fator chave para o sucesso do desenvolvimento do software e para atender às necessidades da equipe de forma mais eficiente. 
$\mathrm{Na}$ implementação o software é instalado no hardware do servidor, dispositivos do usuário, infraestrutura de rede, etc., e podem ser testados também, seguidos do treinamento do usuário. Quando os clínicos começam a usar o software, é possível verificar se o software tem todos os recursos necessários e executa todas as funções especificadas no documento de requisitos (Wilcox et al, 2014).

É importante ressaltar que o PEG-software não substituiu os sistemas fornecidos pela instituição, mas complementou, de maneira a sanar as necessidades dos médicos da UG, para o atendimento especializado e para pesquisa.

O PEG-software, para funcionar corretamente necessita de uma versão do sistema operacional Windows ${ }^{\circledR}$, que possa ser instalado ou já com o dot net framework (Ex.: Windows XP, Windows Vista, Windows 7, Windows 8 e Windows 10). Os requisitos de hardware mínimos são: processador de um GHz, RAM de 512 MB, espaço de disco mínimo de 4.5 GB para 32 ou 64 bits.

Conforme o pedido do TIS, o PEG-software foi desenvolvido com o Visual Basic.Net ${ }^{\circledR}$ (VB.Net - uma linguagem de programação da Microsoft $\left.{ }^{\circledR}\right)$, usa um banco de dados Oracle $\AA$, e tem uma estrutura Cliente-Servidor, sendo concedido acesso apenas para médicos autorizados na rede local do $\mathrm{ICr}$ HCFMUSP. O PEG-software foi desenvolvido de acordo com o Conselho Federal de Medicina (CFM), através da Resolução CFM №1638 (2002a), 
substituída pela Resolução CFM №1821. Ele gera um relatório do registro clínico padrão, para arquivamento e digitalização no SAME, permitindo o armazenamento de dados. Foi ajustado para receber dados de outras aplicações e permitir o envio e/ou deixar disponível, dados para outra aplicação da instituição (CFM, 2002b, 2007).

Em meados de 2015, o TIS, departamento de informática disponibilizou em seu sistema, SIGMA - eDoc (evolução médica e multiprofissional), um campo apropriado para o médico registrar a sua consulta e a equipe da enfermagem. Em geral, o Registro Eletrônico de Saúde (RES), que trabalha com várias especialidades médicas, só permite manejar as informações de forma mais genérica, sem suprir, por completo, as necessidades de segmentos mais específicos, como é o caso da genética. Por se tratar de software criado para todos, então as especialidades devem se adequar ao seu uso. A genética clínica é uma especialidade que abrange doenças extremamente raras, com peculiaridades muito particulares, tanto no que se refere ao exame físico, quanto ao diagnóstico, assim como aos exames complementares específicos.

Em consequência da alteração realizada no SIGMA pelo TIS, foi solicitado para a equipe da UG se adequar ao novo modelo e deixar disponível um resumo dos dados das consultas para ser incluído no software da instituição, possibilitando a integração total do PEG-software com o SIGMA, apesar da disponibilidade do prontuário digitalizado, que fica a disposição das outras especialidades. 
O PEG-software, possui cadastrados 17 grupos (tipos) de achados clínicos, com 544 subgrupos (itens) de achados clínicos e 6 grupos (tipos) de diagnósticos, com 171 subgrupos (itens) de diagnósticos, com respectivos Código Internacional de Doença (CID10), específicos para a área de genética clínica, inserido pelos médicos da UG. Permite ainda o cadastro de protocolos clínicos, possibilitando cadastrar um protocolo especifico para cada paciente, dependendo do seu diagnóstico, como recomenda a Associação Brasileira de Normas Técnicas (ABNT) ISO/TS 18308 e 20514 (ABNT, 2008a; ABNT, 2013).

Para ser útil, o software deve ser desenvolvido com uma compreensão do seu papel no ambiente de cuidados, que seja orientado para as funções específicas que são necessárias, e deve ser desenvolvido corretamente. O software deve ser integrado para suportar o fluxo de trabalho (Wilcox et al, 2014).

Atualmente a UG conta com cinco computadores em sua sala, além dos computadores disponíveis nas salas de atendimento ao paciente, todos em rede com a seguinte configuração (dados fornecidos pelo TIS): Computador ALL IN ONE 5348 (DELL) Core i5 Windows 8, computador 800G1 (HP) Core i7 Windows 7, computador DX7400 (HP) Corei5 Windows xp, computador 6000 (HP) Dual Core Windows 7 e computador OPTIPLEX 9010 (DELL) Core i7 Windows 7. Nos ambulatórios contam com computadores 8200 (HP) Core i5 Windows 7. 


\section{AVALIAÇÃO DE QUALIDADE DE SOFTWARE}

O comprometimento da qualidade de um software pode afetar a segurança humana, a confiabilidade de informações geradas ou resultados esperados, promovendo danos financeiros e de segurança entre outros reflexos, dependendo dos setores envolvidos (Grady, 1992; ISO/IEC 25010, 2011). Nesse sentido, o mercado de software vem exigindo cada vez mais que eles tenham qualidade, pois deles dependem 0 gerenciamento das informações e a credibilidade da empresa, podendo acarretar um comprometimento operacional.

A qualidade de software deve ser garantida pelo uso e/ou criação de métricas de detecção de defeitos e por uma metodologia de adaptação de software, para que as correções possam ser realizadas o mais breve possível (Grady, 1992; Pressman, 2011, Wazlawick, 2013). Apresentamos nesse capítulo literatura sobre qualidade e avaliação de software.

\subsection{Qualidade de Software}

Para Pressman (2011) a qualidade de software engloba os requisitos, as especificações e o projeto de sistema. Se o software satisfaz os requisitos e metas de desempenho, a qualidade de conformidade é alta, mas deve-se levar em consideração a satisfação do usuário, que será obtida com um produto adequado. 
Ainda que o software atenda aos requisitos iniciais solicitados, é importante que o usuário esteja satisfeito, uma vez que sua opinião pode afetar o juízo de valor da qualidade do software desenvolvido (Sommerville, 2007; Pressman, 2011).

Para Costa (2013), uma estrutura do sistema da qualidade deve ter quatro pontos:

1) Estabelecimento de responsabilidades gerenciais;

2) Definição e documentação do próprio sistema da qualidade;

3) Procedimentos para auditoria interna do sistema da qualidade; e

4) Procedimentos para ações corretivas.

O conjunto acima, visa um software com qualidade, mas sem as ações para correção dos problemas levantados, existe um comprometimento de todo o trabalho realizado. Fazer um software com qualidade reduz a quantidade de retrabalho, diminuindo o custo e prazos de entrega. Todos os envolvidos no processo de engenharia de software são considerados responsáveis pela qualidade (Pressman, 2011).

Para garantir a qualidade, muitas empresas estão desenvolvendo padrões próprios, baseados nos padrões internacionais, tais como a norma ISO 9001, que não é especificamente voltado para software, mas pode ser aplicado ao software (Pressman, 2011). São considerados atributos de qualidade de software: segurança, facilidade de compreensão, portabilidade, proteção, 
facilidade de testes, facilidade de uso, confiabilidade, adaptabilidade, facilidade de reuso, facilidade de recuperação, modularidade, eficiência, robustez, complexidade e facilidade de aprendizado (Sommerville, 2007). Dentro das diretrizes básicas da norma ISO 9001, destacamos: "promover a importância da qualidade entre todos os interessados e enfocar a satisfação do cliente", conforme Pressman (2011).

\subsubsection{Padrão de Qualidade de Software - ISO/IEC}

A International Organization for Standardization (ISO) e a International Electrotechnical Commission (IEC) formam o sistema especializado de padronização mundial, participando do desenvolvimento de Normas Internacionais por meio de comitês técnicos (ISO/IEC 25010, 2011). O conjunto das normas ISO/IEC 9126 e 14598, e a família de normas Software Quality Requiriments and Evaluation (SQuaRe) descrevem um modelo de qualidade, um processo de avaliação e um conjunto de métricas que podem ser utilizadas para realizar a avaliação de um software, de acordo com várias características e subcaracterísticas. Esta seção tem por objetivo dar uma visão geral da qualidade e roteiro para avaliação de produtos de software, conforme estas normas.

Segundo a ISO/IEC 25010 (2011) e ABTN Norma Brasileira (NBR) ISO/IEC 9126-1 (2003), a qualidade do software se refere: a totalidade de características que the confere a capacidade de satisfazer necessidades 
explícitas e implícitas, quando o software estiver sendo usado em condições especificadas (ABNT, 2008b; ABNT, 2003). Nessa perspectiva, as medidas de qualidade de software em uso, que avaliam a qualidade do produto em seu ambiente final, são medidas pelos usuários.

Com relação à qualidade da engenharia de software, a ISO/IEC emitiu várias normas para servir como padrões internacionais de avaliação da qualidade do software. A ISO/IEC 9126 apresentava seis características da qualidade do produto de software: funcionalidade, usabilidade, confiabilidade, eficiência, manutenibilidade e portabilidade (ABNT, 2003).

O modelo de qualidade do produto de software que estão descritas na norma ABNT NBR ISO/IEC 9126-1 (2003) considerando as suas características e as subcaracterísticas relacionadas, estão descritas a seguir.

Funcionalidade: "capacidade do produto de software de prover funções que atendam às necessidades explicitas e implícitas, quando o produto estiver sendo utilizado sob condições especificadas". Suas subcaracterísticas tratam da capacidade do produto de software de ter:

- Adequação: fornecendo um conjunto de funções para tarefas e objetivos solicitados pelo usuário.

- Acurácia: fornecendo com o grau de exatidão necessário, os resultados ou efeitos certos conforme solicitado.

- Interoperabilidade: interagindo com um ou mais sistemas mencionados. 
- Segurança de Acesso: protegendo as informações e dados, de forma que pessoas ou sistemas não autorizados não tenham acesso, impossibilitando de ler ou modificar.

- Conformidade relacionada à funcionalidade: estando conforme as normas, convenções ou regulamentações determinadas em leis e similares referentes à funcionalidade.

Usabilidade: "capacidade do produto de software de ser compreendido, aprendido, operado e atraente ao usuário, quando usado sob condições especificadas". Suas subcaracterísticas tratam da capacidade do produto de software de ter:

- Inteligibilidade: possibilitando ao usuário entender se o software é adequado e como ele pode ser usado para afazeres e condições de uso especificados.

- Apreensibilidade: possibilitando ao usuário aprender sua aplicação.

- Operacionalidade: possibilitando ao usuário operá-lo e controlá-lo.

- Atratividade: sendo atraente ao usuário.

- Conformidade relacionada à usabilidade: estando conforme as normas, convenções ou regulamentações determinadas em leis e similares referentes à usabilidade. 
Confiabilidade: "capacidade do produto de software de manter um nível de desempenho especificado, quando usado em condições especificadas". Suas subcaracterísticas tratam da capacidade do produto de software de ter:

- Maturidade: evitando falhas decorrentes de defeitos no software.

- Tolerância a falhas: mantendo um determinado nível de desempenho em casos de defeitos no software.

- Recuperabilidade: restabelecendo nível de desempenho e recuperando os dados afetados em caso de uma falha.

- Conformidade relacionada à confiabilidade: estando conforme as normas, convenções ou regulamentações determinadas em leis e similares referentes à confiabilidade.

Eficiência: "capacidade do produto de software de apresentar desempenho apropriado, relativo à quantidade de recursos usados, sob condições especificadas". Suas subcaracterísticas tratam da capacidade do produto de software de ter:

- Comportamento em relação ao tempo: fornecendo tempos, resposta de processamento, e taxas de transferência, adequados, quando o software estiver funcionando em condições estabelecidas.

- Utilização de recursos: usando tipos e recursos em quantidade apropriadas, quando o software estiver funcionando em condições estabelecidas. 
- Conformidade relacionada à eficiência: estando conforme as normas, convenções ou regulamentações determinadas em leis e similares referentes à eficiência.

Manutenibilidade: "capacidade do produto de software de ser modificado. As modificações podem incluir correções, melhorias ou adaptações do software devido a mudanças no ambiente e nos seus requisitos ou especificações funcionais". Suas subcaracterísticas tratam da capacidade do produto de software de ter:

- Analisabilidade: permitindo o diagnóstico de falhas ou causas de falha no software, ou identificação de partes a serem alteradas.

- Modificalibilidade: permitindo que uma alteração especificada seja realizada.

- Estabilidade: evitando efeitos inesperados provenientes de alterações no software.

- Testabilidade: permitindo que o software, quando alterado, seja avaliado.

- Conformidade relacionada à manutenibilidade: estando conforme as normas, convenções ou regulamentações determinadas em leis e similares referentes à manutenibilidade.

Portabilidade: "capacidade do produto de software de ser transferido de um ambiente para outro". Suas subcaracterísticas tratam da capacidade do produto de software de ter: 
- Adaptabilidade: sendo adaptado para diferentes ambientes, não necessitando de empregar outras ações ou meios, daqueles fornecidos pelo software considerado.

- Capacidade para ser instalado: sendo instalado e desinstalado em um ambiente especificado.

- Coexistência: coexistindo com outros softwares autônomos, em um ambiente comum, dividindo recursos comuns.

- Capacidade para substituir: sendo usado em substituição a software especificado, como a mesma finalidade e no mesmo ambiente.

- Conformidade relacionada à portabilidade estando conforme as normas, convenções ou regulamentações determinadas em leis e similares referentes à portabilidade.

A ISO/IEC 9126 foi substituída pela ISO/IEC 25010 e passou a ter oito características: adequação funcional (funcionalidade), eficiência de desempenho, compatibilidade, usabilidade, confiabilidade, segurança, manutenção e portabilidade. A subcaracterística segurança que era subcaracterísticas de funcionalidade na ISO/IEC 9126-1, ganha destaque pela sua importância na qualidade do produto de software e passou a ser característica, tendo suas próprias subcaracterísticas. Interoperabilidade e coexistência foram realocadas e passaram a ser subcaracterísticas de uma nova característica, a compatibilidade. Ainda foram adicionadas as subcaracterísticas: integridade funcional, capacidade, proteção de erro do 
usuário, acessibilidade, disponibilidade, modularidade e reutilização. As subcaracterísticas de conformidade foram removidas (ISO/IEC 25010, 2011).

As características e subcaracterísticas do modelo de qualidade do produto, na ISO/IEC 25010 (2011), passam a abranger também sistemas informáticos e qualidade de utilização do ponto de vista do sistema relacionado, como segue.

Adequação Funcional: "Grau em que as necessidades declaradas e implícitas quando usadas em condições específicadas". Suas subcaracterísticas referem-se ao grau com que o sistema ou produto de software tem:

- Completude funcional: fornecendo um conjunto de funções que abrange todas as tarefas especificadas.

- Correção funcional: fornecendo os resultados corretos e precisos.

- Adequação funcional: fornecendo um conjunto de funções para as tarefas e objetivos especificados.

Segurança: "Grau que um produto ou sistema protege as informações e dados, de modo que as pessoas ou outros produtos ou sistemas tenham o grau de acesso aos dados adequado os seus tipos e níveis de autorização". Suas subcaracterísticas referem-se ao grau com que o sistema ou produto de software tem: 
- Confidencialidade: garantindo que somente os autorizados tenham acesso os dados.

- Integridade: impedindo o acesso não autorizado ou a modificação dos softwares ou dados.

- Não Repúdio: estando de acordo com os eventos que ocorreram, de maneira que possam ser provados, e não possam ser repudiados mais tarde.

- Responsabilidade: tendo a possibilidade de uma ação ou entidade poder ser rastreada.

- Autenticidade: tendo a identidade provada, se reivindicada.

Eficiência de Desempenho: "Grau de desempenho em relação à quantidade de recursos utilizados nas condições especificadas". Suas subcaracterísticas referem-se ao grau com que o sistema ou produto de software tem:

- Comportamento do tempo: conseguem a resposta e os tempos de processamento, ao executar suas funções, em condições estabelecidas.

- Utilização de recursos: ao executar suas funções, utilizando os recursos, atendem aos requisitos.

- Capacidade: satisfazendo as necessidades utilizando os limites máximos de largura de banda, taxa de transferência, etc. 
Compatibilidade: "Grau em que um produto, sistema ou componente pode trocar informações com outros produtos, sistemas ou componentes e/ou executar suas funções solicitadas, ao mesmo tempo em que compartilha o mesmo hardware e/ou o mesmo ambiente de software". Suas subcaracterísticas referem-se ao grau com que o sistema ou produto de software tem:

- Coexistência: podendo desempenhar suas funções da forma requerida, ao mesmo tempo em que compartilha um ambiente e recursos.

- Interoperabilidade: interagindo com um ou mais sistemas, produtos ou componentes podendo trocar informações e usar as informações trocadas.

Usabilidade: "Grau em que um produto ou sistema pode ser usado por usuários, para atingir as metas especificadas com eficácia, eficiência e satisfação em um contexto especificado de uso". Suas subcaracterísticas referem-se ao grau com que o sistema ou produto de software tem:

- Reconhecimento de adequação: através dos usuários podem reconhecer se um produto ou sistema é adequado as suas necessidades.

- Capacidade de aprendizado: pode ser usado por usuários especificados para atingir objetivos específicos de aprendizado para usá-lo.

- Operabilidade: tem atributos que facilitam a operação e o controle.

- Proteção de erro do usuário: protege os usuários contra erros. 
- Interface do usuário: grau em que uma interface de usuário permite uma interação agradável e satisfatória para o usuário.

- Acessibilidade: a possibilidade de um produto ou sistema poder ser usado por usuários com incapacidades especificadas.

Confiabilidade: "Conjunto de atributos que evidenciam a capacidade do software de manter seu desempenho em condições estabelecidas em um determinado período de tempo". Suas subcaracterísticas referem-se ao grau com que o sistema ou produto de software tem:

- Maturidade: em condições normais de processamento, não apresenta falhas, atendendo as necessidades de confiabilidade.

- Disponibilidade: permanece acessível, quando necessário, para utilização.

- Tolerância a falhas: continuar funcionando com a presença de falhas de hardware ou software.

- Recuperabilidade: podendo recuperar os dados diretamente afetados e restabelecer o sistema em caso de falha.

Manutenibilidade: "Conjunto de atributos que evidenciam o grau de que um produto ou sistema pode ser eficientemente modificado". Suas subcaracterísticas referem-se ao grau com que o sistema ou produto de software tem: 
- Analisabilidade: permitindo o diagnóstico de falhas ou partes a serem modificadas no sistema, com eficácia e eficiência.

- Modificabilidade: podendo ser alterado sem apresentar defeitos degradantes.

- Modularidade: podendo ser composto por componentes discretos de tal modo que a mudança em um componente tem impacto mínimo sobre outros componentes.

- Reusabilidade: podendo ser usado em mais de um sistema ou reusado na construção de outro software.

- Testabilidade: podendo ser testado para verificar se os resultados especificados foram atingidos.

Portabilidade: "Grau de eficiência com que, um sistema, produto ou componente pode ser transferido de um hardware, software ou de outro ambiente operacional". Suas subcaracterísticas referem-se ao grau com que o sistema ou produto de software tem:

- Adaptabilidade: podendo ser adaptado de forma eficaz e eficiente, para software ou hardware diferente.

- Capacidade para ser instalado: podendo ser instalado e desinstalado com sucesso em ambiente especificado.

- Capacidade para substituir: podendo substituir outro produto de software especificado, com a mesma finalidade, no mesmo ambiente. 
O Quadro 2 a seguir, mostra o relacionamento das normas das famílias ISO/IEC 9126 e ISO/IEC 14598 e a série de normas SQuaRe.

Quadro 2 - Relacionamento entre as séries ISO/IEC 9126 e ISO/IEC 14598 e a série de normas SQuaRe

\begin{tabular}{|c|c|c|c|}
\hline & ATUAL & SQuaRE & Relacionamento \\
\hline $\begin{array}{l}\text { Ref. } \\
1 \\
2 \\
3 \\
4\end{array}$ & $\begin{array}{l}\text { 9126:Qualidade do produto } \\
\text { 1: Modelo de qualidade } \\
\text { 2: Métricas externas } \\
\text { 3: Métricas internas } \\
\text { 4: Métricas de qualidade em } \\
\text { uso } \\
\text { Nova proposta } \\
\text { Guia para usar } 9126 \quad \text { \& } \\
\text { 14598 } \\
\text { Medidas básicas } \\
\text { Requisitos de Qualidade } \\
\text { 14598: Avaliação } \\
\text { produto de } \\
\text { 1: Visão Geral } \\
\text { 2: Planejamento e Gestão } \\
\text { 3:Proc.para desenvolvedores } \\
\text { 4: Proc. para compradores } \\
\text { 5: Proc. para avaliadores } \\
\text { 6: Doc. de módulo de } \\
\text { avaliação }\end{array}$ & $\begin{array}{l}\text { 25000: Divisão de Gestão de Qualidade } \\
\text { 25000: Guia do SQuaRe } \\
\text { 25001: Planejamento e Gestão } \\
\text { 25010: Divisão de Modelo de Qualidade } \\
\text { 25010: Modelo de Qualidade } \\
\text { 25020: Divisão de Medição de } \\
\text { Qualidade } \\
\text { 25020: Guia e modelo de referencia para } \\
\text { medição } \\
\text { 25021: Elementos de medida de } \\
\text { qualidade } \\
\text { 25022: Medição de qualidade interna } \\
\text { 25023: Medição de qualidade externa } \\
\text { 25024: Medição de qualidade em uso } \\
\text { 25030: Divisão de Requisitos de } \\
\text { qualidade } \\
\text { 25030: Requisitos de qualidade } \\
\text { 25040: Divisão de Avaliação de } \\
\text { Qualidade } \\
\text { 25040: Guia e modelo referencia para } \\
\text { avaliação } \\
\text { 25041: Módulos de Avaliação } \\
\text { 25042: Processo para desenvolvedores } \\
\text { 25043: Processo para compradores } \\
\text { 25044: Processo para avaliadores }\end{array}$ & $\begin{array}{l}1,2,3,4 \\
6 \\
3 \\
2 \\
4\end{array}$ \\
\hline
\end{tabular}

Fonte: Adaptado da ABNT (2008c).

As medições são ferramentas que fazem parte do processo de gerenciamento de qualidade. Cada empresa deve descobrir as métricas mais adequadas, para verificar os componentes anômalos do software e, com isso, assegurar que ele tenha um baixo número de defeitos, a fim de que a 
qualidade atingida seja compatível com a esperada (Sommerville, 2007; Wazlawick, 2013). Nessa perspectiva é necessário que as características de qualidade dos produtos de software sejam especificadas, medidas e avaliadas, usando-se um processo de avaliação de qualidade, com métodos de medição e modelos internacionalmente aceitos (ISO/IEC 25010, 2011).

\subsection{Avaliação de Software}

Conforme Pressman (2011) para se conseguir qualidade de software é necessário:

(...) criar um conjunto de atividades que ajudarão a garantir que todo o produto de trabalho de engenharia de software exibe alta qualidade, realizar atividades de controle e garantia de qualidade de software em todo o projeto, usar métricas para desenvolver estratégias para aperfeiçoar seu processo de software e, como consequência a qualidade do produto final.

Devemos fazer medição de softwares, para verificar sua eficácia, se o solicitado foi ou está sendo realizado, de maneira a termos um software com qualidade. Define-se por métrica (Waslawick, 2013): "escala na qual os valores de uma medida são tomados". Nesse sentido devemos entender que a medida, refere-se ao valor que é resultado para alguma dimensão de software. 
Para Sommerville (2007), métricas de software "são as medições que necessitam ser coletadas para auxiliar a responder às questões e confirmar se os aprimoramentos de processos alcançaram o objetivo desejado.".

Um número inicial de métricas deve ser selecionado para ser consistente com o processo de desenvolvimento de software existente e os objetivos da organização e do projeto. Algumas métricas se referem a medições relativas ao: tamanho do programa, esforço, horário, número de falhas, custos de qualidade (Möller e Paulish, 1993).

Para Costa (2013), a avaliação deve atuar sobre todo o ciclo de vida do software: definição de requisitos, elaboração das funcionalidades, estruturação física do sistema, programação, implantação, e manutenção.

As métricas mais importantes estão relacionadas com a qualidade do software. Estas são usadas para vários objetivos distintos: verificar número de defeitos, eficiência, confiabilidade, etc. Para Waslawick (2013) há pelo menos quatro formas de relativizar uma métrica:

1) Pelo Tamanho: dividindo o valor absoluto da métrica pelo número de linhas de código;

2) Pela Funcionalidade: dividindo o valor absoluto da métrica pelo número de pontos de função;

3) Pelo Tempo: dividindo o valor absoluto da métrica pelo período de tempo; 
4) Pelo Esforço: dividindo o valor absoluto da métrica pelo despendido (desenvolvedor por mês ou desenvolvedor por hora).

Mesmo o software atendendo as suas especificações, os usuários podem não considerar que ele é um produto adequado para o uso diário, pois não correspondeu ao que ele esperava, afetando no juízo de valor de qualidade ao software desenvolvido. Nesse sentido, a garantia de qualidade deve ser através de uma verificação independente do processo de desenvolvimento de software (Sommerville, 2007).

Para Sommerville (2007): "A medição de software se dedica a derivar um valor numérico para algum atributo de um produto de software ou de um processo de software." Nessa perspectiva é necessário comparar os valores para tirar conclusões sobre a qualidade de software. Essas métricas são especialmente valiosas para verificar componentes anômalos, assegurando que o software tenha um baixo número de defeitos e atinja os padrões préestabelecidos de manutenção, confiabilidade, portabilidade, entre outros.

\subsubsection{Processo de Avaliação ISO/IEC}

As avaliações e modificações são ferramentas importantes do processo de gerenciamento de qualidade. Quando é realizada uma alteração no software, existe a possibilidade do software apresentar falhas geradas por defeitos não aferidos na fase de testes, sendo necessário ter constantemente uma métrica para contabilizar defeitos e efetuar as correções necessárias, 
garantindo a qualidade. Nesse sentido, o software permite que suas propriedades de qualidade sejam avaliadas (quantificadas e categorizadas) em suas características e/ou subcaracterísticas de qualidade, através de um processo de avaliação (ABNT, 2008b).

Para fazer um processo de avaliação de acordo com a ABNT NBR ISO/IEC 14598-1 é necessário quatro fases: estabelecer requisitos de avaliação, especificar a avaliação, projetar a avaliação e executar a avaliação (ABNT, 2008c):

1) Estabelecer requisitos de avaliação:

- Estabelecer o propósito da avaliação;

- Identificar tipos de produto(s);

- Especificar modelo de qualidade.

2) Especificar a avaliação:

- Selecionar métricas;

- Estabelecer níveis de pontuação para as métricas;

- Estabelecer critérios para julgamento.

3) Projetar a avaliação:

- Produzir o plano de avaliação.

4) Executar a avaliação: 
- Obter as medidas;

- Comparar os critérios;

- Julgar os resultados.

Para fazer um processo de avaliação de acordo com a ISO/IEC 25040 é necessário estabelecer requisitos de avaliação, especificar a avaliação, projetar a avaliação, executar a avaliação e concluir a avaliação. Foi incluído uma quinta etapa no processo de avaliação, que se refere ao feedback e disponibilização do resultado da avaliação, como segue (ISO/IEC 25040, 2011):

1) Estabelecer requisitos de avaliação:

- Estabelecer o propósito da avaliação;

- Obter os requisitos de qualidade do produto de software;

- Identificar tipos de produto a serem avaliados;

- Definir o rigor da avaliação.

2) Especificar a avaliação:

- Selecionar métricas de qualidade;

- Estabelecer níveis de pontuação para as métricas;

- Estabelecer critérios para julgamento da avaliação.

3) Projetar a avaliação: 
- Produzir o plano de avaliação.

4) Executar a avaliação:

- Obter as medidas;

- Comparar com os critérios;

- Julgar os resultados.

5) Concluir a avaliação:

- Analisar os resultados da avaliação;

- Elaborar relatório da avaliação;

- Analisar a qualidade da avaliação e fornecer feedback da avaliação para a organização;

- Disponibilizar os dados da avaliação.

\subsubsection{Mensuração de Defeitos}

As métricas de defeitos são especialmente aplicadas para medir a qualidade de software, e usam várias técnicas como: número de alterações de design ou código, número de erros detectados nas inspeções de código, número de erros detectados nos testes do programa ou defeitos detectados pelos usuários após a liberação de uso do software (Waslawick, 2013). Em se encontrado o número de defeitos é possível calcular sua confiabilidade com relação ao número de defeitos encontrados. 
Se aceita, geralmente, que não é possível criar um software perfeito. É, portanto, necessário testar o software antes de ser liberado para os usuários a fim de reduzir o risco de falhas no software em produção que causam um impacto negativo quando o software é usado. É igualmente necessário assegurar que o teste seja realizado corretamente (ABNT, 2014).

As pessoas não gostam de ser informadas que cometeram erros, pois é difícil admitir estar errado (Grady, 1992). Para o desenvolvedor é difícil detectar erros naquilo que ele mesmo construiu, caso a empresa não possua equipe própria para teste de software, devemos envolver a participação do usuário também.

Conforme Pressman (2011) considera-se erro, um problema de qualidade encontrado antes que o software seja entregue aos usuários finais e um defeito, como um problema de qualidade encontrado depois que o software foi entregue aos usuários finais.

Uma falha é um erro no software que faz com que o produto produza um resultado incorreto para entrada válida. Contaremos falhas em dois momentos específicos no ciclo de vida do desenvolvimento de software: falhas de teste do sistema e uso de campo (Möller e Paulish, 1993). Para Grady e Caswel (1987) um defeito é “... um desvio da especificação do produto, e se pudessem ter sido detectados, teriam sido corrigidos". 
As discussões sobre defeitos de software são confusas porque pessoas diferentes as descrevem de diferentes perspectivas. Nesse sentido a visão do usuário é uma perspectiva. Quando os usuários tem um software que não funciona do jeito que eles esperam, o nível de preocupação dos usuários reflete o quanto seu trabalho é afetado, usando o software defeituoso. Quantos aos defeitos podemos especificar (Grady, 1992):

a) Quais as origens (onde?): Especificações ou requisitos, design, código, documentação;

b) Quais os tipos (o que?): Conforme as origens (requisitos ou especificações funcionalidade; interface de hardware ou software; descrição funcional; interface do usuário; definição de dados; módulo de design; lógica; tratamento de dados; teste de software e hardware, ferramentas de desenvolvimento; integração do software; padrões).

c) Quais os modos (por quê?): Falta, errado, mudou, melhor maneira;

d) Classificação do impacto de defeitos: Crítico, sério, médio ou leve;

e) Densidade de defeitos: São considerados os defeitos encontrados em uma determinada atividade, sem duplicatas.

Pressman (2011) afirma que para garantir a estatística de qualidade de software, deve-se criar um processo de adaptação de software, pela qual são feitas modificações de maneira a sanar os defeitos, como o que segue:

a) Defeitos de software são coletados e categorizados; 
b) Rastrear os defeitos até sua causa;

c) Identificar as causas vitais de defeitos;

d) Corrigir os problemas que causaram os defeitos.

Para Costa (2013), "deve ser usado algum tipo de indicador para expressar falhas e/ou defeitos que façam sentido do ponto de vista do cliente."

O levantamento de defeitos, mesmo depois da liberação do software para o usuário, sua classificação e resolução, faz parte do processo da governança do software, além da segurança e é uma garantia de qualidade de software que está direcionado para a identificação e a avaliação de riscos (Pressman, 2011).

\subsubsection{Avaliação de Tecnologias em Saúde (ATS)}

A ATS, em sua definição mais abrangente, tem como ponto de partida uma tecnologia, ou produto, ou processo, que seja possível de ser caracterizada na sua dimensão temporal e espacial (que, onde, como, quando, para quem, para quê), com a finalidade de se ampliar a perspectiva da análise sobre o objeto de estudo, havendo uma valorização do conhecimento (Novaes, 2000).

Nos anos 60, a ATS surgiu na esfera internacional, como um instrumento valioso para o auxílio à tomada de decisão para os profissionais de saúde. No Brasil, na década de 80 , as atividades nesse campo tiveram inicio, 
tanto no meio acadêmico como nas políticas públicas. No governo o marco oficial foi com o projeto Reforço à Reorganização do sistema Único de Saúde (REFORSUS), em 1998, responsável pela avaliação tecnológica em saúde: subsidiando a melhoria da qualidade e eficiência do Sistema Único de Saúde (SUS). Com a criação da Secretaria de Ciência, Tecnologia e Insumos Estratégicos (SCTIE) e do Departamento de Ciência e Tecnologia (DECIT), foi instituído o Conselho de Ciência, Tecnologia e Inovação em Saúde do Ministério da Saúde (CCTI), esse conselho, tem como objetivo promover a avaliação tecnológica no SUS (Brasil, 1998).

Para incentivar a pesquisa em saúde e aumentar a interlocução entre gestores e pesquisadores foi realizada, em 2006, a Oficina de Prioridades de Pesquisa em Saúde. Nessa oficina verificou-se a necessidade de estruturação de ações de ATS no Brasil, então foi criada a Rede Brasileira de Avaliação de Tecnologias em Saúde (REBRATS), que usou como estratégia a capacitação de profissionais e especialização para promover estudos em ATS no Brasil. Os objetivos da capacitação em gestão de saúde foram: às revisões sistemáticas ou avaliações de tecnologias; avaliação da implementação de evidências na prática de atenção à saúde; avaliação de impactos de Tecnologias da Informação e Comunicação (TIC) em saúde; estruturação de área de gestão de tecnologias; elaboração de diretriz clínica ou de saúde coletiva (Brasil, 2006). Nesse sentido, algumas instituições de ensino e pesquisa ficaram responsáveis pela realização dos cursos: Universidade Federal do Rio Grande do Sul (UFRGS), Universidade Federal de São Paulo (UNIFESP), Universidade 
Estadual do Rio de Janeiro (UERJ), Escola Nacional de Saúde Pública Arouca (ENSP/Fiocruz), e Universidade Federal da Bahia (UFBA) (Brasil, 2006).

Claramente, o software pode ser usado em diferentes maneiras de gerenciar e manipular informações de saúde para facilitar a prestação de cuidados de saúde. Contudo, se a informação crítica não está disponível, ou se os processos não estão organizados para operar sem problemas, um programa de computador será apenas um desafio e perda de tempo do pessoal clínico (Wilcox et al, 2014).

Existem evidentes dificuldades contraditórias no uso das TIC na gestão pública, que podem ser verificadas através da avaliação, pois considerando sua finalidade, não foi verificada a sua eficácia, outras não fazem o que deveriam fazer, o que foi pedido não foi atendido, mas continuam sendo utilizadas, e outras que fazem, sendo eficazes, mas tem pouco uso. Nesse sentido a ATS tem um campo de atuação muito extenso, abrangendo a eficácia, efetividade, segurança, riscos, custos, ética, implicações econômicas e ambientais das tecnologias, entre outras possibilidades (Brasil, 2006).

$\mathrm{Na}$ ATS no setor público há maior interesse pelas avaliações de programas e discretas avaliações de qualidade e tecnológicas (Novaes, 2000).

Conforme Novaes (2000) para a construção dos processos de avaliação é necessário se seguir os seguintes passos:

1) objetivo da avaliação; 
2) posição do avaliador;

3) enfoque priorizado;

4) metodologia predominante;

5) forma de utilização da informação;

6) contexto da avaliação;

7) temporalidade da avaliação; e

8) tipo de juízo formulado.

Considerando esses passos podemos fazer três tipos de avaliação, segundo Novaes (2000):

1) investigação avaliatória - conhecimento com a identificação de impactos obtidos pelas ações a serem avaliadas;

2) avaliação para decisão - tomada de decisão, que produza respostas para perguntas colocadas por aqueles que usam o objeto avaliado; e

3) avaliação para gestão - aperfeiçoamento do objeto avaliado.

A área da informática na saúde esta centralizada na coleta, processamento e comunicação de informações relacionadas à saúde e implementação de recursos de informação, geralmente para facilitar as atividades da área. Esses recursos de informação podem coletar, armazenar e processar dados relacionados à saúde de pessoas; gerenciar e argumentar sobre conhecimento biomédico e suporte a atividades relacionadas à saúde 
pública, permitindo muitas informações e consequentemente várias possibilidades de avaliação (Friedman e Wyatt, 2014).

Em conformidade, na avaliação de uma tecnologia ou programa, de início, deve haver o estabelecimento de um parâmetro de qualidade, a partir do qual serão construídos os instrumentos a serem utilizados na avaliação de qualidade. A avaliação da qualidade no serviço poderá constituir-se em pesquisa de avaliação, de avaliação para decisão ou avaliação para gestão (Novaes, 2000).

As avaliações de tecnologias devem permitir aos gestores a escolha dessas tecnologias ou não, para isso devem produzir conhecimentos, com fundamentação científica e metodológica, sobre a utilidade, benefícios e eficiência, entre outras informações, sobre o produto avaliado (Novaes, 2006).

A avaliação será influenciada por fatores de risco que podem afetar um determinado segmento do ciclo de vida do software. Uma organização pode executar avaliações formativas durante cada fase, dependendo das necessidades específicas, para avaliar as entradas, processos e recursos empregados durante o desenvolvimento (Wilcox et al, 2014).

Vários trabalhos foram publicados na área de avaliação em saúde, com foco na avaliação de RES, desses, 98 foram considerados relevantes e analisados no estudo realizado por Nguyen et al (2014). O período da pesquisa de revisão de literatura realizado foi de dez anos (2001-2011). Dos quais 39 
eram estudos de caso simples, e outros dez estudos de caso múltiplos, e outros tipos de pesquisa, 34. As pesquisas quantitativas foram os mais populares, com 62 artigos. Quase dois terços de artigos são de RES implementados nos Estados Unidos da América.

Isso pode ter sido influenciado por uma política que deu certo, mas custou investimento do governo dos Estados Unidos, por Obama, em 2009. O então presidente assinou a Lei Health Information Technology for Economic and Clinical Health (HITECH), que agora é dirigido pelo Office of the National Coordinator for Health Information Technology (ONC) - que comanda esforços para apoiar a adoção de TIC na saúde e a promoção de intercâmbio de informações em saúde a nível nacional. Essa Lei dá incentivos financeiros para melhorar o sistema de saúde através do uso do RES. Para receber um incentivo, os provedores devem mostrar que estão usando de forma significativa (meaningful use) seus RES cumprindo limites para um número de objetivos pré-estabelecidos (Thurston, 2014). Os dados de 2013 da Pesquisa Ambiental Anual de Cuidados Médicos Ambulatórios são encorajadores; cerca de $80 \%$ dos médicos usaram algum tipo de sistema RES, um aumento de 60 pontos percentuais desde 2001 (16\%) e quase o dobro da porcentagem em 2008 (42\%), ano anterior à Lei (ONC, 2014; Thurston, 2014).

Em 2001, países desenvolvidos como a Suécia e Países Baixos já tinham um intenso uso do RES pelos médicos, comparado com outros países, respectivamente $90 \%$ e $88 \%$ (Rudin et al, 2014). 
A maioria (37) dos trabalhos, no estudo realizado por Nguyen et al (2014), avaliou o impacto da implementação de RES em artigos terciários e cuidados primários (34). Estudos longitudinais predominaram. Os clínicos (médicos e enfermeiras) foram considerados o grupo dominante de participantes da pesquisa. Uma abordagem mista para a coleta de dados foi encontrada em 28 artigos. Os questionários foram os instrumentos de pesquisas mais usados (50), como um único método de coleta de dados (37), em conjunto com outro método de coleta de dados (13 artigos). A análise quantitativa de dados foi a mais popular (62 artigos), entre elas 57, com análise estatística. A análise qualitativa foi à base para 30 estudos.

No estudo realizado por Nguyen et al (2014), a preocupação com a qualidade das informações do RES foi importante em 23 estudos, dos 98 artigos. Nesses estudos precisava ser melhorada a acessibilidade, precisão, disponibilidade, mas teve um retorno positivo para legibilidade. Atributos de qualidade do sistema foram avaliados em 32 estudos. Os estudos abordaram características de segurança, confidencialidade, privacidade, usabilidade, utilidade, interface de saída (design), eficiência, navegabilidade, suporte, insuficiente para a tomada de decisão. A interoperabilidade dos sistemas de RES também foi considerada questão importante, além dela a portabilidade, a qualidade dos sistemas de pacientes (usuários diretos em portais da web), e a funcionalidade. A qualidade de serviço foi considerada como o suporte pela adoção do RES, treinamento de pessoal, suporte técnico (manutenção e 
alterações). Alguns estudos também abordaram questões de confiabilidade, estudando falhas no sistema (cinco artigos) associadas à implementação de RES. Nos estudos de ATS, para as características funcionalidade, usabilidade, e confiabilidade, destacamos os trabalhos de Pereira et al (2012); Pereira et al (2011); e o de Oliveira (2012). Para as características funcionalidade e usabilidade, destacamos o estudo de Rangel et al (2012); e para os estudos sobre usabilidade e confiabilidade, o estudo de Flores et al (2013).

Os artigos que focaram na satisfação com a adoção e o uso do RES, no estudo realizado por Nguyen et al (2014), levantaram uma atitude relativamente positiva na maioria dos trabalhos analisados, corroborado pelo estudo de Duarte e Azevedo (2017) em estudo realizado no Brasil.

No Brasil, segundo estimativas da SBIS apud Silva e Correia (2015), em 2012, aproximadamente entre $20 \%$ e $25 \%$ dos hospitais brasileiros possuíam algum tipo de sistema de informação, sendo que, 5\% destes contam com prontuário digital. 


\section{GESTÃO DE RISCO}

Chamamos de incerteza a possibilidade de um evento ocorrer, podendo haver uma ou mais consequências. Conforme ABNT (2009) incerteza "é o estado, mesmo que parcial, da deficiência das informações relacionadas a um evento, sua compreensão, seu conhecimento, sua consequência ou sua probabilidade". O risco é o efeito da incerteza nos seus objetivos, considerando que o efeito é um desvio em relação ao esperado, que pode ser positivo e/ou negativo e pode ser aplicado em diferentes níveis do produto de software (ABNT, 2009).

Existe o reconhecimento da necessidade de fazer com que a informática em saúde cresça, mas de forma segura. A possibilidade de se perder informações importantes no cuidado ao paciente, são uma das preocupações na adoção de sistemas para a área de saúde. No processo de informatização, a estabilidade do software pode permitir que a organização tenha riscos de comprometer as atividades do atendimento médico, de perder as informações, entre outras, sendo necessário conhecer esses riscos. Nesse sentido é importante investir em medidas que permitam a proteção dos dados e priorize a resolução o mais breve possível (Wazlawick, 2013; Gil e Arima, 2019): 
- Backups: a realização de backups periódicos permite que dados importantes sejam salvos no sistema de gestão e, então, estejam livres de riscos.

- Investir em prevenção de situações de contingência: riscos de danos aos equipamentos, roubos, incêndios e inundações que podem levar à perda dos dados ou comprometer a segurança das informações.

- Falhas de acesso à rede e ao equipamento que permite o acesso ao software, de maneira que comprometam o uso.

- Proteção dos dados: o acesso ao sistema deve ser feito apenas por meio de senhas de acesso, com a possibilidade de criar um histórico de acesso e disposição de funcionalidades para cada, dependendo de nível de acesso. Os dados devem atender à legislação brasileira.

- Suporte a falhas: os softwares estão sujeitos a falhas diversas, sendo importante o suporte técnico imediato, para ser identificado e reparado o problema.

Para que o gerenciamento de risco se torne eficaz, é necessário desenvolver e implementar um plano, visando a integração do processo de gerenciar riscos (Figura 1) na governança da organização.

A estruturação da gestão de riscos é estratégica e fornecem os objetivos e as atividades organizacionais para a concepção, implementação, monitoramento, análise crítica e melhoria contínua da gestão de riscos na organização (ABNT, 2009). 


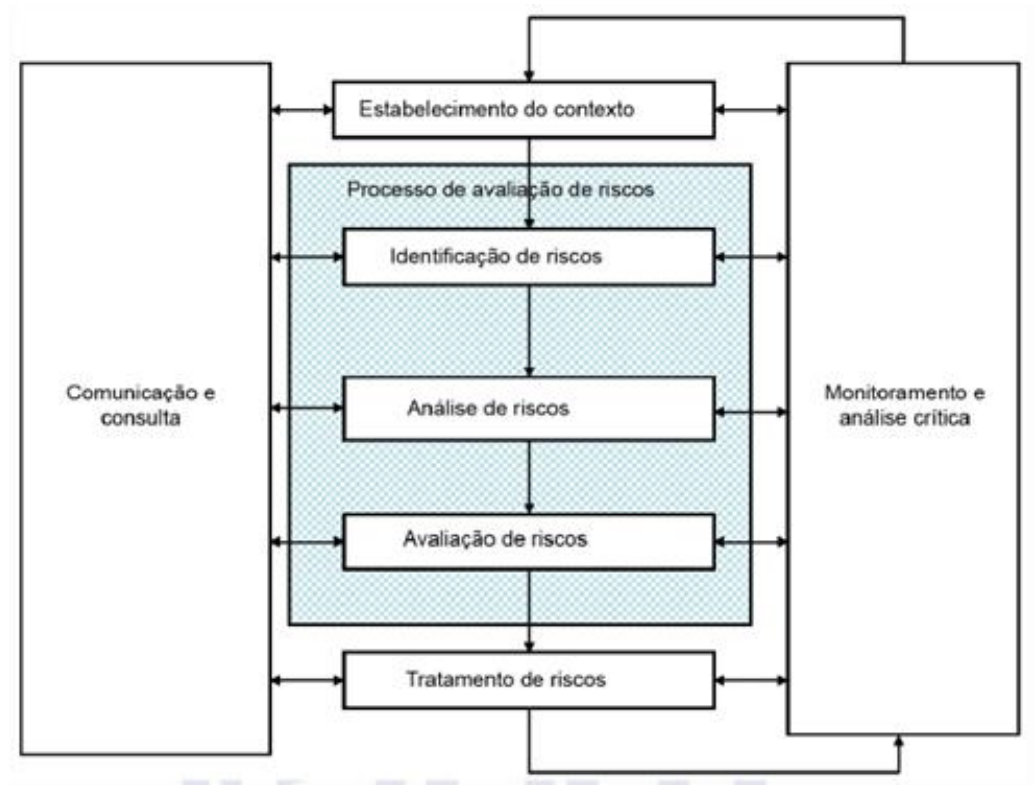

Figura 1 - Processo de gestão de riscos Fonte: ABNT, 2009.

No processo de gestão de riscos (Figura 1), a comunicação e a consulta dos interessados deve acontecer durante todas as fases do processo de gestão de riscos assim como o monitoramento e a análise crítica, que devem envolver a vigilância periódica e análise dos eventos. $O$ estabelecimento do contexto se refere a definição de parâmetros externos e internos a serem levados em consideração, definição de escopo e os critérios de risco para o processo de avaliação de riscos. O processo de avaliação de riscos é o processo que envolve a identificação, análise, avaliação e tratamento de riscos, conforme (ABNT, 2009):

- Identificação de riscos: As fontes de riscos devem ser identificadas pela organização, além das causas e consequências, com a finalidade de 
prever consequências aos objetivos. Deve-se dar atenção as causas e os cenários onde possam ocorrer.

- Análise de riscos: Refere-se à compreensão dos riscos, através da identificação dos fatores que afetam as consequências e probabilidades nos objetivos.

- Avaliação de riscos: Fase para tomadas as decisões conforme os resultados apresentados na análise de riscos. Há a necessidade de se identificar o tratamento e a prioridade para o tratamento acontecer, conforme o nível do risco encontrado e critérios pré-estabelecidos.

- Tratamento de riscos: Processo que é usado para alterar o risco, quer seja pela remoção da fonte de risco, e/ou descontinuar a atividade que dá origem ao risco, e modificação das consequências causadas.

A IEC 31010 fornece orientação sobre técnicas de processo de avaliação de riscos.

\subsection{Orthogonal Defect Classification (ODC)}

A ODC é a classificação de defeitos ortogonais usada pela International Business Machines (IBM), e permite a classificação dos defeitos relatados a partir de falhas encontradas nas várias fases do software, e propõe um impacto dependendo do defeito encontrado (Chillarege et al, 1992).

Para fazer essa classificação é necessário fazer as seguintes etapas: selecionar o gatilho que mais se aproxima do catalisador que gerou o defeito; e 
identificar qual a atividade desencadeante no momento em que aconteceu a falha. No Quadro 3 a seguir apresentamos os atributos ODC que estão disponíveis quando o defeito é aberto.

Quadro 3 - Atividade de remoção de defeitos, gatilhos e impacto na abertura do defeito

\begin{tabular}{|c|c|c|}
\hline $\begin{array}{l}\text { Atividades de } \\
\text { remoção de defeitos }\end{array}$ & Gatilhos & Impacto \\
\hline $\begin{array}{l}\text { Revisão do design } \\
\text { Inspeção de código } \\
\text { Teste de unidade } \\
\text { Teste de função } \\
\text { Teste do sistema } \\
\text { Campo }\end{array}$ & $\begin{array}{l}\text { Conformidade do projeto } \\
\text { Lógica / Fluxo } \\
\text { Compatibilidade com versões anteriores } \\
\text { Compatibilidade lateral } \\
\text { Concorrência } \\
\text { Documento interno } \\
\text { Dependência da linguagem } \\
\text { Efeito colateral } \\
\text { Situações raras } \\
\text { Cobertura do teste } \\
\text { Variação de teste } \\
\text { Sequenciamento de teste } \\
\text { Interação de teste } \\
\text { Carga de trabalho / estresse } \\
\text { Recuperação / Exceção } \\
\text { Iniciar / reiniciar } \\
\text { Configuração de Hardware } \\
\text { Configuração de software } \\
\text { Caminho Simples } \\
\text { Caminho Complexo } \\
\text { Teste Bloqueado }\end{array}$ & $\begin{array}{l}\text { Instalabilidade } \\
\text { Facilidade de manutenção } \\
\text { Padrões } \\
\text { Integridade / Segurança } \\
\text { Migração } \\
\text { Confiabilidade } \\
\text { Desempenho } \\
\text { Documentação } \\
\text { Requisitos } \\
\text { Manutenção } \\
\text { Usabilidade } \\
\text { Acessibilidade } \\
\text { Capacidade }\end{array}$ \\
\hline
\end{tabular}

Fonte: Adaptado de IBM (2013) e Chillarege et al (1992).

As várias atividades de remoção de defeitos se referem à fase em que se encontra o software que terá seus defeitos classificados (Chillarege et al, 1992 e IBM, 2013):

1) Revisão do design: Revisão ou comparação do design documentado com os requisitos conhecidos.

2) Inspeção de código: Examinar ou comparar o código com o design documentado. 
3) Teste de unidade: Testar ou executar a caixa branca com base no conhecimento detalhado do código interno.

4) Teste de função: Executar a caixa preta com base em especificações externas de funcionalidade.

5) Teste do sistema: Testar ou executar o sistema completo, no ambiente real, exigindo todos os recursos.

6) Campo: Defeitos relatados pelo cliente, que compartilham um banco de dados com descobertas em processo, devem seguir as etapas em relação à atividade e gatilho:

a) Selecionar o gatilho que mais se aproxima como catalisador do defeito apontado.

b) Selecionar a atividade interna que tem a responsabilidade principal de gerar o gatilho selecionado e mostrar em um campo.

Os gatilhos ODC (Quadro 3) estão brevemente descritos a seguir (Chillarege et al, 1992 e IBM, 2013):

1) Conformidade do projeto: Conformidade das especificações com etapas anteriores para garantir a falta ou imprecisão dos requisitos (documentos de design, código, práticas de desenvolvimento e padrões).

2) Lógica / Fluxo: Conhecer padrões básicos de programação para examinar o fluxo da lógica para garantir que eles estejam corretos.

3) Compatibilidade com versões anteriores: Identificar uma incompatibilidade entre os requisitos ou o código e as versões anteriores do mesmo 
produto. $\mathrm{O}$ aplicativo que foi executado com sucesso na versão anterior, falha na versão atual.

4) Compatibilidade lateral: Incompatibilidade entre os requisitos ou o código de um produto, e os outros sistemas, produtos, serviços, componentes ou módulos com os quais ele deve interagir.

5) Concorrência: Serialização para controlar um recurso compartilhado quando o defeito é descoberto; incluindo as múltiplas funções e processos.

6) Documento interno: Informações incorretas, inconsistência ou incompletude dentro da documentação interna (comentários de código).

7) Dependência da linguagem: Conflitos com os padrões, compilação de linguagem em uso (linguagem de implementação).

8) Efeito colateral: Resultado de uso comum ou configurações, mas fora do escopo do componente ou função com a qual o design ou código em análise está associado.

9) Situações raras: Comportamento do sistema que não é considerado pelo projeto ou código documentado em análise, e normalmente seria associado a configurações ou uso incomuns.

10) Cobertura do teste: Tentativa direta de exercer o código para uma única função, sem usar parâmetros ou um único conjunto de parâmetros.

11) Variação de teste: Tentativa direta de exercer o código para uma única função, mas usando uma variedade de entradas e parâmetros. 
12) Sequenciamento de teste: Execução de várias funções em uma sequência muito específica. Cada função é executada com sucesso quando executado de forma independente, mas falha nessa sequência específica.

13) Interação de teste: Interação entre dois ou mais corpos de código, quando cada função é executada com sucesso quando executado de forma independente, mas falha nesta combinação específica.

14) Carga de trabalho / Estresse: Operação do sistema perto de algum limite de recursos, superior ou inferior, criados por meio de uma variedade de mecanismos.

15) Recuperação / Exceção: Invocar um manipulador de exceção ou algum tipo de código de recuperação, se o defeito estiver na capacidade do sistema ou do produto de se recuperar de uma falha, e não da própria falha.

16) Iniciar / reiniciar: O sistema estava sendo inicializado ou reiniciado após algum desligamento anterior ou falha completa no sistema ou no subsistema.

17) Configuração de hardware: $O$ sistema estava sendo testado para garantir que as funções sejam executadas corretamente em configurações de hardware específicas.

18) Configuração de software: $O$ sistema estava sendo testado para garantir que as funções sejam executadas corretamente em configurações de software específicas. 
19) Caminho Simples: No teste o testador invocou o conhecimento de ramos específicos no código e não pelo conhecimento externo da funcionalidade.

20) Caminho Complexo: No teste o testador tentou invocar a execução de vários ramos em várias condições diferentes.

21) Teste Bloqueado: O produto está funcionando bem dentro dos limites de recursos e o defeito surgiu ao tentar executar um cenário de teste do sistema.

A análise dos dados fornecidos pela aplicação do ODC é valiosa como diagnóstico para avaliar o software em suas várias fases: projeto, desenvolvimento, teste e campo, podendo impactar a instalabilidade, a facilidade de manutenção, padrões, a integridade/segurança, a migração, a confiabilidade, o desempenho, a documentação, os requisitos, manutenção, a usabilidade, a acessibilidade e a capacidade, e consequentemente a qualidade do produto de software. A ODC prevê ainda atributos para quando o defeito for corrigido, como o local e tipo de defeito encontrado (Chillarege et al, 1992).

\subsection{Failure Mode and Effect Analysis (FMEA)}

A metodologia FMEA - análise do modo e efeito de falha, é uma técnica que permite avaliar e minimizar riscos através da análise das possíveis falhas, determinando a causa, o efeito e o risco da cada tipo de falha e respectivos defeitos, permitindo implantar ações para resolver os defeitos e aumentar a 
confiabilidade, atuando principalmente na prevenção de falhas, mas também pode ser usado para análise, como complemento de outras técnicas, visando o controle do risco (ABNT, 2009).

A análise FMEA pode ser usada para projetos de novos produtos ou processos e pode ser aplicada para diminuir a probabilidade da ocorrência de falhas; de falhas que ainda não tenham ocorrido e de erros; aumentando assim a confiabilidade e a qualidade. Essa análise baseia-se na formação de uma equipe de profissionais que identificam para o produto/processo em análise, suas funções, os tipos de falhas que podem ocorrer, os efeitos e as possíveis causas desta falha. A seguir índices de severidade, probabilidade de ocorrência e riscos são levantados e as ações necessárias para diminuir os riscos são realizadas para aumentar a confiabilidade do produto/processo. A técnica FMEA deve ser continuada, e revisada sempre que ocorrerem alterações para um produto/processo específico, inclusive verificando se não há falhas não previstas (ABNT, 2009).

\subsection{Considerações Finais}

O grande avanço da tecnologia tem estimulado as instituições de saúde a adquirirem ou desenvolverem um sistema próprio com aplicativos personalizados que satisfaçam melhor suas necessidades e complementem outros. Assim a engenharia de software deve prover o mercado de novos 
sistemas capazes de serem integrados com os já existentes que funcionem corretamente e permitam aferições de seu desempenho de forma seriada para que medidas saneadoras sejam instituídas, sempre que for necessário (Wilcox et al, 2014).

$\mathrm{Na}$ área de saúde, para garantir que o software satisfaça os requisitos solicitados, uma verificação formal e validação do software são necessárias. O software também é validado para mostrar que ele executa de acordo com os requisitos operacionais especificados, que produz saídas válidas, e que pode ser operado de forma segura. Nesse sentido, os usuários podem ajudar a identificar inconsistências de dados ou funções do software. São importantes: o monitoramento da aplicação e o feedback dos usuários (Wilcox et al, 2014).

Considerando a implantação do PEG-software, pretendemos responder algumas questões nesse estudo:

a) Os usuários estão satisfeitos com o PEG-software (quanto à usabilidade, funcionalidade, confiabilidade e serviço)?

b) Facilita o trabalho médico durante a consulta?

c) Disponibiliza informações referentes ao histórico de atendimentos dos pacientes, com a finalidade de estudo para atendimento do paciente e/ou para pesquisa e trabalhos científicos?

d) Proporciona segurança das informações clínicas através do sistema, considerando o que era usado em papel? 
Considerando as questões levantadas, faz-se necessário verificar se as solicitações dos usuários foram atendidas e satisfazem as necessidades do departamento da UG como software de repositório eletrônico de dados clínicos e pesquisa. Conforme ABNT NBR ISO/IEC 9126-1 (2003, pág. 15):

É importante que medições assinalem valores que coincidam com expectativas normais. Por exemplo, se a medição sugere que o produto é de alta qualidade, então convém que o respectivo produto satisfaça necessidades específicas do usuário.

Dessa forma é necessária uma aferição da qualidade do PEG-software já implantado e de suas alterações, fazendo os ajustes necessários para que sejam sanados os defeitos apontados, melhorando a qualidade do software. Sem essas medidas, poderia haver um prejuízo das informações obtidas a partir do atendimento médico de forma geral. Entretanto, na genética, esse prejuízo seria ainda maior, uma vez que as informações obtidas são extremamente específicas e, muitas vezes, só importam para esse campo de atuação. Portanto, a criação do PEG-software, sistema específico para a área de genética e a sua avaliação, é de fundamental importância para a manipulação das informações coletadas e armazenadas no banco de dados gerado, permitindo ampliar as pesquisas da UG, presentes e futuras, com maior fidedignidade e precisão, além de facilitar os serviços dos médicos no atendimento ambulatorial. 


\section{OBJETIVOS}

A seguir, apresentamos o objetivo geral e os objetivos específicos desse estudo.

\subsection{Objetivo Geral}

O presente estudo tem o objetivo de fazer a avaliação e evolução temporal do PEG-software, quanto à qualidade, levantando seus defeitos e sugestões de melhorias.

\subsection{Objetivos Específicos}

A avaliação e evolução de qualidade do PEG-software verificará suas evolutivas quanto aos seguintes tópicos:

a) Características funcionalidade, usabilidade, e confiabilidade conforme ISO/IEC 25010 e suas antecessoras;

b) Quanto ao serviço de atendimento médico;

c) Levantamento e classificação dos defeitos;

d) Sugestões de melhorias. 
A seguir apresentamos a metodologia que será adotada, os resultados, discussão desses resultados obtidos comparando com outros estudos semelhantes, a conclusão, os anexos, e referências bibliográficas. 


\section{METODOLOGIA}

Nesse capítulo, descrevemos a metodologia que foi usada para avaliar a qualidade do PEG-software, e o levantamento e classificação de defeitos.

\subsection{Processo de Avaliação da Qualidade}

Os sujeitos para esse estudo foram os integrantes do grupo de médicos que atende na UG (usuários), composto por quatro assistentes, e um número variável de residentes e de estagiários. Todos assinaram o Termo de Consentimento Livre e Esclarecido, em cumprimento à Resolução 196/96 do Conselho Nacional de Saúde (CNS). O projeto se encontra devidamente registrado na Comissão de Ética para Análise de Projetos de Pesquisa (CAPPesq) da Faculdade de Medicina da Universidade de São Paulo (FMUSP) sob o no. $0257 / 08$.

Foram aplicados dois questionários específicos, um baseado no sistema de avaliação de qualidade de software, a Ficha de Avaliação (Anexo D), baseado em algumas das características de qualidade da ABNT NBR ISO/IEC 9126-1(2003) e ISO/IEC 25010 (2010), visando avaliação semiquantitativa dos recursos de qualidade do PEG-software, e outro para mensuração dos defeitos, Ficha de Detecção de Defeitos (Anexo E), baseado no PEG-software. 
A periodicidade da avaliação do PEG-software foi a cada seis meses, totalizando seis avaliações, sendo que a primeira avaliação ocorreu em 04/2015, e a sexta avaliação em 10/2017.

\subsubsection{Avaliação ISO/IEC 25010 e suas antecessoras}

A Ficha de Avaliação do PEG-software foi realizada com as características de qualidade funcionalidade, usabilidade e confiabilidade e algumas de suas subcaracterísticas (Anexo D), conforme definido pela ISO/IEC 25010 (2011) (ABNT, 2003 e 2010). Além disso, propomos e incluímos um quarto recurso de qualidade de software, denominado Serviço: que trata do layout funcional do PEG-software: suas funções; o vocabulário utilizado e a sua clareza para a equipe médica; o tempo necessário para preencher os registros médicos; a possibilidade de fazer inserções relacionadas à assistência posteriormente e permitir consultas de dados para atendimento ambulatorial e pesquisa.

A conformidade, que é subcategoria de todas as características de qualidade de software é usada para verificar se o software obedece aos requisitos de legislação e padrões estabelecidos no projeto (Costa, 2013). Para esse estudo avaliamos conformidade, interoperabilidade e segurança como subcaracterísticas apenas para a característica Funcionalidade, conforme prescrito na norma ABNT NBR ISO/IEC 9126-1(2003). 


\subsubsection{Definição da forma de avaliação}

Para fazer essa avaliação sob a perspectiva do usuário, foram propostas 34 afirmações que descrevem as características no serviço de atendimento e nas características de funcionalidade, usabilidade e confiabilidade do software, na Ficha de Avaliação (Anexo D), relativas ao PEGsoftware. Os usuários foram solicitados a avaliar cada afirmação de acordo com cinco notas (Likert, 1935; Pereira, 2001) (Anexo H), pontuadas como Discordo Totalmente (1); Discordo (2); Indiferente (ou neutro) (3); Concordo (4) e Concordo Plenamente (5).

As respostas aos itens da avaliação de satisfação do usuário foram ainda classificadas como respostas (Anexo $\mathrm{H})$ :

- negativas, para as opções 1 e 2;

- neutras, para a opção 3; e

- positivas, para as opções 4 e 5 .

Qualquer característica avaliada será considerada satisfatória se obter mais de $70 \%$ de respostas positivas (ABNT, 2010).

\subsubsection{Variáveis Explicativas de Qualidade}

O Quadro 4 apresenta as características e subcaracterísticas de qualidade que nos propomos a avaliar, e sua relação com a afirmação da Ficha 


\section{de Avaliação (Anexo D) que será usada para o levantamento da opinião dos}

médicos, usuários do PEG-software.

Quadro 4 - Definição de características e subcaracterísticas com as respectivas questões para avaliação

\begin{tabular}{|c|c|c|}
\hline Carac. & Subcaracterísticas & Afirmações chave \\
\hline \multirow[t]{6}{*}{ 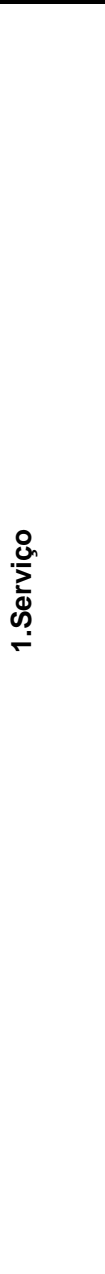 } & $\begin{array}{l}\text { Organização das } \\
\text { Funções do Sistema - } \\
\text { Layout }\end{array}$ & 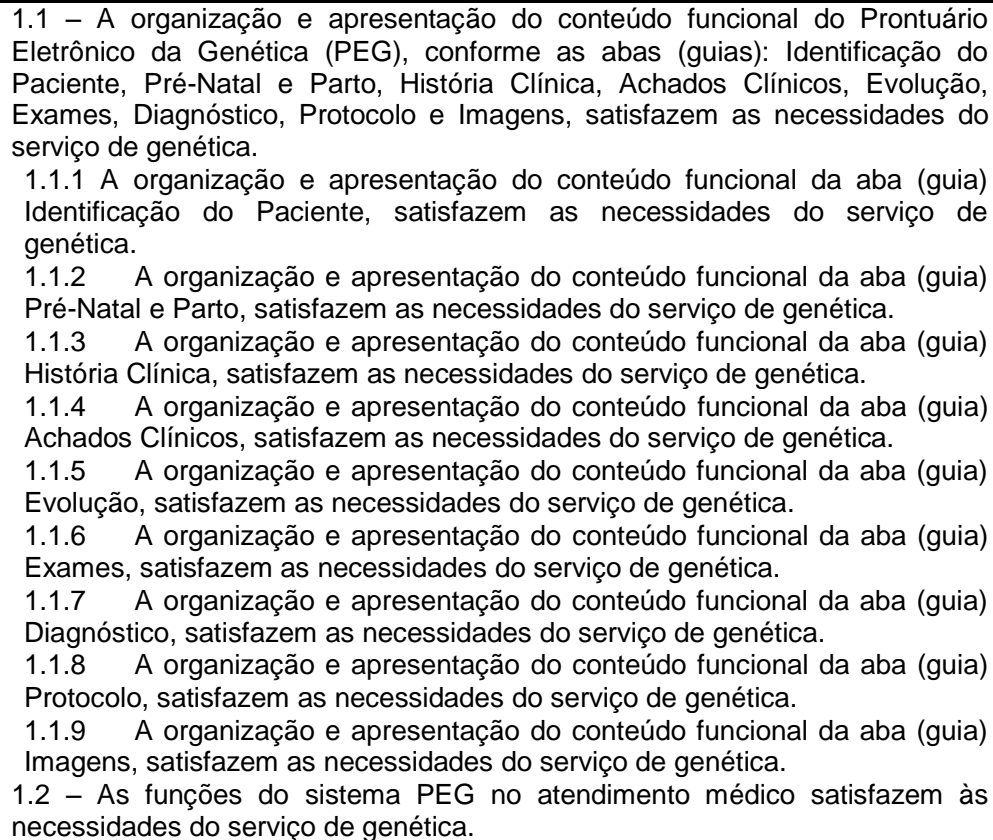 \\
\hline & $\begin{array}{l}\text { Clareza das } \\
\text { Informações }\end{array}$ & $\begin{array}{l}1.3 \text { - O uso do sistema permite maior clareza na leitura do histórico do } \\
\text { paciente. } \\
1.4-\mathrm{A} \text { linguagem usada é natural, os termos, frases, conceitos são similares } \\
\text { àqueles usados no meu dia-a-dia ou no ambiente de estudo. }\end{array}$ \\
\hline & $\begin{array}{l}\text { Tempo de } \\
\text { Preenchimento }\end{array}$ & $\begin{array}{l}1.5-\text { O tempo para preencher a ficha clínica através do sistema é menor que o } \\
\text { preenchimento manual (no papel). }\end{array}$ \\
\hline & Manutenção & $\begin{array}{l}1.6 \text { - Na impossibilidade de inclusão da consulta agendada no sistema PEG, } \\
\text { por problemas na rede, posso inserir a consulta manual em outro momento. }\end{array}$ \\
\hline & Diminuição de Papéis & $\begin{array}{l}1.7 \text { - Houve diminuição de papéis na sala de genética com o uso do sistema } \\
\text { de PEG. }\end{array}$ \\
\hline & Consultas & $\begin{array}{l}1.8 \text { - Faço consultas no sistema, com a finalidade de atendimento } \\
\text { ambulatorial. } \\
1.9 \text { - Faço consultas no sistema, com a finalidade de pesquisa. }\end{array}$ \\
\hline \multirow{5}{*}{ 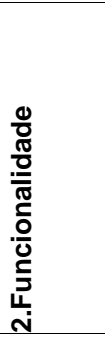 } & Adequação & 2.1 -O PEG é adequado para o registro dos dados do paciente. \\
\hline & Acurácia & $\begin{array}{l}2.2 \text { - Considerando que o propósito é substituir a Ficha do Paciente antiga } \\
\text { (manuscrita) pela eletrônica, o PEG, faz isso de forma correta. }\end{array}$ \\
\hline & Interoperabilidade & 2.3 - Interage com sistema agenda, já existente. \\
\hline & Segurança de acesso & $\begin{array}{l}2.4 \text { - Evita acesso não autorizado aos dados. } \\
2.5 \text { - Faço uso de senha de acesso para poder usar o sistema PEG. }\end{array}$ \\
\hline & nformidade & $\begin{array}{l}2.6 \text { - O Sistema está de acordo com as normas, leis, etc. (mantém a } \\
\text { impressão em papel, mesmo tendo a forma eletrônica). }\end{array}$ \\
\hline
\end{tabular}




\begin{tabular}{|c|c|c|}
\hline Carac. & Subcaracterísticas & Afirmações chave - continuação \\
\hline \multirow{3}{*}{ 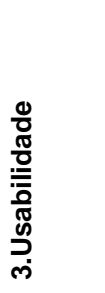 } & Intelegibilidade & 3.1 - É fácil entender o conceito e aplicação. \\
\hline & Apreensibilidade & $\begin{array}{l}3.2 \text { - É fácil aprender a usar. } \\
\text { 3.3 - Estão disponíveis instruções de como usar o sistema. }\end{array}$ \\
\hline & Operacionalidade & $\begin{array}{l}3.4 \text { - É fácil de operar e controlar. } \\
\text { 3.5 - O Sistema PEG é ágil. } \\
\text { 3.6 - O Sistema PEG possui boa navegabilidade. }\end{array}$ \\
\hline \multirow{3}{*}{ 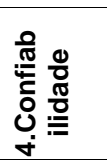 } & Maturidade & 4.1 - Não apresenta falhas frequentemente. \\
\hline & Tolerância a falhas & 4.2 - Na ocorrência de falhas, não ocorre perda de dados. \\
\hline & Recuperabilidade & 4.3 - É capaz de recuperar dados em caso de falhas. \\
\hline
\end{tabular}

Fonte: Característica Serviço - da autora e características Funcionalidade, Usabilidade e Confiabilidade adaptado da ABNT NBR ISO/IEC 9126 (1996), Sperandio (2008), Pereira et al (2012) e Flores et al (2013).

As variáveis explicativas de qualidade serão as características e subcaracterísticas relacionadas, referente ao serviço, funcionalidade, usabilidade e confiabilidade.

O Quadro 4 gerou o seguinte resumo que será mostrado no resultado da avaliação, calculados através da média do conjunto de afirmações chave positivas para cada subcaracterística.

a) Variáveis explicativas de qualidade no serviço:

- Organização das Funções do Sistema - Layout

- Clareza das Informações;

- Tempo de Preenchimento;

- Manutenção;

- Diminuição de Papéis;

- Consultas. 
b) Variáveis explicativas de qualidade na funcionalidade:

- Adequação;

- Acurácia;

- Interoperabilidade;

- Segurança de acesso;

- Conformidade.

c) Variáveis explicativas de qualidade na usabilidade:

- Intelegibilidade;

- Apreensibilidade;

- Operacionalidade.

d) Variáveis explicativas de qualidade na confiabilidade:

- Maturidade;

- Tolerância a falhas;

- Recuperabilidade.

\subsubsection{Definição de Indicador de Satisfação (IS)}

Consideramos o percentual das respostas classificadas como satisfatórias dentre o total de respostas da ficha de avaliação (Serviço, Funcionalidade, Usabilidade e Confiabilidade) por semestre, conforme ABNT 
NBR ISO/IEC 14958-6 (2010). O indicador de satisfação (IS) será obtido através do número de respostas satisfatórias por período de tempo (ST) dividido pelo número total de respostas durante o período de tempo (TT) (Wazlawick, 2013):

$$
I S=\frac{S T}{T T}
$$

Os valores obtidos do IS (respostas positivas) para cada característica e subcaracterística, será desejável ser maior que $70 \%$ de respostas positivas, para ser considerado satisfatório, conforme orienta a ABNT NBR ISO/IEC 14598-6 (2010).

A seguir apresentamos como serão realizadas as aferições dos defeitos do PEG-software.

\subsection{Mensurando os Defeitos do Software}

Dois instrumentos diferentes foram desenvolvidos e utilizados para registrar e calcular os defeitos do PEG-software, conforme detectado pelos usuários. Primeiro, uma Pasta de Defeitos introduzida no diretório da UG para permitir o registro imediato de qualquer defeito observado pelos usuários, sob a forma de uma lista de defeitos. Nesse sentido, os administradores do software também poderiam registrar as medidas corretivas adotadas e legíveis pelos usuários e gestor da UG. Em segundo lugar, uma ficha específica de detecção 
de defeitos (Anexo E) também foi desenvolvida e usada para ajudar a detectar e posteriormente remover defeitos do software. Esta folha é estruturada de acordo com as seções do PEG-software e foi distribuída ativamente entre os usuários a cada seis meses, juntamente com a Folha de Avaliação. Nesta folha, o usuário aponta qualquer falha que tenha ocorrido ao usar o PEGsoftware, conforme indicado no próprio formulário.

Os defeitos poderiam ser considerados válidos ou não válidos. Os defeitos válidos eram apenas aqueles que afetavam o serviço, a usabilidade ou a funcionalidade do software, além daqueles que comprometiam 0 armazenamento de dados. Os pedidos de alterações para melhorar o software eram defeitos não válidos; e considerados como novos requisitos que só seriam implementados com a autorização do diretor da unidade. Além disso, os defeitos eram considerados internos, quando diretamente relacionados ao PEG-software, ou externos, quando relacionados à interconectividade (conexão, dados recebidos, etc.) entre o PEG-software e o software principal Institucional.

Os defeitos do PEG-software também são classificados de acordo com os gatilhos da Orthogonal Defect Classification (ODC). E a análise de defeitos realizada através do método Failure Mode and Effect Analysis (FMEA), a seguir descritos. 


\subsubsection{ODC}

Para fazer essa classificação de defeitos ortogonais pela ODC, como vimos, é necessário selecionar o gatilho que originou o defeito; e identificar a atividade que estava sendo usada no momento em que aconteceu a falha. No Quadro 5 a seguir apresentamos os gatilhos que usaremos como base para nossos estudos. 
Quadro 5 - Gatilhos da Orthogonal Defect Classification (ODC)

\begin{tabular}{|cl|}
\hline Número & \multicolumn{1}{c|}{ Gatilhos } \\
\hline 1 & Conformidade do projeto \\
2 & Lógica / Fluxo \\
3 & Compatibilidade com versões anteriores \\
4 & Compatibilidade lateral \\
5 & Concorrência \\
6 & Documento interno \\
7 & Dependência de idioma \\
8 & Efeito colateral \\
9 & Situações raras \\
10 & Cobertura do teste \\
11 & Variação de teste \\
12 & Sequenciamento de teste \\
13 & Interação de teste \\
14 & Carga de trabalho / estresse \\
15 & Recuperação / Exceção \\
16 & Iniciar / reiniciar \\
17 & Configuração de Hardware \\
18 & Configuração de Software \\
19 & Caminho Simples \\
20 & Caminho Complexo \\
21 & Teste Bloqueado \\
\hline
\end{tabular}

Fonte: Adaptado de IBM (2013) e Chillarege et al (1992)

Quando uma falha é informada pelo usuário e um defeito é aberto, o impacto para o cliente é iminente. Procurando uma melhor análise, atributos adicionais não ODC podem ser usados em conjunto, visto que a ODC não impõe uma estrutura específica, usa o conjunto de dados em relação ao produto, para organizar a análise de maneira mais eficiente visando ações técnicas de saneamento. Nesse sentido, usaremos o FMEA, a seguir descrito, para auxiliar em nossos estudos. 


\subsubsection{FMEA}

Usaremos a metodologia FMEA como auxiliar na análise dos defeitos apontados pelos usuários, permitindo anotar adequadamente o levantamento da severidade, probabilidade de ocorrência e os riscos. Com base nos resultados obtidos nos riscos, priorizar ações para solução de defeitos (Anexo F).

\subsubsection{Classificação de Defeitos (Severidade, Ocorrência e Risco)}

Os quadros apresentados a seguir mostram as faixas de severidade, ocorrência e risco, que usaremos para a classificação dos defeitos no formulário FMEA, em local apropriado para o registro sobre a avaliação do PEG-software. O Quadro 6, mostra a classificação dos defeitos segundo sua severidade, como Leve, Moderado, Elevado e Crítico, considerando os critérios a seguir descritos.

Quadro 6 - Classificação dos Defeitos do PEG-software quanto à Severidade

\begin{tabular}{|c|c|c|}
\hline Índice & Severidade & Critério \\
\hline 1 & Leve & $\begin{array}{l}\text { Defeitos de layout, estética ou exibição que não provoquem nenhum tipo } \\
\text { de perda de dados ou o andamento do serviço de atendimento do } \\
\text { paciente. }\end{array}$ \\
\hline 2 & Moderado & $\begin{array}{l}\text { Defeitos em funcionalidades secundárias do software, permitindo o uso } \\
\text { da aplicação no atendimento do paciente, e que não sejam significativas } \\
\text { para a continuidade do atendimento. }\end{array}$ \\
\hline 3 & Elevado & $\begin{array}{l}\text { Defeitos em funcionalidades principais do software, impossibilitando o } \\
\text { uso do software para determinada situação, mas não impede a } \\
\text { continuidade do uso da aplicação para outros pacientes. }\end{array}$ \\
\hline 4 & Crítico & $\begin{array}{l}\text { Defeitos em funcionalidades principais do software, que impossibilitam a } \\
\text { utilização do software no atendimento ao paciente. }\end{array}$ \\
\hline
\end{tabular}

Fonte: Adaptado de Hutcheson (2003) 
A Quadro 7 apresenta a classificação dos defeitos quanto à Probabilidade de Ocorrência com critérios em percentuais.

Quadro 7 - Classificação dos Defeitos quanto à Probabilidade de Ocorrência

\begin{tabular}{|c|l|l|}
\hline \multicolumn{2}{|c|}{ Probabilidade de Ocorrência } \\
\hline Índice & Ocorrência & Critério \\
\hline 1 & Raro & $<25 \%$ \\
2 & Incomum & $>=25 \%$ e $<50 \%$ \\
3 & Ocasional & $>=50 \%$ e $<75 \%$ \\
4 & Comum & $>=75 \%$ \\
\hline
\end{tabular}

Fonte: Adaptado de Hutcheson (2003)

Para se calcular a avaliação dos Riscos, é necessário serem definidos os índices de severidade e probabilidade de ocorrência para cada causa de falha, de acordo com os quadros anteriores, depois é encontrada a prioridade de risco, utilizando o Quadro 8. A matriz de risco possibilita ver rapidamente quais são os riscos sobre os defeitos que precisam receber correção com mais urgência. A prioridade segundo o valor de risco, para o nosso estudo, segue a classificação a seguir:

1) Crítica (vermelho) - o defeito deve ser corrigido imediatamente;

2) Elevada (amarelo) - o defeito tem prioridade alta e tem prioridade sobre os defeitos de nível médio e baixo;

3) Moderada (verde) - o defeito deve ser corrigido assim que possível, mas tem prioridade sobre o nível baixo; 
4) Leve (branco) - o defeito pode ser corrigido em outro momento, entrando na lista de espera.

Quadro 8 - Matriz de Risco - Severidade e Probabilidade de Ocorrência

\begin{tabular}{|l|c|c|c|c|}
\hline \multirow{2}{*}{$\begin{array}{l}\text { Severidade } \\
\text { (linhas) }\end{array}$} & \multicolumn{4}{|l|}{ Probabilidade de Ocorrência (colunas) } \\
\cline { 2 - 5 } & Comum (4) & Ocasional (3) & Incomum (2) & Raro (1) \\
\hline Crítica (4) & $4 ; 4$ & $4 ; 3$ & $4 ; 2$ & $4 ; 1$ \\
\hline Elevada (3) & $3 ; 4$ & $3 ; 3$ & $3 ; 2$ & $3 ; 1$ \\
\hline Moderada (2) & $2 ; 4$ & $2 ; 3$ & $2 ; 2$ & $2 ; 1$ \\
\hline Leve (1) & $1 ; 4$ & $1 ; 3$ & $1 ; 2$ & $1 ; 1$ \\
\hline
\end{tabular}

Fonte: Adaptado de Farkas (2017).

Nota: Para os valores na matriz considerar Linha; Coluna.

O número e o tipo de defeitos serão registrados e computados para uma análise do PEG-software.

\subsubsection{Definição de Indicadores de Defeitos}

Para fazer a definição de indicadores é necessário relembrar que os defeitos serão classificados como válidos ou não válidos. Os defeitos válidos são aqueles que afetavam o serviço, a usabilidade ou a funcionalidade do software, além daqueles que comprometem o armazenamento de dados. Os pedidos de alterações para melhorar o software são defeitos não válidos e considerados como novos requisitos que só seriam implementados com a autorização do gestor da unidade. Além disso, os defeitos são considerados internos, quando diretamente relacionados ao PEG-software, ou externos, 
quando relacionados à interconectividade (conexão, dados recebidos, etc) entre o PEG-software e o software principal Institucional.

Usamos dois indicadores para avaliar quantitativamente a ocorrência de defeitos no PEG-software.

a) Primeiro, a partir da apuração dos defeitos apontados na Ficha de Detecção de Defeitos (Anexo E), e na lista de defeitos diários, usou-se o indicador de TD obtido pelo número de defeitos válidos, informados no período de tempo (DT) avaliado, dividido pelo número de usuários do software durante o período de tempo (UT) estudado (Wazlawick, 2013), como segue:

$$
\mathrm{TD}=\underline{\mathrm{DT}}
$$

UT

Vamos considerar que quanto menor a TD maior é a confiabilidade. Cada alteração de software pode aumentar o número de defeitos, portanto, deve ser informado por ocasião do resultado da avaliação.

b) Em segundo lugar, usamos um indicador de taxa de defeitos relacionado ao número de linhas de código do software. Este indicador, conhecido como KSLoC (Wazlawick, 2013), é definido como o número de defeitos válidos no período de tempo (DT) relatados pelos usuários, dividido pelo número de linhas de código (NLoc) do software, em um determinado 
intervalo de tempo, normalizado por mil linhas de código (KsLoC = (DT / NLoC) *1000).

Vamos considerar que quanto menor o resultado de KsLoC maior é a confiabilidade.

\subsection{Tratamento dos dados e análise}

Os dados serão digitados e armazenados em planilha eletrônica Excel ${ }^{\circledR}$, e as análises feitas por períodos semestrais, assim que obtidas todas as avaliações. A frequência de respostas positivas entre as fases serão comparadas através de testes qui-quadrado, quando apropriado. Os defeitos também serão comparados, considerando todas as fases. Outros tipos de análise poderão ser usados para complementar o presente estudo. 


\section{RESULTADO}

A avaliação do programa implantado se deu a cada seis meses, iniciando em 04/2015, totalizando seis avaliações realizadas, todas com uma nova versão do PEG-software. O número e a proporção de usuários respondentes aumentaram ao longo do período de avaliação. Na primeira e segunda fase, $8 / 10(80 \%)$ de usuários responderam aos questionários. No entanto, a partir da segunda fase, tanto o número como a proporção de usuários respondentes aumentou progressivamente de 9/11 (82\%) no terceiro, para $11 / 13(85 \%)$ no quarto e para $14 / 16(88 \%)$ na quinta fase. Diminuindo na sexta fase para 12/14 (86\%). Estes resultados satisfazem os requisitos ABNT NBR ISO/IEC 14598-6 (2010), de no mínimo oito usuários respondentes.

A Tabela 1 descreve as características dos sujeitos que utilizaram o PEG-software e que responderam a avaliação.

Tabela 1 - Caracterização dos usuários do PEG-software nas Fases 1 a 6

\begin{tabular}{c|ccccc|c|c}
\hline \multirow{2}{*}{ Fases } & \multicolumn{2}{|c|}{$\begin{array}{c}\text { Número de usuários do PEG-software (entre parênteses } \\
\text { aqueles que responderam ao questionário de avaliação) }\end{array}$} & \multicolumn{3}{c}{ Somente Respondentes } \\
\cline { 2 - 8 } & Total & $\begin{array}{c}\text { Médicos } \\
\text { Assistentes }\end{array}$ & $\begin{array}{c}\text { Médicos } \\
\text { Residentes }\end{array}$ & $\begin{array}{c}\text { Médicos } \\
\text { Estagiários }\end{array}$ & Idade & Feminino & Masculino \\
\hline 1 & $10(8)$ & $3(1)$ & $5(5)$ & $2(2)$ & $30,1(23-43)$ & $4(0,50)$ & $4(0,50)$ \\
2 & $10(8)$ & $3(1)$ & $4(4)$ & $3(3)$ & $30,8(27-43)$ & $5(0,63)$ & $3(0,37)$ \\
3 & $11(9)$ & $4(2)$ & $3(3)$ & $4(4)$ & $30,3(25-36)$ & $4(0,44)$ & $5(0,56)$ \\
4 & $13(11)$ & $5(3)$ & $4(4)$ & $4(4)$ & $29,3(25-36)$ & $7(0,64)$ & $4(0,36)$ \\
5 & $16(14)$ & $4(2)$ & $7(7)$ & $5(5)$ & $29,9(26-36)$ & $9(0,64)$ & $5(0,36)$ \\
6 & $14(12)$ & $4(2)$ & $10(10)$ & $0(0)$ & $29,9(26-37)$ & $7(0,58)$ & $5(0,42)$ \\
\hline
\end{tabular}


O número e a proporção de mulheres participantes da pesquisa variaram, assim como o número de residentes e bolsistas, mas a faixa etária média permaneceu estável ao longo do período avaliado $(29,3$ - 30,8).

A Tabela 2 resume as respostas dos usuários (em termos de frequências absolutas e relativas) para às questões de cada característica avaliada nas fases 1 a 6 . 
Tabela 2 - Distribuição das frequências absolutas e relativas [N (\%)] das avaliações dos usuários do PEG-software para cada uma das características avaliadas, nas Fases 1 a 6

\begin{tabular}{|c|c|c|c|c|c|c|c|c|}
\hline $\begin{array}{c}\text { Itens } \\
\text { Avaliados }\end{array}$ & Fase & $\begin{array}{c}\text { Discordo } \\
\text { Plenamente } \\
(1) \\
\end{array}$ & $\begin{array}{c}\text { Discordo } \\
(2) \\
\end{array}$ & $\begin{array}{c}\text { Indiferente } \\
\\
(3)\end{array}$ & $\begin{array}{c}\text { Concordo } \\
\text { (4) } \\
\end{array}$ & $\begin{array}{c}\text { Concordo } \\
\text { Plenamente } \\
(5) \\
\end{array}$ & $\begin{array}{l}\text { Respostas } \\
\text { Positivas }\end{array}$ & $\begin{array}{l}\chi^{2} \\
(p)\end{array}$ \\
\hline \multirow{6}{*}{ 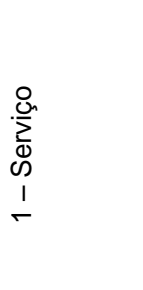 } & 1 & $3(0,02)$ & $0(0,0)$ & $15(0,12)$ & $45(0,35)$ & $67(0,51)$ & $112(0,86)$ & \multirow{6}{*}{$\begin{array}{l}1,6534 \\
(0,895)\end{array}$} \\
\hline & 2 & $3(0,025)$ & $3(0,025)$ & $7(0,05)$ & $65(0,49)$ & $55(0,41)$ & $120(0,90)$ & \\
\hline & 3 & $5(0,03)$ & $3(0,02)$ & $21(0,13)$ & $34(0,21)$ & $97(0,61)$ & $131(0,82)$ & \\
\hline & 4 & $7(0,03)$ & $4(0,02)$ & $21(0,10)$ & $65(0,31)$ & $111(0,54)$ & $176(0,85)$ & \\
\hline & 5 & $6(0,02)$ & $15(0,06)$ & $31(0,11)$ & $111(0,40)$ & $112(0,41)$ & $223(0,81)$ & \\
\hline & 6 & $1(0,01)$ & $9(0,04)$ & $41(0,17)$ & $63(0,25)$ & $135(0,54)$ & $198(0,80)$ & \\
\hline \multirow{6}{*}{$\begin{array}{l}\frac{0}{8} \\
\frac{\pi}{0} \\
\frac{0}{\bar{T}} \\
\frac{0}{0} \\
. \frac{0}{0} \\
\frac{5}{5} \\
1 \\
1 \\
\sim\end{array}$} & 1 & $2(0,04)$ & $1(0,02)$ & $4(0,09)$ & $16(0,33)$ & $25(0,52)$ & $41(0,85)$ & \multirow{6}{*}{$\begin{array}{l}0,8101 \\
(0,976)\end{array}$} \\
\hline & 2 & $0(0,0)$ & $4(0,09)$ & $5(0,10)$ & $16(0,33)$ & $23(0,48)$ & $39(0,81)$ & \\
\hline & 3 & $1(0,02)$ & $1(0,02)$ & $7(0,13)$ & $11(0,20)$ & $34(0,63)$ & $45(0,83)$ & \\
\hline & 4 & $1(0,02)$ & $2(0,03)$ & $4(0,06)$ & $24(0,37)$ & $34(0,52)$ & $58(0,89)$ & \\
\hline & 5 & $0(0,0)$ & $2(0,02)$ & $7(0,08)$ & $24(0,29)$ & $51(0,61)$ & $75(0,90)$ & \\
\hline & 6 & $0(0,0)$ & $1(0,01)$ & $3(0,05)$ & $20(0,28)$ & $47(0,66)$ & $67(0,94)$ & \\
\hline \multirow{6}{*}{ 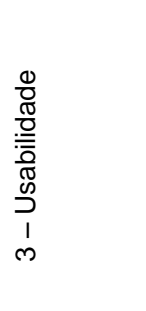 } & 1 & $1(0,02)$ & $0(0,0)$ & $8(0,17)$ & $16(0,33)$ & $23(0,48)$ & $39(0,81)$ & \multirow{6}{*}{$\begin{array}{l}19,6672 \\
(0,001)\end{array}$} \\
\hline & 2 & $0(0,0)$ & $1(0,02)$ & $5(0,10)$ & $27(0,56)$ & $15(0,32)$ & $42(0,88)$ & \\
\hline & 3 & $0(0,0)$ & $0(0,0)$ & $4(0,07)$ & $15(0,28)$ & $35(0,65)$ & $50(0,93)$ & \\
\hline & 4 & $0(0,0)$ & $1(0,02)$ & $6(0,09)$ & $23(0,35)$ & $36(0,54)$ & $59(0,89)$ & \\
\hline & 5 & $1(0,01)$ & $4(0,05)$ & $6(0,07)$ & $24(0,29)$ & $49(0,58)$ & $73(0,87)$ & \\
\hline & 6 & $0(0,0)$ & $1(0,01)$ & $6(0,09)$ & $14(0,20)$ & $50(0,70)$ & $64(0,90)$ & \\
\hline \multirow{6}{*}{ 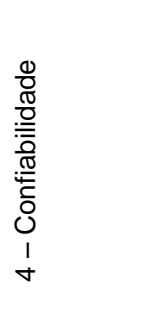 } & 1 & $3(0,12)$ & $5(0,21)$ & $11(0,46)$ & $5(0,21)$ & $0(0,0)$ & $5(0,21)$ & \multirow{6}{*}{$\begin{array}{l}15,7306 \\
(0,008)\end{array}$} \\
\hline & 2 & $0(0,0)$ & $5(0,21)$ & $10(0,42)$ & $7(0,29)$ & $2(0,08)$ & $9(0,37)$ & \\
\hline & 3 & $0(0,0)$ & $9(0,33)$ & $13(0,48)$ & $5(0,19)$ & $0(0,0)$ & $5(0,19)$ & \\
\hline & 4 & $0(0,0)$ & $3(0,09)$ & $13(0,39)$ & $15(0,46)$ & $2(0,06)$ & $17(0,52)$ & \\
\hline & 5 & $0(0,0)$ & $8(0,19)$ & $12(0,29)$ & $17(0,40)$ & $5(0,12)$ & $22(0,52)$ & \\
\hline & 6 & $0(0,0)$ & $3(0,08)$ & $7(0,20)$ & $18(0,50)$ & $8(0,22)$ & $26(0,72)$ & \\
\hline
\end{tabular}

Variações pequenas e não significativas nas respostas positivas ocorreram nos indicadores Serviço $\left(\chi^{2}=1,6534 ; p=0,895\right)$ e Funcionalidade $\left(\chi^{2}=0,8101 ; p=0,976\right)$ das fases 1 a 6 . Em contraste, a frequência de respostas positivas aumentou para Usabilidade $\left(\chi^{2}=19,6672 ; p=0,001\right)$ e Confiabilidade $\left(\chi^{2}=15,7306 ; p=0,008\right)$ das fases 1 a 6 . Além disso, para 0 
Serviço, Funcionalidade e Usabilidade, os valores da mediana e dos intervalos interquartil estavam sempre na região positiva, conforme mostrado nas tabelas S1 e S2 (Anexo H). No entanto, no que diz respeito à Confiabilidade, o PEGsoftware apresentou um incremento nas avaliações positivas ao longo do período do estudo, com a mediana passando de indiferente a concordante (primeira avaliação positiva) e interquartil passando de discordante-indiferente a indiferente-concordante comparando a $1^{\underline{a}}$ fase com a $5^{\underline{a}}$ e $6^{\underline{a}}$ avaliações. Os índices de satisfação específicos se encontram na Tabela 3 a seguir.

Tabela 3 - Distribuição dos índice de satisfação [ST/TT(\%)] das variáveis explicativas da qualidade para cada uma das características avaliadas, do PEG-software, nas Fases 1 a 6

\begin{tabular}{|c|c|c|c|c|c|c|c|}
\hline $\begin{array}{l}\text { Caracte- } \\
\text { rísticas. }\end{array}$ & Variáveis & $04 / 2015$ & $10 / 2015$ & $04 / 2016$ & $10 / 2016$ & $04 / 2017$ & $10 / 2017$ \\
\hline \multirow{6}{*}{$\frac{0}{\sum^{\infty}}$} & $\begin{array}{l}\text { Org. das funções do } \\
\text { sistema - Layout }\end{array}$ & $57 / 68(0,79)$ & $62 / 69(0,9)$ & $70 / 80(0,88)$ & $97 / 120(0,81)$ & $126 / 163(0,77)$ & $114 / 153(0,75)$ \\
\hline & Clareza das Informações & $15 / 16(0,94)$ & $16 / 16(1)$ & $17 / 18(0,95)$ & $22 / 22(1)$ & $27 / 28(0,97)$ & $23 / 24(0,96)$ \\
\hline & $\begin{array}{l}\text { Tempo de } \\
\text { Preenchimento }\end{array}$ & $8 / 8(1)$ & $7 / 8(0,88)$ & $9 / 9(1)$ & $10 / 11(0,91)$ & $13 / 14(0,93)$ & $10 / 12(0,83)$ \\
\hline & Manutenção & $4 / 6(0,67)$ & $4 / 8(0,5)$ & $4 / 9(0,45)$ & $6 / 11(0,55)$ & $8 / 14(0,57)$ & $9 / 12(0,75)$ \\
\hline & Diminuição de Papéis & $8 / 8(1)$ & $8 / 8(1)$ & $7 / 9(0,78)$ & $11 / 11(1)$ & $12 / 14(0,86)$ & $9 / 12(0,75)$ \\
\hline & Consultas & $13 / 16(0,81)$ & $15 / 16(0,94)$ & $15 / 18(0,84)$ & $20 / 22(0,91)$ & $23 / 28(0,83)$ & $22 / 24(0,92)$ \\
\hline \multirow{5}{*}{$\begin{array}{l}\frac{0}{0} \\
\frac{\pi}{0} \\
\frac{.0}{\overline{0}} \\
\frac{0}{0} \\
\frac{0}{0} \\
\frac{5}{5} \\
\frac{1}{4}\end{array}$} & Adequação & $8 / 8(1)$ & $8 / 8(1)$ & $9 / 9(1)$ & $10 / 11(0,91)$ & $13 / 14(0,93)$ & $11 / 11(1)$ \\
\hline & Acurácia & $8 / 8(1)$ & $8 / 8(1)$ & $9 / 9(1)$ & $11 / 11(1)$ & $14 / 14(1)$ & $12 / 12(1)$ \\
\hline & Interoperabilidade & $8 / 8(1)$ & $4 / 8(0,5)$ & $6 / 9(0,67)$ & $8 / 11(0,73)$ & $9 / 14(0,64)$ & $11 / 12(0,92)$ \\
\hline & Segurança de acesso & $11 / 16(0,69)$ & $12 / 16(0,75)$ & $16 / 18(0,89)$ & $19 / 22(0,86)$ & $27 / 28(0,97)$ & $22 / 24(0,92)$ \\
\hline & Conformidade & $6 / 8(0,75)$ & $7 / 8(0,88)$ & $5 / 9(0,56)$ & $10 / 11(0,91)$ & $12 / 14(0,86)$ & $11 / 12(0,92)$ \\
\hline \multirow{3}{*}{ 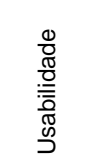 } & Intelegibilidade & $7 / 8(0,88)$ & $8 / 8(1)$ & $9 / 9(1)$ & $11 / 11(1)$ & $14 / 14(1)$ & $11 / 12(0,92)$ \\
\hline & Apreensibilidade & $11 / 16(0,69)$ & $11 / 16(0,69)$ & $14 / 18(0,78)$ & $17 / 22(0,77)$ & $23 / 28(0,82)$ & $21 / 24(0,88)$ \\
\hline & Operacionalidade & $21 / 24(0,88)$ & $23 / 24(0,96)$ & $27 / 27(1)$ & $31 / 33(0,94)$ & $36 / 42(0,86)$ & $32 / 36(0,89)$ \\
\hline \multirow{3}{*}{ 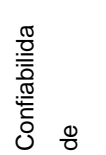 } & Maturidade & $1 / 8(0,13)$ & $3 / 8(0,38)$ & $4 / 9(0,44)$ & $7 / 11(0,64)$ & $9 / 14(0,64)$ & $11 / 12(0,92)$ \\
\hline & Tolerância a falhas & $1 / 8(0,13)$ & $3 / 8(0,38)$ & $1 / 9(0,11)$ & $4 / 11(0,36)$ & $6 / 14(0,43)$ & $8 / 12(0,67)$ \\
\hline & Recuperabilidade & $3 / 8(0,38)$ & $3 / 8(0,38)$ & - & $6 / 11(0,55)$ & $7 / 14(0,5)$ & $7 / 12(0,59)$ \\
\hline
\end{tabular}


A Tabela 3 acima, é originaria da tabela suplementar S2 (Anexo H) e apresenta os percentuais obtidos nas seis fases de avaliação, considerando as variáveis das subcaracterísticas avaliadas.

As variáveis para as subcaracterísticas de Serviço, Funcionalidade e usabilidade, tiveram poucas variações ao longo das avaliações, sendo que valores abaixo de $70 \%$ foram encontrados em Manutenção, Interoperabilidade e Conformidade, mas acabaram se recuperando e atingindo valores positivos na última avaliação. As subcaracterísticas de confiabilidade também tiveram uma evolução positiva, mas ficaram na maior parte da avaliação abaixo de 70\%, e na última avaliação, somente Maturidade atingiu índices expressivos de $92 \%$.

Observou-se que nas respostas dos usuários, foi assinalado como defeitos e não era defeito, a média de 30,6\%; e foram marcados como defeitos e eram alterações de requisitos, ou novos requisitos, a média de $25 \%$. A lista desses não defeitos e alterações do PEG-software ou novos requisitos se encontram no Anexo G. Na sugestão para novas melhorias percebe-se um aumento da Fase 1, para a Fase 2, entrando em declínio nas fases seguintes, mas ainda sendo solicitado pelos usuários (Tabela 4 ). 
Tabela 4 - Número de defeitos apontados (do PEG-software e Externos que afetam o PEGsoftware), Total de Defeitos Válidos, Não Defeitos, Alterações e/ou Novos Requisitos marcados como defeitos e Sugestões de Melhoria nas Fases 1 a 6

\begin{tabular}{c|c|c|c|c|c|c|c}
\hline Fases & $\begin{array}{c}\text { Número de } \\
\text { Defeitos } \\
\text { do PEG- } \\
\text { software }\end{array}$ & $\begin{array}{c}\text { Número } \\
\text { de } \\
\text { Defeitos } \\
\text { Externos }\end{array}$ & $\begin{array}{c}\text { Número } \\
\text { Total de } \\
\text { Defeitos } \\
\text { Válidos }\end{array}$ & $\begin{array}{c}\text { Não Defeitos } \\
\text { (não é } \\
\text { defeito, mas } \\
\text { foi marcado } \\
\text { como defeito) }\end{array}$ & $\begin{array}{c}\text { Alterações } \\
\text { e/ou Novos } \\
\text { Requisitos } \\
\text { marcados } \\
\text { como } \\
\text { defeitos }\end{array}$ & $\begin{array}{c}\text { Número } \\
\text { Total de } \\
\text { Defeitos } \\
\text { Marcados } \\
\text { (Válidos e } \\
\text { Não } \\
\text { Válidos) }\end{array}$ & $\begin{array}{c}\text { Sugestões } \\
\text { de } \\
\text { Melhoria }\end{array}$ \\
\hline 1 & 49 & 19 & 68 & 25 & 37 & 130 & 6 \\
2 & 5 & 1 & 6 & 8 & 11 & 25 & 13 \\
3 & 4 & 6 & 10 & 5 & 7 & 22 & 7 \\
4 & 4 & 6 & 10 & 8 & 2 & 20 & 8 \\
6 & 1 & 8 & 9 & 7 & 2 & 18 & 5 \\
\hline
\end{tabular}

A Tabela 5 mostra o indicador de defeitos KSLoC, conforme descrito em Métodos.

Tabela 5 - Total de Defeitos Válidos, Total de Linhas de Código e Indicador de defeitos KSLoc das Fases 1 a 6

\begin{tabular}{c|ccc}
\hline Fases & Defeitos Válidos & Linhas de Código & KSLoC \\
\hline 1 & 68 & 26022 & 2,613 \\
2 & 6 & 31212 & 0,192 \\
3 & 10 & 32145 & 0,311 \\
4 & 10 & 32840 & 0,305 \\
5 & 9 & 35140 & 0,256 \\
6 & 3 & 36342 & 0,083 \\
\hline
\end{tabular}

Houve uma redução considerável no número de defeitos válidos junto com um aumento no número de linhas de código de software, implicando assim 
uma redução significativa no $\mathrm{KSLoC}$ ao longo do período analisado $\left(\chi^{2}=\right.$ 236,6672; $p<0,001)$.

A Tabela 6 a seguir foi formada a partir das respostas das Fichas de Detecção de Defeitos (Anexo E) e da Severidade de defeitos aplicadas no método FMEA (Anexo F), que resume a evolução das seis fases do levantamento de defeitos do PEG-software por seus usuários, acrescentadas da TD e KSLoc, para comparação. A tabela mostra o número de usuários entrevistados, o número de defeitos válidos de acordo com seu grau de severidade, as proporções de defeitos válidos e externos e os indicadores de defeitos medidos por TD e KSLoC.

Tabela 6 - Número de Usuários, Classificação dos defeitos do PEG-software e Externos que afetam o PEG-software, nível de severidade, Total de Defeitos, KSLoc e TD nas fases 1 a 6

\begin{tabular}{|c|c|c|c|c|c|c|c|c|c|c|c|c|c|c|c|c|}
\hline \multirow{4}{*}{ 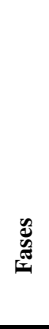 } & \multirow{4}{*}{ 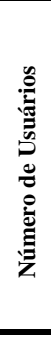 } & \multirow{4}{*}{ 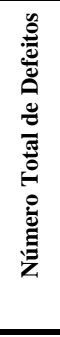 } & \multirow{4}{*}{ 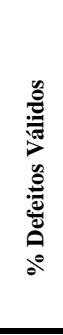 } & \multicolumn{10}{|c|}{ Defeitos Válidos } & \multirow{4}{*}{ 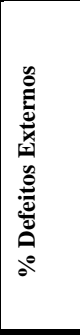 } & \multirow{4}{*}{$\hat{F}$} & \multirow{4}{*}{ 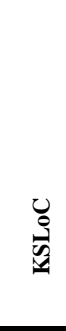 } \\
\hline & & & & \multicolumn{5}{|c|}{ Defeitos do PEG-software (Internos) } & \multicolumn{5}{|c|}{ Defeitos Externos } & & & \\
\hline & & & & \multirow[t]{2}{*}{ Número } & \multicolumn{4}{|c|}{ Severidade } & \multirow[t]{2}{*}{ Número } & \multicolumn{4}{|c|}{ Severidade } & & & \\
\hline & & & & & Leve & Moderada & $\begin{array}{l}\begin{array}{l}\text { Eleva } \\
\text { da }\end{array} \\
\end{array}$ & Critica & & Leve & Moderada & \begin{tabular}{|l|} 
Eleva \\
da
\end{tabular} & Critica & & & \\
\hline 1 & 8 & 130 & 52,3 & 49 & 40 & 8 & 1 & 0 & 19 & 0 & 1 & 18 & 0 & 27,9 & 8,5 & 2,613 \\
\hline 2 & 8 & 25 & 24,0 & 5 & 3 & 2 & 0 & 0 & 1 & 0 & 0 & 1 & 0 & 16,7 & 0,8 & 0,192 \\
\hline 3 & 9 & 22 & 45,5 & 4 & 1 & 3 & 0 & 0 & 6 & 0 & 0 & 6 & 0 & 60,0 & 1,1 & 0,311 \\
\hline 4 & 11 & 20 & 50,0 & 4 & 2 & 1 & 1 & 0 & 6 & 0 & 0 & 6 & 0 & 60,0 & 0,9 & 0,305 \\
\hline 5 & 14 & 18 & 50,0 & 1 & 1 & 0 & 0 & 0 & 8 & 0 & 0 & 8 & 0 & 88,9 & 0,6 & 0,256 \\
\hline 6 & 12 & 5 & 60,0 & 1 & 1 & 0 & 0 & 0 & 2 & 0 & 0 & 2 & 0 & 66,7 & 0,3 & 0,083 \\
\hline
\end{tabular}

Como mostrado na Tabela 6, à proporção de defeitos válidos diminuiu nas duas primeiras avaliações e aumentou a partir da fase três em diante, mas principalmente porque o número de defeitos extrínsecos aumentou. Vale 
ressaltar que 0 número total de defeitos $\left(\chi^{2}=288,9729 ; p<0,001\right)$, particularmente os defeitos intrínsecos (PEG-software relacionados) válidos $\left(\chi^{2}=161,6363 ; p<0,001\right)$ e ambos TD e KSLoC diminuíram acentuadamente de Fase 1 em diante. Em conjunto, essas descobertas demonstram a melhoria no desempenho do PEG-software.

Também a partir do método FMEA (Anexo F) pudemos extrair a classificação ODC (Tabela 7), para os gatilhos dos defeitos em campo, que foram apurados: 1 - Conformidade do Projeto; 2 - Lógica/Fluxo; 3 Compatibilidade com versões anteriores; 4 - Compatibilidade Lateral; 7 Dependência de idioma; e 9 - Situações raras. Desses houve uma predominância de gatilhos ocasionados por Lógica/Fluxo do código, seguido por Compatibilidade Lateral (constante em todas as fases) e uma incidência significativa de Situações Raras no início das avaliações.

Tabela 7 - Densidade de Defeitos, incidência ODC, incidência de Riscos dos Defeitos nas Fases 1 a 6

\begin{tabular}{|c|c|c|c|c|c|c|c|c|c|c|c|}
\hline \multirow[b]{2}{*}{ 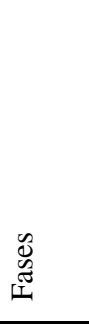 } & \multirow{2}{*}{ 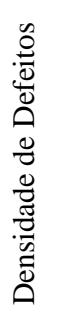 } & \multicolumn{6}{|c|}{ Classificação ODC } & \multicolumn{4}{|c|}{ Riscos } \\
\hline & & 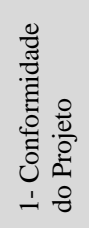 & 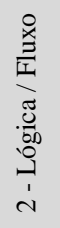 & 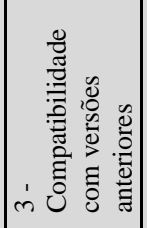 & 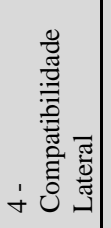 & 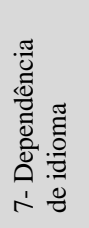 & 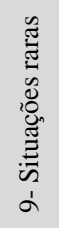 & 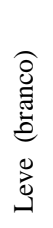 & 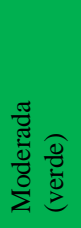 & 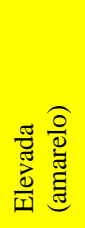 & \\
\hline 1 & 11 & 1 & 4 & 0 & 1 & 1 & 4 & 0 & 6 & 3 & 2 \\
\hline 2 & 4 & 0 & 3 & 0 & 1 & 0 & 0 & 2 & 1 & 1 & 0 \\
\hline 3 & 3 & 0 & 2 & 0 & 1 & 0 & 0 & 1 & 1 & 0 & 1 \\
\hline 4 & 5 & 1 & 2 & 1 & 1 & 0 & 0 & 2 & 1 & 2 & 0 \\
\hline 5 & 2 & 0 & 0 & 1 & 1 & 0 & 0 & 1 & 0 & 0 & 1 \\
\hline 6 & 2 & 1 & 0 & 0 & 1 & 0 & 0 & 1 & 0 & 0 & 1 \\
\hline Totais & 27 & 3 & 11 & 2 & 6 & 1 & 4 & 7 & 9 & 6 & 5 \\
\hline
\end{tabular}


Nos riscos (Tabela 7), observou-se uma maior incidência para os defeitos de porte médio (verde), seguidos pelos de nível leve (branco) e elevado (amarelo), e por último os de nível crítico (vermelho). Na sua maioria os defeitos puderam ser corrigidos, faltando um de nível baixo, em lista de espera e outro, que permaneceu durante todas as fases da avaliação, que se refere a um defeito de outro software que fornece dados para o PEG-software, e que aguarda solução dos responsáveis por aquela aplicação. 


\section{DISCUSSÃO}

Os principais propósitos de um RES, padronizado pelas normas ISO, são permitir e incentivar a interoperabilidade entre diferentes registros eletrônicos e sistemas compartilháveis, independentemente da tecnologia e plataforma utilizadas (ABNT, 2008a), mas assegurando uma operação fácil e confiável dos dados armazenados. Embora o desenvolvimento de PEGsoftware tenha aderido estritamente a essas premissas desde a sua criação, vários problemas de interoperabilidade com o software institucional ainda ocorrem (discutidos a seguir), exigindo um esforço contínuo para contorná-los.

Outro objetivo do RES é fornecer registro documentado que apoie a continuidade, a eficiência e a qualidade de assistência médica abrangente e futura, fornecendo meios de comunicação entre os médicos que atendem pacientes. Deve ser capaz de suportar diretrizes, protocolos e sistemas de apoio à decisão (ABNT, 2008a; ABNT, 2013). A genética clínica priorizou a implantação de um RES específico devido ao aumento de sua importância em unidades de referência em saúde (Horovitz et al, 2006). Isto é particularmente verdadeiro para a Unidade de Genética do ICr-HCFMUSP (UG), porque o software institucional não atendia as suas necessidades específicas. Portanto, - PEG-software foi criado para atender às necessidades desse grupo específico de médicos e pacientes. 
O desenvolvimento de PEG-software começou seguindo o método em cascata, mas devido à necessidade dos usuários de retornar rapidamente a várias modificações sugeridas, a metodologia de desenvolvimento acabou mudando para o modelo ágil. Para garantir que um software atenda a seus requisitos, é necessário um processo formal de avaliação e validação. A avaliação demonstra o conceito de julgamento e emissão de opinião, enquanto a validação exprime a ideia de teste e garante que ele funcionará de acordo com as demandas operacionais especificadas, produz saídas válidas e opera de forma segura (Wazlawick, 2013). Nesse sentido, a comunidade de usuários do software deve estar profundamente envolvida nos processos de avaliação e garantia de qualidade. Os médicos que atendem na UG (descritos na Tabela 1) são os usuários do PEG-software. A avaliação do usuário do PEG-software desenvolvido ao longo de seis fases diferentes após sua implementação e uso na UG (Tabela 2).

Questões relacionadas à satisfação do usuário referente ao Serviço médico mostraram resultados positivos, demonstrando que o software facilita 0 trabalho médico durante a consulta (média de 83\%), mas a sua subcaracterística manutenção apresentou valores negativos durante o decorrer da avaliação, atingindo valores maiores que $70 \%$ na última avaliação (Tabela 3). Isso demonstra que poucos médicos sabem que o software permite, em situações de contingência (problemas na rede, sem acesso ao sistema, falha no sistema etc.) a inserção posterior dos dados entregues manualmente no 
SAME, para que componha o banco de dados dos pacientes de maneira fidedigna, merecendo orientação. Com relação à subcaracterística tempo para preenchimento, $92,4 \%$ afirmam ter melhorado muito comparado com 0 preenchimento em papel (Tabela 3). Para consultas, $87,3 \%$ afirmam usar ativamente, tanto para consulta clínica, quanto para consulta com fins de pesquisa (Tabela 3).

A funcionalidade e usabilidade avaliadas obtiveram bons escores de avaliação, semelhantes aos apresentados por outros autores (Pereira et al, 2011; Pereira et al, 2012; Rangel et al, 2012; Flores et al, 2013; Oliveira e Peres, 2015).

Nesses estudos, como proposto por Pereira et al (2012), as opiniões dos usuários refletiram a porcentagem de funcionalidade, com uma aprovação superior a 70\%, enquanto que no estudo de Rangel et al (2012), a porcentagem foi de $96,5 \%$ e no apresentado por Pereira et al (2011), a funcionalidade obteve uma porcentagem de $94 \%$ das respostas consideradas positivas. Tanto nossos números (média de $87 \%$ ) e os de Pereira et al (2012), Rangel et al (2012) e Pereira et al (2011) mostraram valores superiores a 70\% para a funcionalidade, de acordo com ISO/IEC 14598-6 (2010), que propõe esse nível de resultado no julgamento positivo da funcionalidade do software.

A subcaracterística de funcionalidade, interoperabilidade, obteve uma queda de $50 \%$ na segunda avaliação (de 100\% para 50\%) e obteve avaliações 
positivas novamente somente na quarta e sexta avaliação. Apesar de fechar com valores positivos (média de $74,3 \%$ ), os médicos apontaram 0 descontentamento com as ocorrências da conexão com o Sistema Agenda (outra aplicação da instituição) que fornece aleatoriamente informações incorretas para o PEG-software (a view gera um novo número da consulta, após o médico estar atendendo o paciente com outro número), necessitando de monitoramento e acertos manuais no banco de dados. Os dados não ficam perdidos, mas o médico não tem acesso a esses dados do paciente temporariamente até 0 acerto manual. Quanto à conformidade, subcaracterística que propõe que o sistema mantém a impressão em papel, mesmo tendo a forma eletrônica apesar de uma média de $81,3 \%$, observamos uma queda na terceira avaliação (56\%).

Quanto à avaliação da usabilidade dos usuários do software, o PEGsoftware mostrou um aumento no número de afirmações positivas (média de 88\%) no decorrer das seis avaliações, o que pode ser explicado pelo fato do PEG-software ter sido criado especificamente para uso da equipe de UG. Desta forma, as necessidades dessa equipe poderiam ser na medida do possível, adequadamente atendidas e modificadas. Pereira et al (2012) apresentaram valores de usabilidade cuja aprovação foi superior a $70 \%$. Um valor um pouco maior foi relatado por Flores et al (2013) que obtiveram valores de $79 \%$ para as respostas positivas; Pereira et al. (2011), 97\%; e Rangel et al (2012), de 100\%, para essa característica. Todas as subcaracterísticas de 
usabilidade tiveram variações não significativas no decorrer da avaliação e em todas as fases apresentaram resultados positivos.

Em termos de confiabilidade, ainda precisa de algumas melhorias. Os valores iniciais de confiabilidade foram baixos, em comparação com outros estudos Pereira et al (2012), Pereira et al (2011), Flores et al (2013), Oliveira e Peres (2015), mas melhoraram significativamente a partir da fase 3 , atingindo $72 \%$ de respostas positivas na última fase. No entanto, eles nunca alcançaram o mesmo nível de avaliações positivas obtidas no Serviço, Funcionalidade e Usabilidade (Tabela 2). Os últimos três são indicadores diretos do desempenho do software, enquanto a confiabilidade é indireta - influenciada pela interação do PEG-software com o software principal institucional. Essa discrepância pode ser devido à repetição de problemas relacionados à integração com o software institucional, pois afetou negativamente a percepção dos usuários sobre a qualidade do PEG-software.

Apesar da evolução positiva (última avaliação com $72 \%$ de respostas positivas) a confiabilidade teve uma média de $42,2 \%$ de respostas positivas e média de $37,3 \%$ de respostas que demonstraram dúvida. Os valores de confiabilidade comparados a outros estudos foram considerados baixos. Pereira et al (2011) obtiveram uma porcentagem de confiabilidade de $81,9 \%$ e, um ano depois; foi superior a 70\% (Pereira et al, 2012). Já Flores et al (2013) obtiveram $45 \%$ das respostas positivas. No entanto, a afirmação feita por Flores et al (2013) na folha de detecção de defeito usou uma proposição 
negativa, quando deveria ter sido realizada de forma positiva, como nas outras proposições feitas para medir a confiabilidade, tem então uma taxa de satisfação de $34,4 \%$ e não de $45 \%$.

Acreditamos que o grande percentual de respostas duvidosas (média de $37,3 \%$ ) pode ocorrer pela dificuldade dos médicos quando da respostas das questões de tolerância a falhas e recuperabilidade, subcaracterística de confiabilidade, pois esse tipo de questão seria mais fácil de ser averiguado e monitorado pelo programador, pois se trata de perda de dados (Anexo $\mathrm{H}$ ).

Dos gatilhos ODC (Tabela 7) a predominância foi ocasionada por problemas de Lógica/Fluxo do código, seguido por Compatibilidade Lateral (constante em todas as fases e não resolvido) e uma incidência significativa de Situações Raras no início das avaliações. Nos riscos (Tabela 7), observou-se uma maior incidência para os defeitos de porte médio (verde), seguidos pelos de nível leve (branco) e elevado (amarelo), e menor os de nível crítico (vermelho).

Foi necessário acompanhar melhor o atendimento diário dos pacientes durante a pesquisa, para entender as respostas fornecidas. Graças a este acompanhamento, observou-se que alguns defeitos relatados pelos médicos foram devidos à interferência de um dos softwares que operavam em conexão com o PEG-software, causando defeitos em cascata. Falha que foi devidamente apontada pelos usuários também na avaliação na variável de 
Interoperabilidade (característica de funcionalidade) que apresentou valores abaixo de $70 \%$, da Fase 2,3 e 5 (Tabela 3). Esta falha devido a defeitos externos ao nosso software comprometeu o acesso a alguns registros no PEGsoftware. Foi necessário alterar os códigos para evitar a entrada de dados que gerariam erros. No entanto, isso não foi suficiente e os responsáveis pelo software defeituoso foram notificados para corrigir os defeitos. Essas falhas comprometeram os cuidados médicos, uma vez que os registros e os dados de consultas médicas inteiras ficaram inacessíveis para os usuários, que foram capazes de acessar apenas arquivos digitalizados e visíveis. Como resultado, não foi possível realizar algum tipo de pesquisa; a consulta médica foi prejudicada pelos dados incompletos disponíveis, o que exigiu o uso de medidas de contingência para remediar os problemas envolvidos.

Nossos índices para confiabilidade podem ter sofrido influência de fatores como: defeitos externos que interferiram com o desempenho do software e incapacidade do usuário para responder com certeza a questão estipulada. Essa última nos instigou a uma questão mais aberta, solicitando ao usuário a justificativa para a sua resposta na avaliação como as apresentadas: "Diminuiu frequência de falhas; dados puderam ser recuperados."; "Raramente apresenta falhas, mas quando apresenta necessitamos de ajuda para recuperar os dados.". 
A metodologia FMEA, juntamente com o ODC e matriz de risco, para levantamento e classificação dos defeitos, permitiu maior controle e possibilidade de priorização na correção dos defeitos, e se mostraram eficazes.

A maioria de sugestões de melhorias dos usuários, no total de 40 , foram aceitas e concretizadas (Tabela 4). Somente algumas que não autorizadas ou que dependem de outro software da instituição não puderam ser realizadas (Anexo G).

Analisando os defeitos observados no PEG-software, aproximadamente $50 \%$ deles eram defeitos válidos (afetando o desempenho do software), mas apenas parte deles eram defeitos intrínsecos do PEGsoftware (Tabela 6). Além disso, seu número caiu muito durante o período de avaliação e os intrínsecos eram geralmente de severidade baixa, causando um impacto menor na operação do PEG-software. Em contraste, a proporção de defeitos extrínsecos (integração com software institucional) aumentou durante as avaliações sucessivas e foi de alta severidade, afetando, portanto, a confiabilidade do PEG-software. No entanto, seu número também diminuiu ao longo do período de avaliação, demonstrando os esforços bem-sucedidos do desenvolvedor do PEG-software em resolver os problemas de integração que surgiram durante o processo de implantação e uso. Estes são problemas habituais durante a implantação e uso de um novo software trabalhando em paralelo com o software institucional existente anteriormente (Chen et al, 2013). 
Vários defeitos apontados pelos usuários foram desconsiderados, uma vez que se referiam a novos requisitos ou a mudanças nos requisitos existentes, cuja modificação só poderia ser aprovada pelo gestor da UG. Muitos desses defeitos puderam ser corrigidos, outros que dependiam da interconectividade entre o PEG-software e outro software externo, defeito descoberto na Fase 3 (já havia acontecido desde a primeira avaliação) aguarda a resolução dos responsáveis por aquele software (total de 25 casos).

Dois instrumentos diferentes e bem estabelecidos também foram usados para registrar e monitorar diretamente os defeitos do PEG-software e servir como indicador de qualidade, ou seja, a Taxa de Defeitos (TD) (Wazlawick, 2013) e a taxa de defeitos por 1000 linhas de código (KSLoC) (Wazlawick, 2013), medida no início e em todas as fases. Ambos os indicadores caíram de forma expressiva ao longo do período analisado (Tabelas 5 e 6) e fornecem medidas do desempenho do PEG-software, permitindo uma avaliação clara da melhoria do software ao longo do processo de avaliação.

A principal limitação deste estudo refere-se ao número relativamente pequeno de usuários e à mudança frequente dos mesmos, devido às características de seu programa de bolsas. Estes, combinados, aumentaram a probabilidade de entender mal as funções do PEG-software e na ocorrência de problemas interoperacionais com o software principal institucional, acabou afetando negativamente a avaliação do PEG-software. 
A relevância do presente estudo é mostrar as dificuldades que surgem durante o uso de um RES novo e específico em instituições que já possuem um sistema RES operacional. Também serve para demonstrar a relevância que um processo contínuo e estruturado de avaliação, de acordo com a ISO/IEC ou qualquer outro sistema de avaliação estabelecido, tem que assegurar que os resultados satisfaçam as expectativas gerais (mas não explicitamente declaradas) de seus usuários.

A detecção de defeitos poderia ter sido anterior e nossos dados teriam sido diferentes ao avaliar as afirmações positivas tanto para a confiabilidade como para outros indicadores de confiabilidade, se tivéssemos:

a) Melhor orientado o usuário;

b) Dado maior importância às respostas envolvendo entrada e saída de dados, uma vez que o usuário não é capaz de identificar a origem do defeito;

c) Analisado e monitorado os dados fornecidos por outras aplicações, a fim de verificar eventuais discrepâncias.

Tanto é verdade e se nossos números não fossem um TD e KSLoc baixa e uma confiabilidade baixa, não compatível com as expectativas (baixo TD e KSLoc; e confiabilidade alta), não teríamos sido encorajados a investigar essa discrepância. Por esta razão, é importante verificar se a interoperabilidade 
entre sistemas conectados está gerando defeitos que surgem nos dados de entrada e estabelecer medidas de contingência.

Em suma, a governança dos sistemas desenvolvidos para a área da saúde deve ser contínua e desenvolvida em conjunto com seus usuários, para garantir o melhor e mais amigável sistema, garantindo sua robustez (na proteção de dados críticos), permitindo ainda a disponibilidade imediata de informações para os usuários, mediante solicitação, de acordo com as regras institucionais pré-estabelecidas. 


\section{CONCLUSÃO}

Com base nos resultados obtidos, o PEG-software satisfaz o usuário como registro eletrônico, mostrando uma facilidade de uso para o cuidado diário de pacientes da UG, justificados pelos elevados índices de usabilidade durante toda a avaliação.

Os dados levantados deram uma visão clara das situação do PEGsoftware, possibilitando as ações corretivas necessárias, mas sugere-se a continuidade de avaliações e controle de defeitos, de maneira a manter efetiva a qualidade do PEG-software.

Para futuras avaliações, recomenda-se uma melhor orientação do usuário na aplicação da avaliação, tanto para a característica confiabilidade quanto para outros indicadores de confiabilidade. É importante considerar que a aplicação de vários indicadores para medir a confiabilidade permite a comparação dos resultados e facilita a detecção de possíveis defeitos, mesmo que provenha de outros softwares.

O número de usuários com dúvidas sobre a confiabilidade do software merece atenção e precisa ser avaliado. Nestas situações, o ideal é o acompanhamento simultâneo do programador com o usuário, caso contrário não é possível identificar defeitos. 
Os defeitos envolvendo entradas e saídas de dados devem ser investigados com o maior rigor e, mesmo que os indicadores estejam dentro dos valores esperados, devem ser resolvidos o mais rápido possível, motivo pelo qual sugerimos o controle de defeitos adotados para esse estudo, que demonstrou ser eficaz e útil para resolver os defeitos na urgência esperada. 0 usuário não pode identificar a gênese do defeito e só é possível com a intervenção do programador. Essa dificuldade pode levar a um maior número de respostas negativas ou duvidosas refletidas nos indicadores que medem a confiabilidade.

O registro médico eletrônico provou ser uma ferramenta extremamente importante para atividades ambulatoriais diárias em geral e, especificamente, na área de genética, é uma ferramenta essencial devido à peculiaridade desta especialidade.

Este trabalho não teve como objetivo resolver todas as dúvidas quanto à avaliação do produto do PEG-software, mas contribuir, alertar e encorajar novos estudos. 
9. ANEXOS 
Anexo A - Prontuário em Papel 


\section{UNIDADE DE GENÉTICA - Instituto da Criança - HC-FMUSP}

Nome:

RG:

DN:

DA:

Cor:

Raça:

Enc:

Res:

CEP

Fone:

e-mail:

Mãe:

Pai:

anos

Pré-Natal:

Parto:

IG:

Sofr. fetal:

Apgar:

PN:

E:

PC:

Alta ( )

dias

Intercor.:

DNPM: cab:

sent:

and:

fala:

escola:

Achados clínicos:

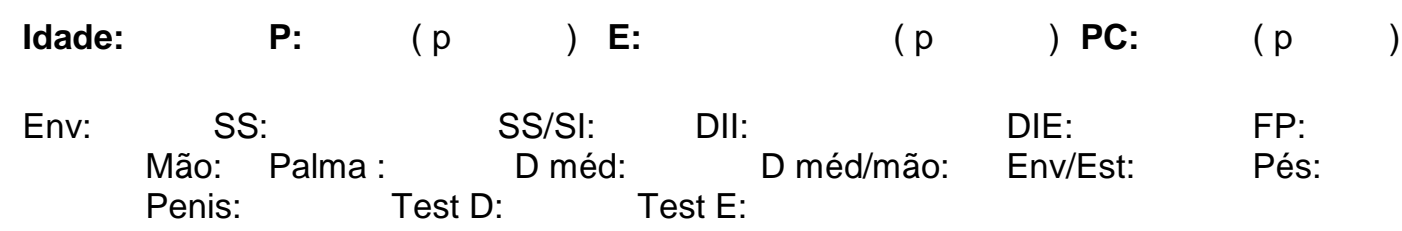

Motivo da consulta/QD:

Ex. Complementares: 
Cariótipo:

DNA: Data

Local

Resultado

Foto:

HD:

M I M\#

Conduta: 


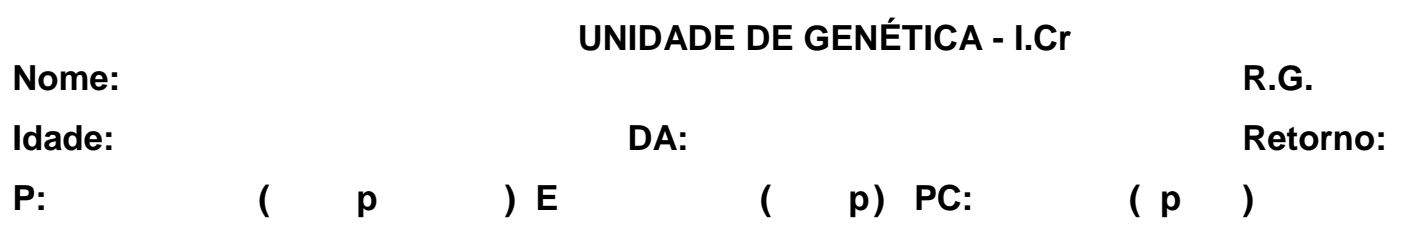

Conduta:

OBS (ret)

Idade:

DA:

Retorno:

$P: \quad\left(\begin{array}{llll} & p\end{array}\right) E\left(\begin{array}{l}p \\ P\end{array}\right)$

Conduta:

OBS (ret)

Idade:

DA:

Retorno:

P: $\quad(p \quad)$ E

p ) PC:

$(p)$

Conduta:

OBS (ret)

Idade:

DA:

Retorno:

P:

$(\mathbf{p}) \mathbf{E}$

( p) PC:

$\left(\begin{array}{ll}p & )\end{array}\right.$

Conduta:

OBS (ret) 
Anexo B - Requisitos Funcionais e Não Funcionais 


\begin{tabular}{|c|c|c|c|}
\hline \multicolumn{4}{|c|}{ Lista de Requisitos } \\
\hline ID & Tipo & Nome & Prioridade \\
\hline RF001 & $\mathrm{F}$ & Efetuar Login & Essencial \\
\hline \multicolumn{2}{|c|}{ Detalhamento } & \multicolumn{2}{|c|}{$\begin{array}{l}\text { O sistema deve conter uma tela inicial para o usuário efetuar o login, } \\
\text { que terá os campos: usuário e senha. }\end{array}$} \\
\hline ID & Tipo & Nome & Prioridade \\
\hline RF002 & $\mathrm{F}$ & Cadastrar Usuários & Essencial \\
\hline \multicolumn{2}{|c|}{ Detalhamento } & \multicolumn{2}{|c|}{$\begin{array}{l}\text { O sistema deve permitir a inclusão, alteração e consulta de novos } \\
\text { usuários. Permitido somente para níveis de acesso autorizado. Terá } \\
\text { os seguintes campos: Código o Usuário, Nome do Usuário, CRM, } \\
\text { Email, Fone, Usuário, Senha, Nível, Logado. }\end{array}$} \\
\hline ID & Tipo & Nome & Prioridade \\
\hline RF003 & $\mathrm{F}$ & Agenda de Atendimento Ambulatorial & Essencial \\
\hline \multicolumn{2}{|c|}{ Detalhamento } & \multicolumn{2}{|c|}{$\begin{array}{l}\text { Deve permitir aos usuários médicos, a seleção do paciente a ser } \\
\text { atendido e abertura de Cadastro de Atendimento Ambulatoria } \\
\text { daquele paciente. Terá os seguintes campos: RG do Paciente, Nome } \\
\text { do Paciente, Data da Agenda, Hora da Consulta, Agenda (código do } \\
\text { TIS para a unidade), Código do Paciente, Código do Atendimento } \\
\text { Status de Atendimento. }\end{array}$} \\
\hline ID & Tipo & Nome & Prioridade \\
\hline RF004 & $\mathrm{F}$ & Cadastro de Pacientes & Essencial \\
\hline \multicolumn{2}{|c|}{ Detalhamento } & \multicolumn{2}{|c|}{$\begin{array}{l}\text { Deve permitir aos usuários médicos, a inclusão, alteração, consulta e } \\
\text { impressão dos dados ambulatoriais dos pacientes, agendados para } \\
\text { aquele dia. Terá os seguintes itens de dados, com seus respectivos } \\
\text { campos: } \\
\text { Identificação: Nome do Paciente, RG do Paciente, ID do Paciente, } \\
\text { Nome Social, Data de Nascimento, Sexo, Data de Cadastro, } \\
\text { Endereço Residencial, Bairro, Cidade, UF, CEP, Fone Residencial } \\
\text { ou Recado, Fone Celular, Nome da Mãe, Nome do Pai. }\end{array}$} \\
\hline
\end{tabular}




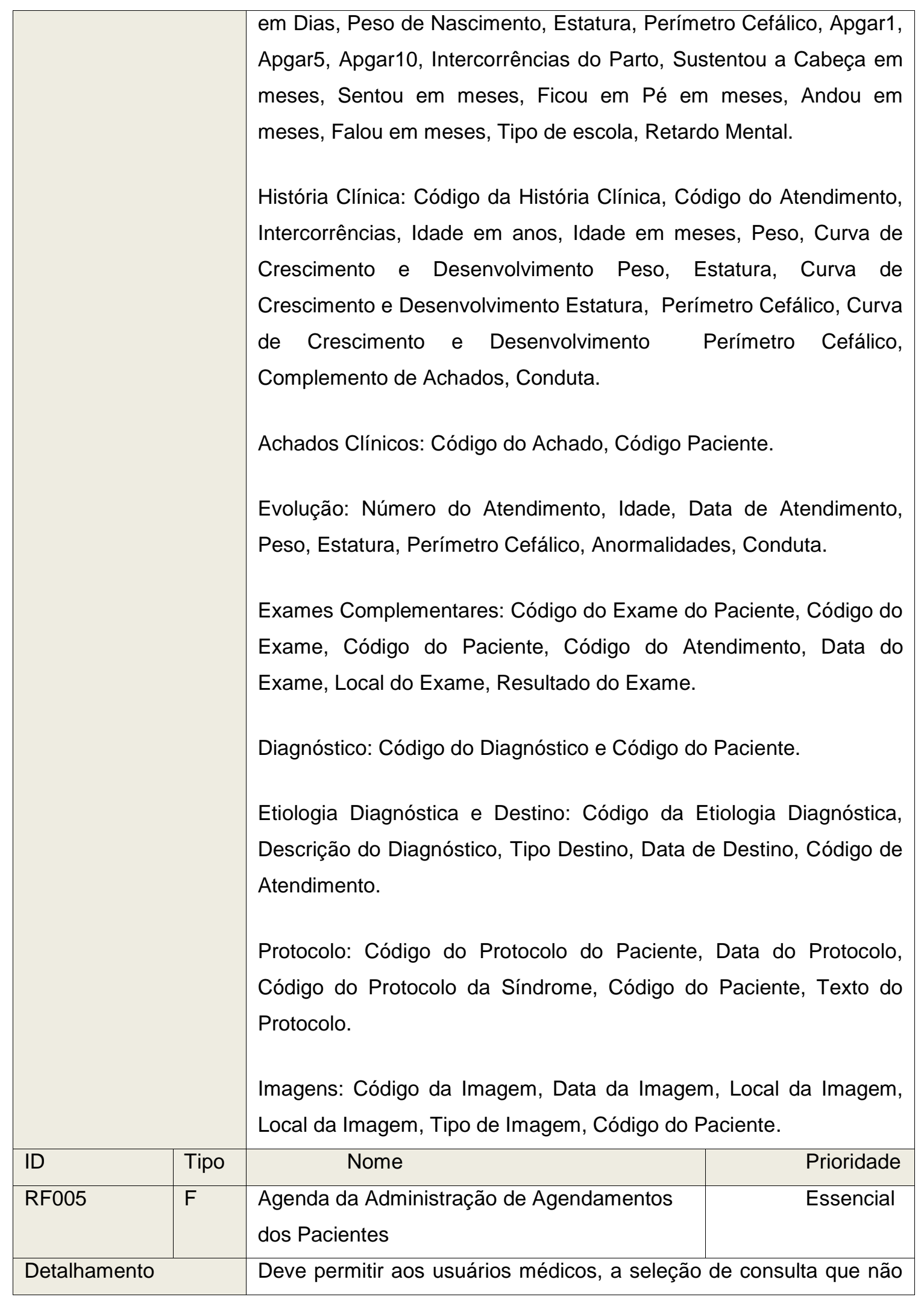




\begin{tabular}{|c|c|c|c|}
\hline & & \multicolumn{2}{|c|}{$\begin{array}{l}\text { foi incluída no sistema, para fazê-lo. Terá os seguintes campos: RG } \\
\text { do Paciente, Nome do Paciente, Data da Agenda, Hora da Consulta, } \\
\text { Agenda, Código do Paciente, Código do Atendimento, Status de } \\
\text { Atendimento. }\end{array}$} \\
\hline ID & Tipo & Nome & Prioridade \\
\hline RF006 & $\mathrm{F}$ & Cadastro de Achados Clínicos & Essencial \\
\hline \multicolumn{2}{|c|}{ Detalhamento } & \multicolumn{2}{|c|}{$\begin{array}{l}\text { Deve permitir ao usuário autorizado, a inclusão, alteração, exclusão } \\
\text { e consulta dos achados clínicos (tipos e itens) da área de genética. } \\
\text { Terá os seguintes itens de dados, com seus respectivos campos: } \\
\text { Tipos de Achados: Código do Achado e Descrição do Achado. } \\
\text { Itens de Achados: Código do Item, Descrição do Item, Código do } \\
\text { Achado. }\end{array}$} \\
\hline ID & Tipo & Nome & Prioridade \\
\hline RF007 & $\mathrm{F}$ & Cadastro de Diagnósticos & Essencial \\
\hline \multicolumn{2}{|c|}{ Detalhamento } & \multicolumn{2}{|c|}{$\begin{array}{l}\text { Deve permitir ao usuário autorizado, a inclusão, alteração, exclusão } \\
\text { e consulta dos diagnósticos (tipos e especificação) da área de } \\
\text { genética. Terá os seguintes itens de dados, com seus respectivos } \\
\text { campos: } \\
\text { Tipos de Diagnósticos: Código do Tipo de Diagnóstico e Descrição } \\
\text { do Diagnóstico. } \\
\text { Especificação dos Diagnósticos: Código da Especificação, Descrição } \\
\text { da Especificação e Código do Tipo de Diagnóstico. }\end{array}$} \\
\hline ID & Tipo & Nome & Prioridade \\
\hline RF008 & $\mathrm{F}$ & Cadastro de Protocolos & Essencial \\
\hline \multicolumn{2}{|c|}{ Detalhamento } & \multicolumn{2}{|c|}{$\begin{array}{l}\text { Deve permitir ao usuário autorizado, a inclusão, alteração, exclusão } \\
\text { e consulta dos protocolos da área de genética. Terá os seguintes } \\
\text { campos: Código do Protocolo, Descrição do Protocolo e Texto do } \\
\text { Protocolo. }\end{array}$} \\
\hline ID & Tipo & Nome & Prioridade \\
\hline RF009 & $\mathrm{F}$ & Cadastro de Exames & Essencial \\
\hline \multicolumn{2}{|c|}{ Detalhamento } & \multicolumn{2}{|c|}{$\begin{array}{l}\text { Deve permitir ao usuário autorizado, a inclusão, alteração, exclusão } \\
\text { e consulta dos exames da área de genética. Terá os seguintes }\end{array}$} \\
\hline
\end{tabular}




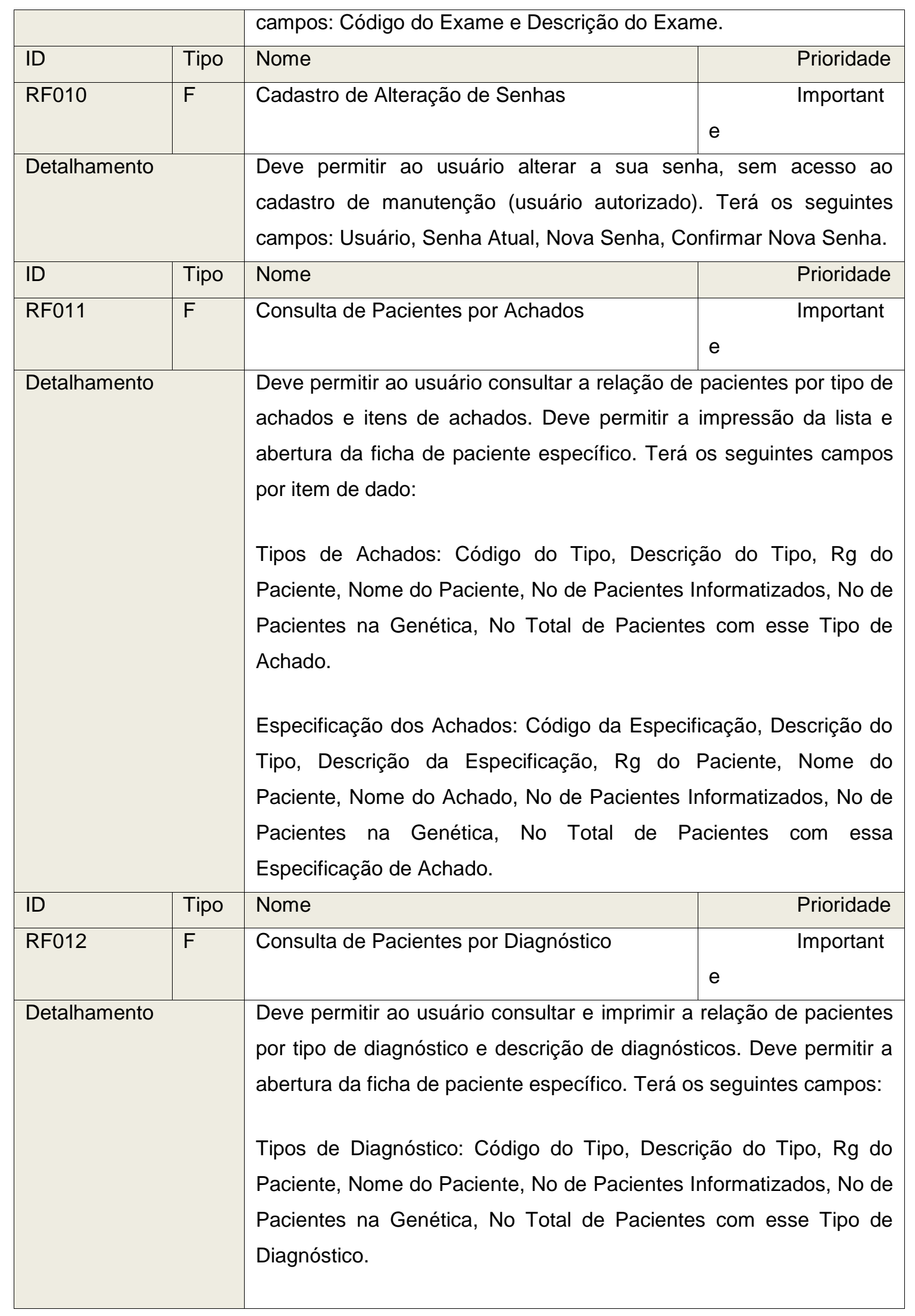




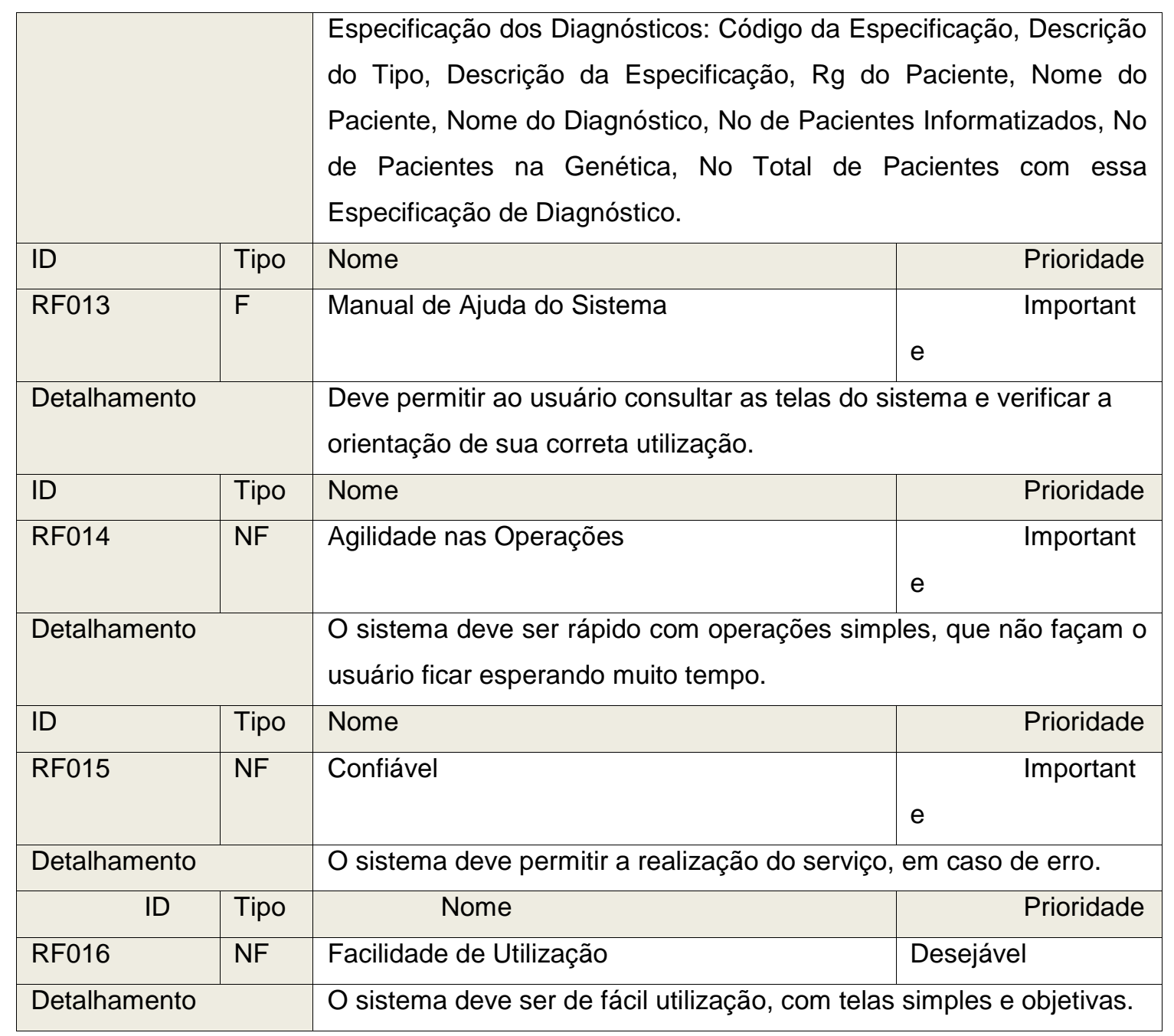


Anexo C - Imagens do PEG-software 


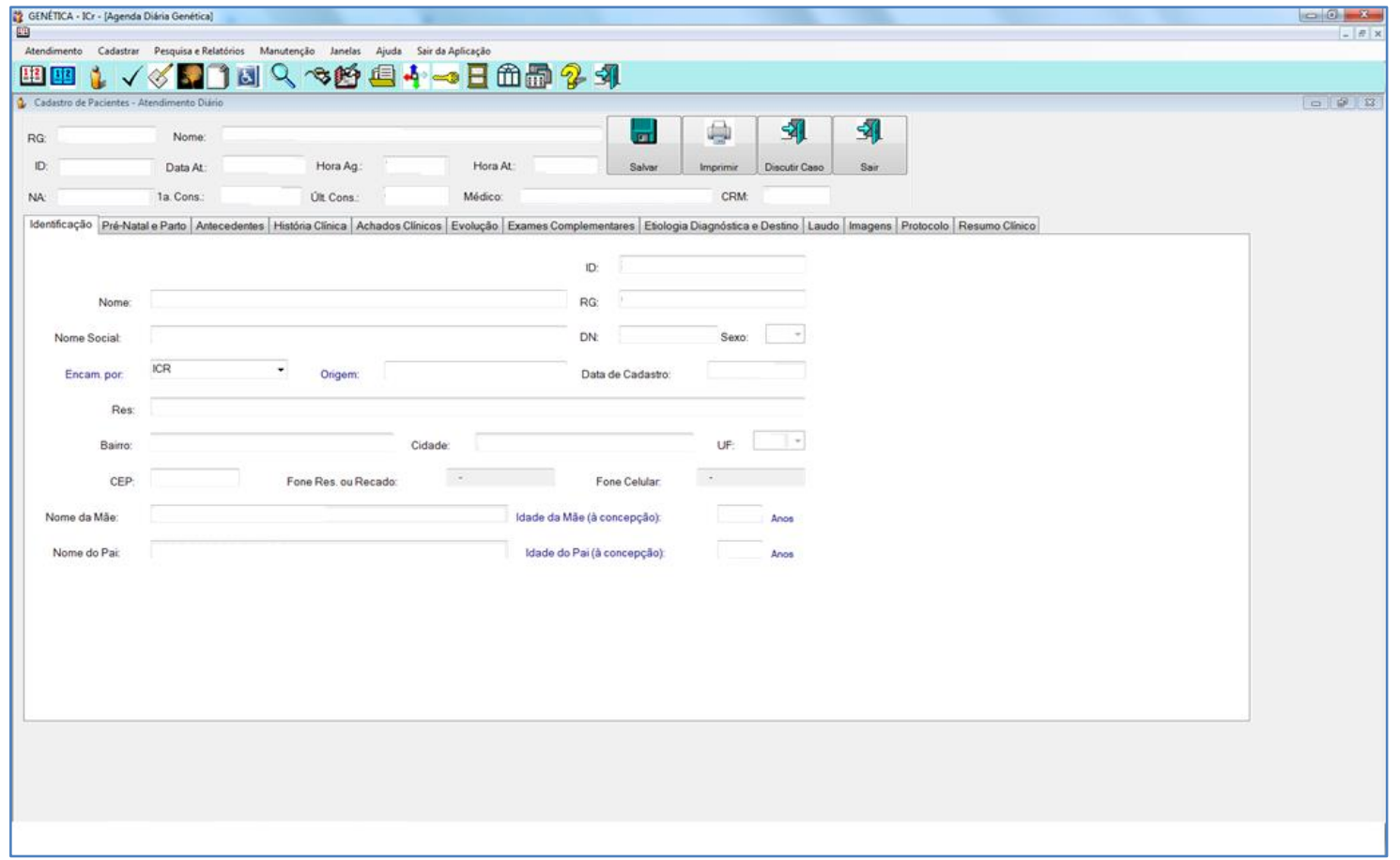

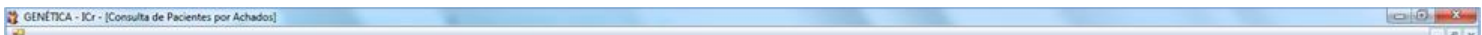

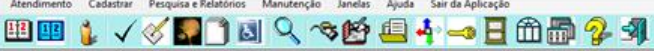

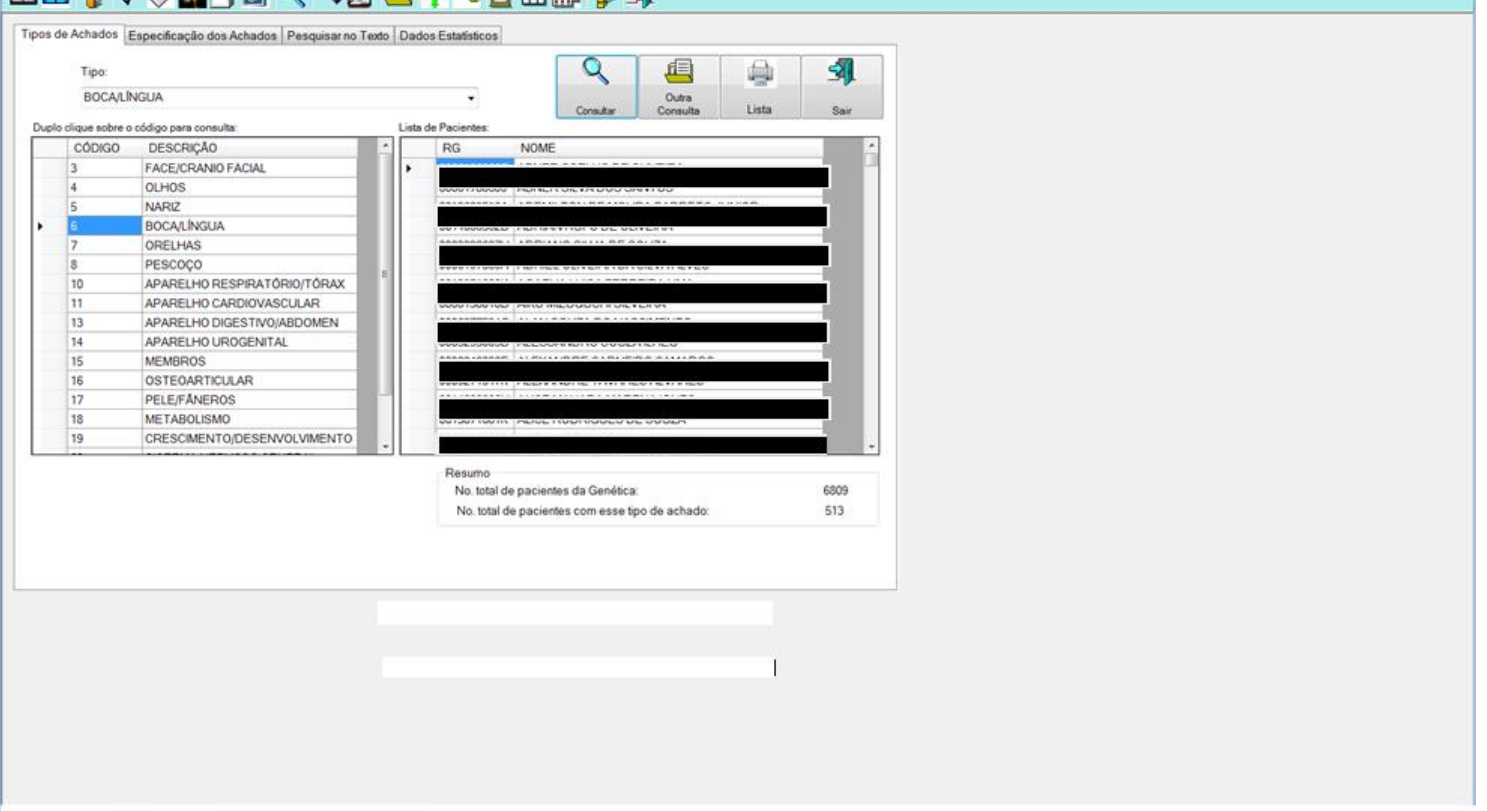


Anexo D - Ficha de Avaliação 
FMUSP - Faculdade de Medicina da Universidade de São Paulo

Avaliação do PEG-software - Departamento de Genética Clínica - Icr

Executante: Irenice de Fátima Carboni

Professores Drs.: Marcelo Nascimento Burattini e Chong Ae Kim

\section{FICHA DE AVALIAÇÃO}

Nome (opcional):

Idade:_ Sexo: Masculino ( ) Feminino ( )

Usuário: Médico Assistente ( ) Médico Residente ( ) Médico Estagiário ( )

Respostas:

Discordo Plenamente (1) Discordo (2) Talvez (3) Concordo (4) Concordo Plenamente (5)

Aspectos a serem avaliados

1. Serviço:

1.1 - A organização e apresentação do conteúdo funcional do Prontuário Eletrônico da Genética (PEG), conforme as abas (guias): Identificação do Paciente, Pré-Natal e Parto, História Clínica, Achados Clínicos, Evolução, Exames, Diagnóstico, Protocolo e Imagens, satisfazem as necessidades do serviço de genética.

1.1.1 A organização e apresentação do conteúdo funcional da aba (guia) Identificação do Paciente, satisfazem as necessidades do serviço de genética.

1.1.2 A organização e apresentação do conteúdo funcional da aba (guia) Pré-Natal e Parto, satisfazem as necessidades do serviço de genética.

1.1.3 A organização e apresentação do conteúdo funcional da aba (guia) História Clínica, satisfazem as necessidades do serviço de genética.

1.1.4 A organização e apresentação do conteúdo funcional da aba (guia) Achados Clínicos, satisfazem as necessidades do serviço de genética.

1.1.5 A organização e apresentação do conteúdo funcional da aba (guia) Evolução, satisfazem as necessidades do serviço de genética.

1.1.6 A organização e apresentação do conteúdo funcional da aba (guia) Exames, satisfazem as necessidades do serviço de genética.

1.1.7 A organização e apresentação do conteúdo funcional da aba (guia) Diagnóstico, satisfazem as necessidades do serviço de genética.

1.1.8 A organização e apresentação do conteúdo funcional da aba (guia) Protocolo, satisfazem as necessidades do serviço de genética.

1.1.9 A organização e apresentação do conteúdo funcional da aba (guia) Imagens, satisfazem as necessidades do serviço de genética.

1.2 - As funções do sistema PEG no atendimento médico satisfazem às necessidades do serviço de genética.

1.3 - O uso do sistema permite maior clareza na leitura do histórico do paciente. 




Sugestões de melhoria:

Responsável pela Avaliação:

São Paulo, 
Anexo E - Ficha de Detecção de Defeitos 
FMUSP - Faculdade de Medicina da Universidade de São Paulo

Avaliação do Prontuário Eletrônico - Departamento de Genética Clínica - ICr

Executante: Irenice de Fátima Carboni

Professores Drs.: Marcelo Nascimento Burattini e Chong Ae Kim

\section{FICHA DE DETECÇÃO DE DEFEITOS}

Nome(opcional):

Idade:

Sexo: Masculino ( ) Feminino ( )

Usuário: Médico Assistente ( ) Médico Residente ( ) Médico Estagiário ( )

Obs.: - Ao lado da Tela, marque quantas vezes por semana usa a tela (__ $)$.

- Marque um X na parte da tela que apresenta defeito.

- Na linha pontilhada especifique a falha. Ex.: .....falta exame incluído...........

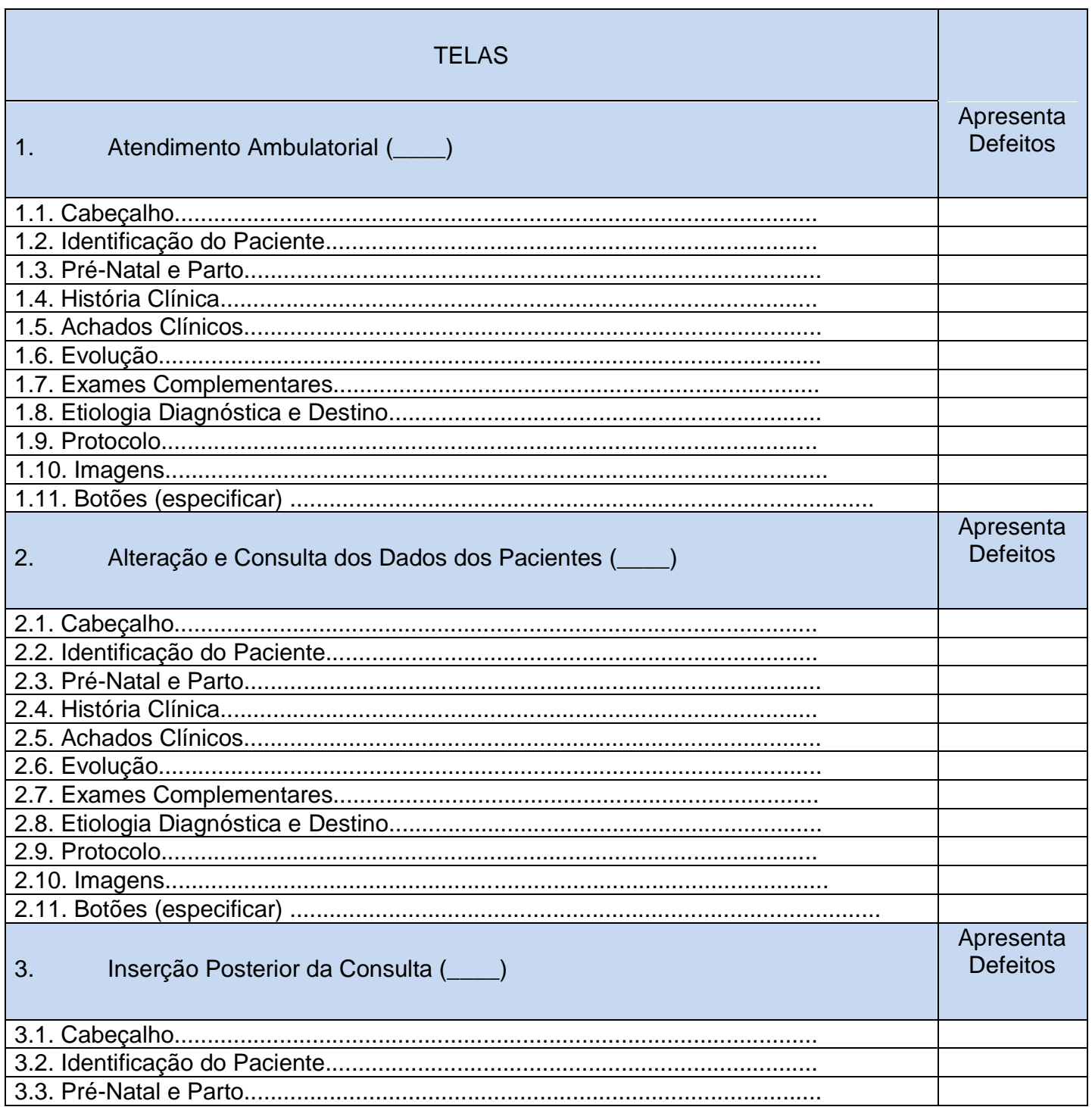




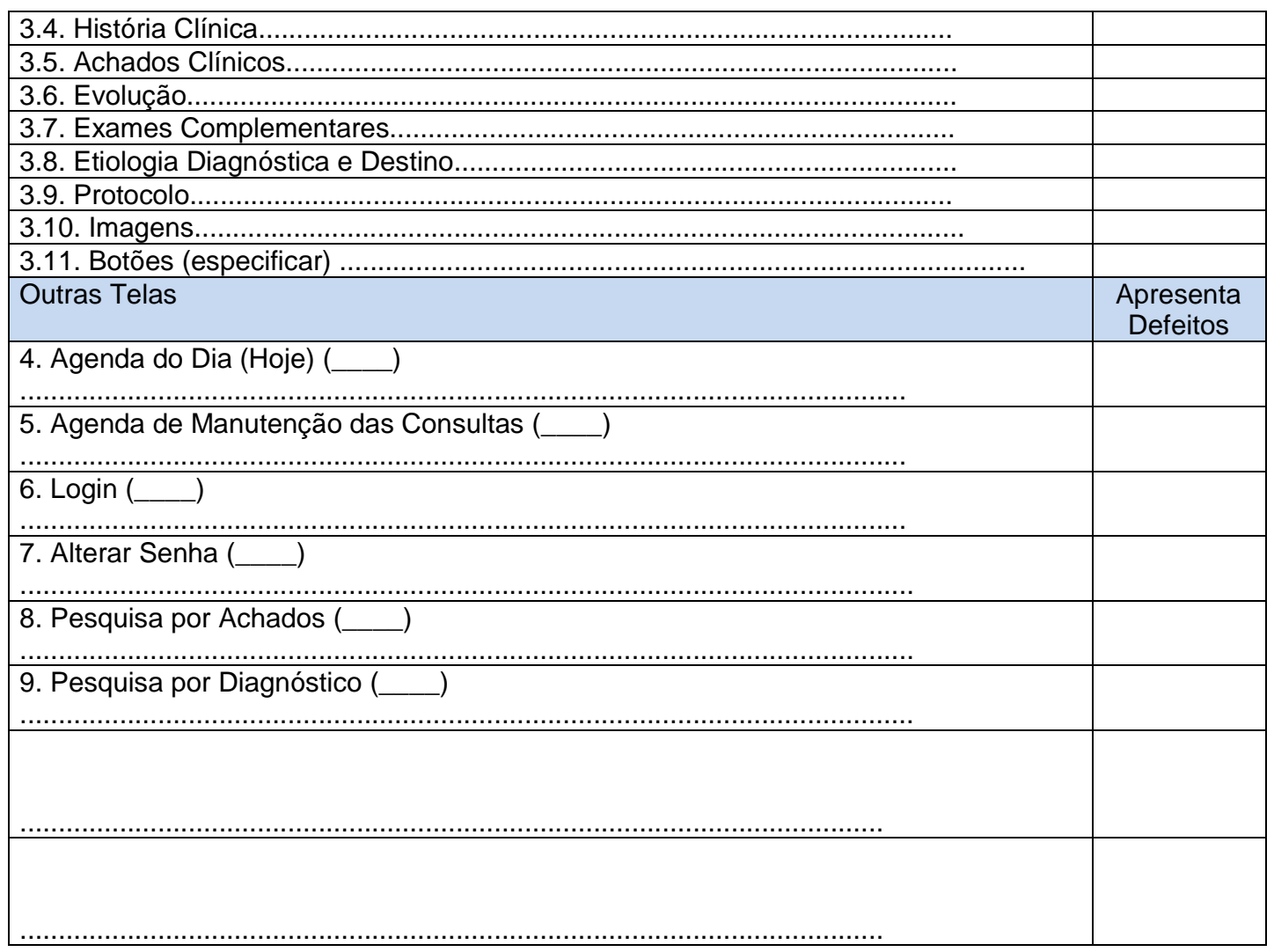

Responsável pela Avaliação:

São Paulo, 
Anexo F - FMEA - Controle de Defeitos 


\begin{tabular}{|c|c|c|c|c|c|c|c|c|c|c|c|c|}
\hline \multicolumn{7}{|c|}{ Lifta de Defeitos - Fare 1 - Abril de 2015} & \multicolumn{4}{|c|}{ Indices } & \multirow{2}{*}{\multicolumn{2}{|c|}{$\begin{array}{l}\text { Aşôe de Melhorizs } \\
\text { Medidas Implartrodes }\end{array}$}} \\
\hline Ordem & \begin{tabular}{|c|c|} 
Local \\
Encontrado
\end{tabular} & Item & Descrị̧öo do Falhe & 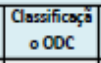 & Efeito do Folhs & Local//Cusa da Falha & Severidode & Ocorrêncis & NA (TA) & Risco & & \\
\hline 1 & 1 & 1.1 & $\begin{array}{l}\text { Poucas veres aparece a consulta anterior do } \\
\text { paciente e deve parecerer a do dia. }\end{array}$ & 9 & $\begin{array}{l}\text { Pode retomar a consulta errada, pois pode ter } \\
\text { douplicidade de campo chive }\end{array}$ & $\begin{array}{l}\text { Banco de Dadoa. Operador de banco apagou chaves } \\
\text { primáriez. }\end{array}$ & 3 & 4 & $8(8)$ & ; 4 & $\operatorname{sim}$ & 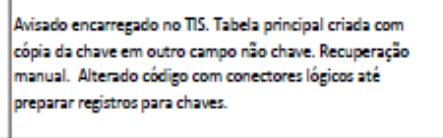 \\
\hline 2 & 1 & 1.4 & Aprecece repetico a consultas anteriores. & 2 & Repetiçâo de resultado de consulta. & $\begin{array}{l}\text { Cócigo. Näo limpou o textbox antes de mostrar nova } \\
\text { consulta. }\end{array}$ & 1 & 4 & $8(8)$ & $1 ; 4$ & $\operatorname{sim}$ & $\begin{array}{l}\text { Atterado código com comando para limpar tentbox antes de } \\
\text { corousta. }\end{array}$ \\
\hline 3 & 1 & 1.4 & Näo permite digitar apostroce.e. & 7 & $\begin{array}{l}\text { Näo é possivel inserir consulta do paciente, pois ñô } \\
\text { acceta a digtaçăo da apostrofe. }\end{array}$ & Código. Apostrofé é palavar reservada do VB. net. & 3 & 1 & $1(8)$ & $3 ; 1$ & $\operatorname{sim}$ & Feita validą̧̃̃o de apostrofe no código. \\
\hline 4 & 1 & 1.7 & $\begin{array}{l}\text { Aparece a data da consulta a o invés da data } \\
\text { doesame. }\end{array}$ & 1 & Mediccos afimam que é para devixar sem a data. & $\begin{array}{l}\text { Código. Quando não havia data do erame, campo } \\
\text { preenchia automaticamente a data do dia. }\end{array}$ & 1 & 4 & $8(8)$ & 1;4 & $\operatorname{sim}$ & Retirido código para o preechimento automático. \\
\hline 5 & 1 & 1.7 & Observamos que faltam a lguns exames. & 2 & $\begin{array}{l}\text { Aprecece retomo de exames do dia, mas deve aparcecer } \\
\text { todos. }\end{array}$ & Código. Consulta traz retomo de evames insericos no dia. & 1 & 4 & $8(8)$ & $1 ; 4$ & $\operatorname{sim}$ & Atterado código para aprececer todos os exames. \\
\hline 6 & 1 & 1.8 & $\begin{array}{l}\text { Algumas verese colocamos a data de retorno e } \\
\text { acciba sumindo depois. }\end{array}$ & 2 & Nö̌ é posasivel salvar data de retomo corretamentite. & $\begin{array}{l}\text { Código. Dependento tipo de deetino é limpo tertbox data } \\
\text { do retorno, antes de zahar. }\end{array}$ & 2 & 4 & $8(8)$ & 2:4 & $\operatorname{sim}$ & Atterado códiga. \\
\hline 7 & 1 & 1.8 & $\begin{array}{l}\text { Aqueles que já tirham diagnóostico, os mais } \\
\text { antigos, zcaba ñ̃o aparecendo na impressấo } \\
\text { de diagnóatico. }\end{array}$ & 2 & 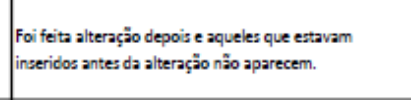 & 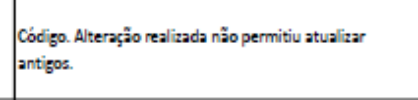 & 1 & 4 & $8(8)$ & $: 4$ & $\operatorname{sim}$ & $\begin{array}{l}\text { Atterado código pars atualizar todos assim que em } \\
\text { ateredimenta. }\end{array}$ \\
\hline 8 & 1 & 1.10 & $\begin{array}{l}\text { Quando clica o botäo salvar aparece uma } \\
\text { mensagem de erro, dicando em continuar, } \\
\text { dezabilita o botäo azhar, mas fica mos em } \\
\text { divida se salvou. }\end{array}$ & 9 & Aprecece mensagen de erro, confito com Oracle. & 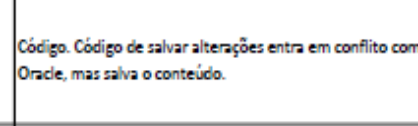 & 1 & 4 & $8(8)$ & 4 & $\operatorname{sim}$ & Alterado código para näo gerar mais mensagem de erro. \\
\hline 9 & 3 & 3 & Consultas real izadas, gó apreceem depois de U. & & Consultas real lizadas, só aparecem depois de uma sema & 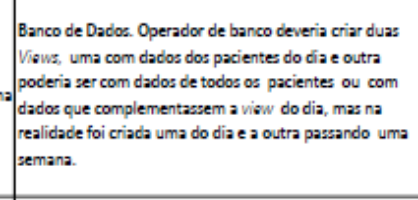 & 2 & 1 & $1(8)$ & 1 & $\sin$ & $\begin{array}{l}\text { Explicado para o encarreegado no TIS e solictado nova criaģa } \\
\text { de visw com dados corretos. }\end{array}$ \\
\hline 10 & 3 & 3.1 & $\begin{array}{l}\text { Poucas vezes aparece a consulta anterior do } \\
\text { paciente e deve paprecer a do dia. }\end{array}$ & 9 & $\begin{array}{l}\text { Pode retomar a consulta errada, pois pode ter } \\
\text { duplicidade de compo chive. }\end{array}$ & $\begin{array}{l}\text { Banco de Dados. Operador de banco apagou chaves } \\
\text { primániza. }\end{array}$ & 3 & 4 & $8(8)$ & 4 & $\operatorname{sim}$ & 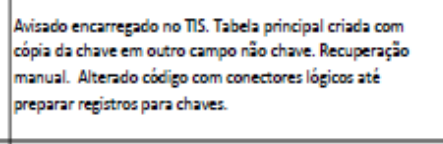 \\
\hline & 4 & 4 & $\begin{array}{l}\text { Duplicidade de consultas na agenda para } \\
\text { mesmo AGT (agenda da genética) diae } \\
\text { horrino. }\end{array}$ & 4 & 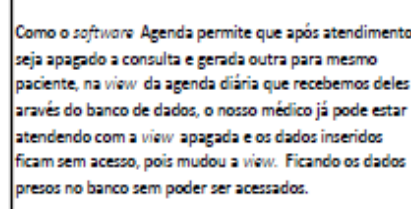 & $\begin{array}{l}\text { Softurere Agendz. Software permite que após } \\
\text { atendimento a consulta seja apagad a e colocada outra } \\
\text { para meamo paciente e horario. }\end{array}$ & 3 & 2 & $2(8)$ & 3;2 & Nă๋ & 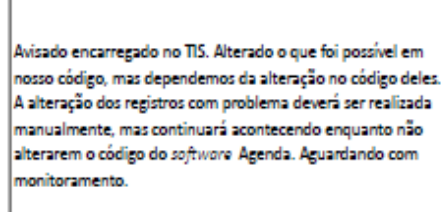 \\
\hline 11 & & & & & & & & & & & & \\
\hline
\end{tabular}




\begin{tabular}{|c|c|c|c|c|c|c|c|c|c|c|c|c|}
\hline \multicolumn{7}{|c|}{ Lista de Defeitos - Fase 2 - Outubro de 2015} & \multicolumn{4}{|c|}{ índices } & \multirow{2}{*}{\multicolumn{2}{|c|}{\begin{tabular}{|l|l} 
& Ações de Melhorias \\
Corrigido & Medidas Implantadas
\end{tabular}}} \\
\hline Ordem & \begin{tabular}{|c|} 
Local \\
Encontrado
\end{tabular} & Item & Descrição da Falha & $\begin{array}{c}\text { Classificação } \\
\text { ODC }\end{array}$ & Efeito da Falha & Local/Causa da Falha & Severidade & Ocorrência & NA (TA) & Risco & & \\
\hline 1 & & 11.7 & Somem exames incluídos previamente. & 2 & $\begin{array}{l}\text { Aparece retorno de exames do dia, mas } \\
\text { deve aparecer todos. }\end{array}$ & $\begin{array}{l}\text { Código. Consulta traz retorno de } \\
\text { exames inseridos no dia. }\end{array}$ & 1 & 2 & $2(8)$ & $1 ; 2$ & Sim & $\begin{array}{l}\text { Alterado código para aparecer } \\
\text { todos os exames. }\end{array}$ \\
\hline 2 & & 1.8 & Por vezes some o complemento. & 2 & $\begin{array}{l}\text { Não é possivel salvar complemento } \\
\text { dependento de destino. }\end{array}$ & $\begin{array}{l}\text { Código. Comandos para limpeza de } \\
\text { campos são acionados em momento } \\
\text { incorreto. }\end{array}$ & 2 & 2 & $2(8)$ & $2 ; 2$ & Sim & Alterado código. \\
\hline 3 & & $\begin{array}{lll}3 & 3.7 \\
\end{array}$ & As vezes os dados somem. & 2 & $\begin{array}{l}\text { Aparece retorno de exames do dia, mas } \\
\text { deve aparecer todos. }\end{array}$ & $\begin{array}{l}\text { Código. Consulta traz retorno de } \\
\text { exames inseridos no dia. }\end{array}$ & 1 & 1 & $1(8)$ & $1 ; 1$ & Sim & $\begin{array}{l}\text { Alterado código para aparecer } \\
\text { todos os exames. }\end{array}$ \\
\hline 4 & & 4 & $\begin{array}{l}\text { Duplicidade de consultas na agenda } \\
\text { para mesmo AGNT (agenda da } \\
\text { genética) dia e horário. }\end{array}$ & 4 & $\begin{array}{l}\text { Como o software Agenda permite que } \\
\text { após atendimento seja apagado a } \\
\text { consulta e gerada outra para mesmo } \\
\text { paciente, na view da agenda diária que } \\
\text { recebemos deles aravés do banco de } \\
\text { dados, o nosso médico já pode estar } \\
\text { atendendo com a view apagada e os } \\
\text { dados inseridos ficam sem acesso, pois } \\
\text { mudou a view. Ficando os dados presos } \\
\text { no banco sem poder ser acessados. }\end{array}$ & $\begin{array}{l}\text { Software Agenda. Software permite } \\
\text { que após atendimento a consulta } \\
\text { seja apagada e colocada outra para } \\
\text { mesmo paciente e horário. }\end{array}$ & 3 & 1 & $1(8)$ & $3 ; 1$ & Não & $\begin{array}{l}\text { Avisado encarregado no TIS. } \\
\text { Alterado o que foi possivel em } \\
\text { nosso código, mas dependemos } \\
\text { da alteração no código deles. A } \\
\text { alteração dos registros com } \\
\text { problema deverá ser realizada } \\
\text { manualmente, mas continuará } \\
\text { acontecendo enquanto não } \\
\text { alterarem o código do software } \\
\text { Agenda. Aguardando com } \\
\text { monitoramento. }\end{array}$ \\
\hline & & & $\begin{array}{l}\text { Local encontrado: se refere ao número } \\
\text { correspondente no formulário de } \\
\text { avaliação }\end{array}$ & & & $\begin{array}{l}\text { NA (TA): Número de avaliaçôes do } \\
\text { Total de Avaliações }\end{array}$ & & & 6 & & & \\
\hline
\end{tabular}




\begin{tabular}{|c|c|c|c|c|c|c|c|c|c|c|c|c|}
\hline \multicolumn{7}{|c|}{ Lista de Defeitos - Fase 3 - Abril de 2016} & \multicolumn{4}{|c|}{ índices } & \multirow[b]{2}{*}{ Corrigido } & \multirow{2}{*}{\begin{tabular}{|l} 
Ações de Melhorias \\
Medidas Implantadas
\end{tabular}} \\
\hline Ordem & $\begin{array}{c}\text { Local } \\
\text { Encontrado }\end{array}$ & Item & Descriç̃o da Falha & Classificação ODC & Efeito da Falha & Local/Causa da Falha & Severidade & Ocorrência & NA (TA) & Risco & & \\
\hline 1 & 1 & 1.8 & $\begin{array}{l}\text { Apaga o } \\
\text { diagnóstico/complemento } \\
\text { e/ou data de retorno }\end{array}$ & 2 & $\begin{array}{l}\text { Não é possivel salvar complemento } \\
\text { dependento de destino. }\end{array}$ & $\begin{array}{l}\text { Código. Comandos para limpeza de } \\
\text { campos são acionados em } \\
\text { momento incorreto. }\end{array}$ & 2 & 2 & $3(9)$ & $2 ; 2$ & Sim & Alterado código. \\
\hline 2 & & 22.7 & $\begin{array}{l}\text { A vezes não consigo salvar } \\
\text { os exames, pois dá erro. }\end{array}$ & 2 & $\begin{array}{l}\text { Outro código em execução que impede } \\
\text { o salvamento. }\end{array}$ & Código. Conflito de código. & 1 & 1 & $1(9)$ & $1 ; 1$ & Sim & $\begin{array}{l}\text { Alterado código para evitar o problema. } \\
\text { Validação. }\end{array}$ \\
\hline 3 & & 4 & \begin{tabular}{|l|} 
Duplicidade de consultas na \\
agenda para mesmo AGNT \\
(agenda da genética) dia e \\
horário.
\end{tabular} & 4 & $\begin{array}{l}\text { Como o software Agenda permite que } \\
\text { após atendimento seja apagado a } \\
\text { consulta e gerada outra para mesmo } \\
\text { paciente, na view da agenda diária que } \\
\text { recebemos deles aravés do banco de } \\
\text { dados, o nosso médico já pode estar } \\
\text { atendendo com a view apagada e os } \\
\text { dados inseridos ficam sem acesso, pois } \\
\text { mudou a view. Ficando os dados presos } \\
\text { no banco sem poder ser acessados. }\end{array}$ & $\begin{array}{l}\text { Software Agenda. Software permite } \\
\text { que após atendimento a consulta } \\
\text { seja apagada e colocada outra para } \\
\text { mesmo paciente e horário. }\end{array}$ & 3 & 3 & $6(9)$ & 3,3 & Não & $\begin{array}{l}\text { Avisado encarregado no TIS. Alterado o que foi } \\
\text { possivel em nosso código, mas dependemos } \\
\text { da alteração no código deles. A alteração dos } \\
\text { registros com problema deverá ser realizada } \\
\text { manualmente, mas continuará acontecendo } \\
\text { enquanto não alterarem o código do software } \\
\text { Agenda. Aguardando com monitoramento. }\end{array}$ \\
\hline & & & $\begin{array}{l}\text { Local encontrado: se refere } \\
\text { ao número correspondente } \\
\text { no formulário de avaliação }\end{array}$ & & & $\begin{array}{l}\text { NA (TA): Número de avaliaçôes do } \\
\text { Total de Avaliações }\end{array}$ & & & 10 & & & \\
\hline
\end{tabular}




\begin{tabular}{|c|c|c|c|c|c|c|c|c|c|c|c|c|}
\hline Ordem & $\begin{array}{c}\text { Local } \\
\text { Encontrado }\end{array}$ & Item & Descrição da Falha & $\left|\begin{array}{c}\text { Classificação } \\
\text { ODC }\end{array}\right|$ & Efeito da Falha & Local/Causa da Falha & Severidade & Ocorrência & NA (TA) & Risco & Corrigido & Medidas Implantadas \\
\hline 1 & & 1.11 & $\begin{array}{l}\text { Médico abre aplicação em dois } \\
\text { lugares, fazendo alteraçãoe } \\
\text { salvando em uma máquina, } \\
\text { depois salva a que está em } \\
\text { branco em cima e perde os dados } \\
\text { de conduta. }\end{array}$ & 3 & \begin{tabular}{|l|} 
Abertura do formulário em dois \\
lugares, para discutir caso, permite \\
que em se fazendo alteração e salvando \\
em uma máquina atualiza o banco, mas \\
quando vai para a outra máquina a \\
versão aberta não foi atualizada e \\
permite que salve-se sem alteração em \\
cima da que já está alterada.
\end{tabular} & $\begin{array}{l}\text { Código. Tipo de abertura do } \\
\text { formulário permite } \\
\text { multiplas aberturas } \\
\text { simultâneas, falta de } \\
\text { atual ização de formulários } \\
\text { abertos automaticamente. }\end{array}$ & 3 & 1 & $1(11)$ & $3 ; 1$ & $\operatorname{sim}$ & $\begin{array}{l}\text { Alterado código para a maneira de } \\
\text { uso da equipe. }\end{array}$ \\
\hline 2 & & 1.1 & $\begin{array}{l}\text { Digitação errada na impressão } \\
\text { da consulta (palavra digitada } \\
\text { erroneamente). }\end{array}$ & 1 & $\begin{array}{l}\text { Na impressão da consulta, uma palavra } \\
\text { constante aparece escrita de forma } \\
\text { incorreta. }\end{array}$ & Código. Digitação errada. & 1 & 1 & $1(11)$ & $1 ; 1$ & Sim & Corrigido digitação da palavra. \\
\hline 3 & & 2.4 & $\begin{array}{l}\text { Quando faz alteração (Inter } \\
\text { consulta) some conduta. }\end{array}$ & 2 & $\begin{array}{l}\text { Quando é feita anotação de pacientes } \\
\text { como inter consulta em campo próprio, } \\
\text { apaga conduta. }\end{array}$ & $\begin{array}{l}\text { Código. Limpeza de campo } \\
\text { real izada em momento } \\
\text { errado. }\end{array}$ & 2 & 1 & $1(11)$ & $2 ; 1$ & sim & $\begin{array}{l}\text { Alterado código. Realizada } \\
\text { digitação de dados apagados. }\end{array}$ \\
\hline 4 & & 2.6 & \begin{tabular}{|l} 
Evolução - as vezes não \\
incorporou a alteração do dia.
\end{tabular} & 2 & $\begin{array}{l}\text { Não aparece a evolução atualizada em } \\
\text { formulário consulta. }\end{array}$ & $\begin{array}{l}\text { Código. Atual lização de } \\
\text { consulta }\end{array}$ & 1 & 1 & $1(11)$ & $1 ; 1$ & Sim & $\begin{array}{l}\text { Alterado código para possibilitar a } \\
\text { consulta atualizada. }\end{array}$ \\
\hline 5 & 4 & & $\begin{array}{l}\text { Duplicidade de consultas na } \\
\text { agenda para mesmo AGNT } \\
\text { (agenda da genética) dia e } \\
\text { horário. }\end{array}$ & 4 & \begin{tabular}{|l|} 
Como o software Agenda permite que \\
após atendimento seja apagado a \\
consulta e gerada outra para mesmo \\
paciente, na view da agenda diária que \\
recebemos deles aravés do banco de \\
dados, o nosso médico já pode estar \\
atendendo com a view apagada e os \\
dados inseridos ficam sem acesso, pois \\
mudou a view. Ficando os dados presos \\
no banco sem poder ser acessados.
\end{tabular} & \begin{tabular}{|l|} 
Software Agenda. Software \\
permite que após \\
atendimento a consulta seja \\
apagada e colocada outra \\
para mesmo paciente e \\
horário.
\end{tabular} & 3 & 3 & $6(11)$ & $3 ; 3$ & Nã。 & $\begin{array}{l}\text { Avisado encarregado no TIS. } \\
\text { Alterado o que foi possivel em } \\
\text { nosso código, mas dependemos da } \\
\text { alteração no código deles. A } \\
\text { alteração dos registros com } \\
\text { problema deverá ser realizada } \\
\text { manualmente, mas continuará } \\
\text { acontecendo enquanto não } \\
\text { alterarem o código do software } \\
\text { Agenda. Aguardando com } \\
\text { monitoramento. }\end{array}$ \\
\hline & & & $\begin{array}{l}\text { Local encontrado: se refere ao } \\
\text { número correspondente no } \\
\text { formulário de avaliação }\end{array}$ & & & $\begin{array}{l}\text { NA (TA): Número de } \\
\text { avaliaç̃es do Total de } \\
\text { Avaliações }\end{array}$ & & & 10 & & & \\
\hline
\end{tabular}




\begin{tabular}{|c|c|c|c|c|c|c|c|c|c|c|c|c|}
\hline \multicolumn{7}{|c|}{ Lista de Defeitos - Fase 5 - Abril de 2017} & \multicolumn{4}{|c|}{ índices } & & \multirow{2}{*}{\begin{tabular}{|l} 
Aç̃oes de Melhorias \\
Medidas Implantadas
\end{tabular}} \\
\hline Ordem & $\begin{array}{c}\text { Local } \\
\text { Encontrado }\end{array}$ & Item & Descrição da Falha & $\begin{array}{c}\text { Classificação } \\
\text { ODC }\end{array}$ & Efeito da Falha & Local/Causa da Falha & Severidade & Ocorrência & NA (TA) & Risco & Corrigido & \\
\hline 1 & & 1.4 & $\begin{array}{l}\text { Impressão da consulta pelo } \\
\text { formulário de consulta não } \\
\text { está justificado. }\end{array}$ & 3 & $\begin{array}{l}\text { Na impressão da consulta, o } \\
\text { alinhamento não está alinhado a } \\
\text { direita e esquerda. }\end{array}$ & $\begin{array}{l}\text { Código. Não colocada a } \\
\text { formatação de saída do relatório } \\
\text { no código. }\end{array}$ & 1 & 1 & $1(14)$ & $1 ; 1$ & Não & Ainda em fila de espera. \\
\hline 2 & 4 & & $\begin{array}{l}\text { Duplicidade de consultas na } \\
\text { agenda para mesmo AGNT } \\
\text { (agenda da genética) dia e } \\
4 \text { horário. }\end{array}$ & 4 & $\begin{array}{l}\text { Como o software Agenda permite que } \\
\text { após atendimento seja apagado a } \\
\text { consulta e gerada outra para mesmo } \\
\text { paciente, na view da agenda diária que } \\
\text { recebemos deles aravés do banco de } \\
\text { dados, o nosso médico já pode estar } \\
\text { atendendo com a view apagada e os } \\
\text { dados inseridos ficam sem acesso, pois } \\
\text { mudou a view. Ficando os dados presos } \\
\text { no banco sem poder ser acessados. }\end{array}$ & $\begin{array}{l}\text { Software Agenda. Software } \\
\text { permite que após atendimento a } \\
\text { consulta seja apagada e } \\
\text { colocada outra para mesmo } \\
\text { paciente e horário. }\end{array}$ & 3 & 3 & $8(14)$ & 3 & Não & $\begin{array}{l}\text { Avisado encarregado no TIS. } \\
\text { Alterado o que foi possivel em } \\
\text { nosso código, mas dependemos da } \\
\text { alteração no código deles. A } \\
\text { alteração dos registros com } \\
\text { problema deverá ser realizada } \\
\text { manualmente, mas continuará } \\
\text { acontecendo enquanto não } \\
\text { alterarem o código do software } \\
\text { Agenda. Aguardando com } \\
\text { monitoramento. }\end{array}$ \\
\hline & & & $\begin{array}{l}\text { Local encontrado: se refere ao } \\
\text { número correspondente no } \\
\text { formulário de avaliação }\end{array}$ & & & $\begin{array}{l}\text { NA (TA): Número de avaliações } \\
\text { do Total de Avaliações }\end{array}$ & & & 9 & & & \\
\hline
\end{tabular}




\begin{tabular}{|c|c|c|c|c|c|c|c|c|c|c|c|c|}
\hline \multicolumn{7}{|c|}{ Lista de Defeitos - Fase 6 - Outubro de 2017} & \multicolumn{4}{|c|}{ índices } & & \multirow{2}{*}{\begin{tabular}{|l} 
Ações de Melhorias \\
Medidas Implantadas
\end{tabular}} \\
\hline Ordem & $\begin{array}{c}\text { Local } \\
\text { Encontrado }\end{array}$ & Item & Descrição da Falha & $\begin{array}{l}\text { Classificação } \\
\text { ODC }\end{array}$ & Efeito da Falha & Local/Causa da Falha & Severidade & Ocorrência & NA (TA) & Risco & Corrigido & \\
\hline 1 & & 22.4 & $\begin{array}{l}\text { Barra de rolagem de } \\
\text { consultas anteriores de } \\
\text { atualizações congeladas. }\end{array}$ & 1 & $\begin{array}{l}\text { Não permite rolar a lista ao } \\
\text { clicar na barra de rolagem. }\end{array}$ & $\begin{array}{l}\text { Código. Configurar } \\
\text { propriedades do objeto. }\end{array}$ & 1 & 1 & $1(12)$ & $1 ; 1$ & Sim & Alterado código. \\
\hline 2 & 4 & & $\begin{array}{l}\text { Duplicidade de consultas } \\
\text { na agenda para mesmo } \\
\text { AGNT (agenda da } \\
\text { genética) dia e horário. }\end{array}$ & 4 & $\begin{array}{l}\text { Como o software Agenda permite } \\
\text { que após atendimento seja } \\
\text { apagado a consulta e gerada } \\
\text { outra para mesmo paciente, na } \\
\text { view da agenda diária que } \\
\text { recebemos deles aravés do } \\
\text { banco de dados, o nosso médico } \\
\text { já pode estar atendendo com a } \\
\text { view apagada eos dados } \\
\text { inseridos ficam sem acesso, pois } \\
\text { mudou a view. Ficando os dados } \\
\text { presos no banco sem poder ser } \\
\text { acessados. }\end{array}$ & \begin{tabular}{|l|} 
\\
Software Agenda. \\
Software permite que após \\
atendimento a consulta \\
seja apagada e colocada \\
outra para mesmo \\
paciente e horário.
\end{tabular} & 3 & 1 & $2(12)$ & $3 ; 1$ & Não & $\begin{array}{l}\text { Avisado encarregado no TIS. } \\
\text { Alterado o que foi possivel em } \\
\text { nosso código, mass dependemos da } \\
\text { alteração no código deles. A } \\
\text { alteração dos registros com } \\
\text { problema deverá ser realizada } \\
\text { manualmente, mas continuará } \\
\text { acontecendo enquanto não } \\
\text { alterarem o código do software } \\
\text { Agenda. Aguardando com } \\
\text { monitoramento. }\end{array}$ \\
\hline & & & $\begin{array}{l}\text { Local encontrado: se } \\
\text { refere ao número } \\
\text { correspondente no } \\
\text { formulário de avaliação }\end{array}$ & & & $\begin{array}{l}\text { NA (TA): Número de } \\
\text { avaliações do Total de } \\
\text { Avaliações }\end{array}$ & & & 3 & & & \\
\hline
\end{tabular}


Anexo G - Solicitação de Alterações e Melhorias 
Alterações e/ou Novos Requitisitos marcados como defeito - Sugestões de Melhorias

\begin{tabular}{|c|c|c|c|c|c|}
\hline \multicolumn{6}{|c|}{ Alterações e/ou Novos Requitisitos marcados como defeito - Sugestões de Melhorias } \\
\hline Ordem & Fase & Item & Alterações e/ou Novos Requitisitos marcados como defeito: & Ocorrência & Realizado? \\
\hline 1 & 1 & 1.7 & Poderá ser mais fácil de ver maior. & 1 & Sim \\
\hline 2 & 1 & 1.9 & Necessita de um botão em achados como atalho para as imagens. & 8 & Sim \\
\hline 3 & 1 & 1.9 & Em imagens deve abrir a pasta de imagens desse paciente. & 8 & Sim \\
\hline 4 & 1 & 1.9 & Incluir campo para saber onde está a foto. & 1 & Sim \\
\hline 5 & 1 & 2.1 & Cabeçalho - não tem opção de busca de paciente pelo nome da mãe. & 8 & Sim \\
\hline 6 & 1 & 2.4 & Temos que escrever dentro de uma data anterior. & 1 & Sim \\
\hline 7 & 1 & 3.4 & Temos que escrever dentro de uma data anterior. & 1 & Sim \\
\hline 8 & 1 & 3.7 & Poderia ser mais fácil de ver maior. & 1 & Sim \\
\hline 9 & 1 & 4 & $\begin{array}{l}\text { As vezes quando clicamos no paciente que será atendido e clicamos no botão abrir consulta, } \\
\text { acontece de abrir outro paciente que não o que selecionamos (tempo de timer) }\end{array}$ & 8 & Sim \\
\hline 10 & 1 & & Na guia achados clínicos - aumentar espaço para escrever complemento. & 1 & Sim \\
\hline 11 & 1 & & $\begin{array}{l}\text { Na guia evolução - separar consultas com barra ou separar com um linha os diferentes itens } \\
\text { das consultas. }\end{array}$ & 1 & Sim \\
\hline 12 & 1 & & Na guia exames - aumentar tamanho da tabela com resumo de exames. & 1 & Sim \\
\hline 13 & 1 & & Maior espaço para visualizar os exames quando passamos consulta sem precisar clicar. & 1 & Sim \\
\hline 14 & 1 & & Incluir mais diagnósticos. & 1 & Sim* \\
\hline 15 & 1 & & Inserir um campo para preencher onde está a foto do paciente (Ex.(D20)). & 1 & Sim \\
\hline 16 & 2 & 1.2 & Idade dos pais tem que alterar todo ano, seria melhor por o nascimento e atualizar sozinho. & 1 & Não autorizado \\
\hline 17 & 2 & 1.11 & Incluir botão finalizar, além de salvar, pois está causando confusão. & 8 & Sim \\
\hline 18 & 2 & 1.11 & Mudar de salvar para finalizar. & 2 & Sim \\
\hline 19 & 2 & & Incluir aba (guia) no prontuário para emitir laudo médico do paciente. & 4 & Sim \\
\hline 20 & 2 & & Possibilidade de preenchimento do prontuário para internados e convênio. & 3 & Não autorizado \\
\hline 21 & 2 & & Relatórios para controle de atendimento diário com dados estatísticos. & 3 & Em execução \\
\hline 22 & 2 & & Outros dados estatísticos para consultas por achados e diagnósticos. & 3 & Sim \\
\hline 23 & 3 & 1.2 & Identificação do Paciente - não é possível alterar telefones. & 1 & Não * \\
\hline 24 & 3 & 1.2 & Idade dos pais deveria colocar ano de nascimento e assim todo ano é atualizada automaticam & 1 & Não * \\
\hline 25 & 3 & 1.7 & Tem caracteres de interrogação ao copiar os relatórios dos exames do sistema icr. & 4 & Não \\
\hline 26 & 3 & 8 & Pesquisa de mais de um achado. & 1 & Sim \\
\hline 27 & 3 & & No campo "Atualizações" diminuir espaço em branco que fica após o salvamento. & 2 & Sim \\
\hline 28 & 3 & & Possibilidade de inserir os heredogramas na aba imagens. & 1 & Já existe \\
\hline 29 & 3 & & Aumento do campo história clinica. & 1 & Sim \\
\hline 30 & 3 & & Usar "e" como soma de achados para pesquisa clínica. & 1 & Sim \\
\hline 31 & 3 & & Aba "exames" é de difícil visualização. & 1 & Não autorizado \\
\hline 32 & 3 & & $\begin{array}{l}\text { Não existem alguns diagnósticos no campo etiologia (na existência desse, precisa escrever } \\
\text { "sem diagnóstico", deveria existir campo outros). }\end{array}$ & 1 & Não autorizado \\
\hline 33 & 4 & 1.2 & Idade dos pais deveria colocar ano de nascimento e assim todo ano é atualizada automaticam & 1 & Não * \\
\hline 34 & 4 & 6 & Trocar senha e pessoa que atendeu. & 1 & Sim \\
\hline 35 & 4 & & Inserir abas de antecedentes pessoais. - 1 alteração realizada & 1 & Sim \\
\hline 36 & 4 & & $\begin{array}{l}\text { As abas de imagens e protocolos não são usadas, nelas podiam ser inseridos heredogramas e } \\
\text { protocolos de síndromes mais frequentes. }\end{array}$ & 1 & Não \\
\hline 37 & 4 & & $\begin{array}{l}\text { Sugiro melhorar a disposição dos dados na aba Exames, pois é difícil visualização -1 não } \\
\text { autorizada a alteração. }\end{array}$ & 1 & Não autorizado \\
\hline 38 & 4 & & $\begin{array}{l}\text { Em caso de ocorrência de falhas a gente tem apresentado perda de dados, por isso seria } \\
\text { interessante ter algum tipo de backup para recuperar os dados. }\end{array}$ & 1 & Já existe \\
\hline 39 & 4 & & Aumentar o campo dos exames - 1 alteração realizada. & 1 & Sim \\
\hline 40 & 4 & & Aumentar o campo do pré-natal -1 alteração realizada. & 1 & Sim \\
\hline 41 & 4 & & $\begin{array}{l}\text { Mudança de idade dos pais para idade dos pais ao nascimento causam confusão }-1 \text { não } \\
\text { autorizada alteração para data de nascimento. }\end{array}$ & 1 & Não autorizado \\
\hline 42 & 4 & & O sistema poderia ser usado para interconsulta. & 1 & Sim \\
\hline 43 & 5 & 3.4 & Só é possível adicionar no dia e aba atualização não pode ser impressa. & 1 & Já existe \\
\hline 44 & 5 & 9 & Não consegue buscar se há letra maiúscula ou minúscula. & 1 & Sim \\
\hline 45 & 5 & & $\begin{array}{l}\text { Na parte de "pesquisas" ao digitar palavras em letras maiúsculas e minúsculas o sistema não } \\
\text { constou diferentes, sendo que só procura palavra como foi escrita (não deve fazer distinção } \\
\text { de maiúsculas e minúsculas na pesquisa) - } 1 \text { alteração realizada }\end{array}$ & 1 & Sim \\
\hline 46 & 5 & & Possibilidade de incluir novos diagnósticos. & 1 & Não autorizada \\
\hline 47 & 5 & & $\begin{array}{l}\text { Busca no "complemento" do diagnóstico sem diferenciar letras maiúsculas e minúsculas -1 } \\
\text { alteração realizada }\end{array}$ & 1 & Sim \\
\hline 48 & 5 & & O programa está lento. & 1 & Verificar \\
\hline 49 & 5 & & $\begin{array}{l}\text { Mudou-se na identificação dos pais (idade atual para idade à concepção) isso trouxe grande } \\
\text { confusão, sugiro digitar ano de nascimento dos pais e a idade ser atualizada } \\
\text { automaticamente. }\end{array}$ & 1 & Não autorizada \\
\hline 50 & 6 & 1.4 & $\begin{array}{l}\begin{array}{l}\text { Aumentar o número máximo de caracteres da aba "História Clínica", acrescentar um campo } \\
\text { descritivo para desenvolvimento após as marcas. }\end{array} \\
\end{array}$ & 1 & Não autorizado \\
\hline
\end{tabular}




\begin{tabular}{|c|c|c|c|c|c|c|}
\hline \multicolumn{7}{|c|}{ Controle de não defeitos marcados como defeitos } \\
\hline Ordem & Fase & Local & Item & Descrição Não Defeitos & Ocorrência & Justificativa \\
\hline 1 & 1 & 1 & 1.5 & $\begin{array}{l}\text { O combo que aparecem os achados, as vezes não } \\
\text { abre corretamente }\end{array}$ & 8 & \\
\hline 2 & 1 & 1 & 1.7 & $\begin{array}{l}\text { Quando colocamos os exames existentes na } \\
\text { instituição, aparecem caracteres estranhos }\end{array}$ & 8 & $\begin{array}{l}\text { No sistema Icr é pdf ou } \\
\text { digitalizado }\end{array}$ \\
\hline 3 & 1 & 2 & 2.5 & $\begin{array}{l}\text { O combo que aparecem os achados, as vezes não } \\
\text { abre corretamente }\end{array}$ & 8 & \\
\hline 4 & 1 & 3 & 3.8 & Faltam diagnósticos - incluir & 1 & $\begin{array}{l}\text { Preceptor pode inseri } \\
\text { novos diagnósticos. }\end{array}$ \\
\hline 5 & 2 & 1 & 1.7 & $\begin{array}{l}\text { Aparecem caracteres estranhos quando copiamos } \\
\text { exames do sistema do Icr. }\end{array}$ & 8 & $\begin{array}{l}\text { No sistema Icr é pdf ou } \\
\text { digitalizado }\end{array}$ \\
\hline 6 & 3 & 1 & 1.7 & Melhoramento do vocabulário e pontuação. & 1 & \\
\hline 7 & 3 & 1 & 1.8 & Inserir novos diagnósticos. & 1 & $\begin{array}{l}\text { Preceptor pode inseri } \\
\text { novos diagnósticos. }\end{array}$ \\
\hline 8 & 3 & 1 & 1.10 & poderíamos adicionar os heredogramas. & 1 & $\begin{array}{l}\text { Qualquer médico pode } \\
\text { fazer isso. }\end{array}$ \\
\hline 9 & 3 & 2 & 2.7 & $\begin{array}{l}\text { Aparecem caracteres estranhos quando copiamos } \\
\text { exames do sistema do Icr. }\end{array}$ & 1 & $\begin{array}{l}\text { No sistema Icr é pdf ou } \\
\text { digitalizado }\end{array}$ \\
\hline 10 & 3 & 3 & 3.7 & $\begin{array}{l}\text { Aparecem caracteres estranhos quando copiamos } \\
\text { exames do sistema do Icr. }\end{array}$ & 1 & $\begin{array}{l}\text { No sistema Icr é pdf ou } \\
\text { digitalizado }\end{array}$ \\
\hline 11 & 4 & 1 & 1.7 & $\begin{array}{l}\text { Aparecem caracteres estranhos quando copiamos } \\
\text { exames do sistema do lcr. }\end{array}$ & 2 & $\begin{array}{l}\text { No sistema Icr é pdf ou } \\
\text { digitalizado }\end{array}$ \\
\hline 12 & 4 & 1 & 1.9 & Não usa. & 1 & É necessário inserir \\
\hline 13 & 4 & 1 & 1.9 & Não há informações. & 1 & É necessário inserir \\
\hline 14 & 4 & 1 & 1.10 & Não usa. & 1 & É necessário inserir \\
\hline 15 & 4 & 1 & 1.10 & Não há informações. & 1 & É necessário inserir \\
\hline 16 & 4 & 1 & 1.12 & Não usa. & 1 & É necessário inserir \\
\hline 17 & 4 & 1 & 1.12 & Não há informações. & 1 & É necessário inserir \\
\hline 18 & 5 & 1 & 1.1 & Não dá para atualizar, não dá para cadastrar. & 1 & Os dados são de consultas \\
\hline 19 & 5 & 1 & 1.7 & $\begin{array}{l}\text { Aparecem caracteres estranhos quando copiamos } \\
\text { exames do sistema do Icr. }\end{array}$ & 1 & $\begin{array}{l}\text { No sistema Icr é pdf ou } \\
\text { digitalizado }\end{array}$ \\
\hline 20 & 5 & 1 & 1.9 & Não há protocolos. & 1 & É necessário inserir \\
\hline 21 & 5 & 1 & 1.10 & Não há imagens. & 1 & É necessário inserir \\
\hline 22 & 5 & 2 & 2.7 & $\begin{array}{l}\text { Aparecem caracteres estranhos quando copiamos } \\
\text { exames do sistema do Icr. }\end{array}$ & 1 & $\begin{array}{l}\text { No sistema Icr é pdf ou } \\
\text { digitalizado }\end{array}$ \\
\hline 23 & 5 & 2 & 2.7 & $\begin{array}{l}\text { Dependendo da forma de abrir o exame inserido, } \\
\text { não dá para ter acesso, para o laudo }\end{array}$ & 1 & Sistemas diferentes \\
\hline 24 & 5 & 3 & 3.7 & impossibilidade de solicitar exames para fora. & 1 & Sistemas diferentes \\
\hline 25 & 6 & 1 & 1.7 & Se for inserido texto longo, é difícil ver & 1 & $\begin{array}{l}\text { Grid aumenta conforme } \\
\text { texto, mas tem que clicar } \\
\text { barra de rolagem }\end{array}$ \\
\hline 26 & 6 & 2 & 2.7 & Botão clique para alteração é confuso & 1 & $\begin{array}{l}\text { Botão só habilita para } \\
\text { preceptor ou assistente, } \\
\text { depende nivel de acesso }\end{array}$ \\
\hline
\end{tabular}


Anexo H - Tabelas Suplementares 
Tabela S1 - Distribuição das frequências absolutas e relativas [N(\%)] das avaliações dos usuários para os itens Serviço, Funcionalidade, Usabilidade e Confiabilidade do PEG-software, nas Fases 1 a 6

\begin{tabular}{|c|c|c|c|c|c|c|c|}
\hline Itens Avaliados & Fase & $\begin{array}{c}\text { Discordo } \\
\text { Totalmente } \\
\text { (1) }\end{array}$ & $\begin{array}{l}\text { Discordo } \\
\text { (2) }\end{array}$ & $\begin{array}{l}\text { Indiferente } \\
\text { (3) }\end{array}$ & $\begin{array}{c}\text { Concordo } \\
\text { (4) }\end{array}$ & $\begin{array}{c}\text { Concordo } \\
\text { Totalmente } \\
\text { (5) }\end{array}$ & $\begin{array}{c}\text { Mediana } \\
\text { (Intervalo } \\
\text { IQ) }\end{array}$ \\
\hline & & & & & & & \\
\hline \multicolumn{8}{|l|}{ 1. Serviço } \\
\hline \multirow{6}{*}{$\begin{array}{l}1.1 \text { - A organização e apresentação do } \\
\text { conteúdo funcional do Registro Genético } \\
\text { Eletrônico (PEG), conforme as guias: } \\
\text { Identificação do Paciente, Pré-natal e Parto, } \\
\text { História Clínica, Achados Clínicos, } \\
\text { Evolução, Exame, Diagnóstico, Protocolo, } \\
\text { Imagens, Relatórios, Resumo Médico e } \\
\text { Antecedentes, satisfazem as necessidades do } \\
\text { serviço de genética. }\end{array}$} & 1 & & & & $4(50)$ & $4(50)$ & $4.5(4-5)$ \\
\hline & 2 & & & & $3(36.5)$ & $5(62.5)$ & $5(4-5)$ \\
\hline & 3 & & & & $2(22)$ & $7(78)$ & $5(5-5)$ \\
\hline & 4 & & & & $4(36)$ & $7(64)$ & $5(4-5)$ \\
\hline & 5 & & & & $8(57)$ & $6(43)$ & $4(4-5)$ \\
\hline & 6 & & & & $5(42)$ & $7(58)$ & $5(4-5)$ \\
\hline \multirow{6}{*}{$\begin{array}{l}\text { 1.1.1 A organização e apresentação do } \\
\text { conteúdo funcional da aba (guia) } \\
\text { Identificação do Paciente, satisfazem } \\
\text { as necessidades do serviço de genética. }\end{array}$} & 1 & & & $1(12.5)$ & $2(25)$ & $5(62.5)$ & $5(4-5)$ \\
\hline & 2 & & & & $4(50)$ & $4(50)$ & $4.5(4-5)$ \\
\hline & 3 & & & $1(11)$ & $3(33)$ & $5(56)$ & $5(4-5)$ \\
\hline & 4 & & & & $5(45)$ & $6(55)$ & $5(4-5)$ \\
\hline & 5 & & & $1(7)$ & $4(29)$ & $9(64)$ & $5(4-5)$ \\
\hline & 6 & & & & $5(42)$ & $7(58)$ & $5(4-5)$ \\
\hline \multirow{6}{*}{$\begin{array}{l}\text { 1.1.2 A organização e apresentação do } \\
\text { conteúdo funcional da guia pré-natal e } \\
\text { parto (guia) atendem às necessidades } \\
\text { do serviço genético. }\end{array}$} & 1 & & & $1(12.5)$ & $2(25)$ & $5(62.5)$ & $5(4-5)$ \\
\hline & 2 & & & & $4(50)$ & $4(50)$ & $4.5(4-5)$ \\
\hline & 3 & & & & $2(22)$ & $7(78)$ & $5(5-5)$ \\
\hline & 4 & & & & $5(45)$ & $6(55)$ & $5(4-5)$ \\
\hline & 5 & & & $1(7)$ & $7(50)$ & $6(43)$ & $4(4-5)$ \\
\hline & 6 & & & & $5(42)$ & $7(58)$ & $5(4-5)$ \\
\hline \multirow{6}{*}{$\begin{array}{l}\text { 1.1.3 A organização e apresentação do } \\
\text { conteúdo funcional da guia (guia) } \\
\text { História clínica satisfazem as } \\
\text { necessidades do serviço de genética. }\end{array}$} & 1 & & & & $4(50)$ & $4(50)$ & $4.5(4-5)$ \\
\hline & 2 & & & & $4(50)$ & $4(50)$ & $4.5(4-5)$ \\
\hline & 3 & & & $2(22)$ & $1(11)$ & $6(67)$ & $5(4-5)$ \\
\hline & 4 & & & $1(9)$ & $3(27)$ & $7(67)$ & $5(4-5)$ \\
\hline & 5 & & & $2(14)$ & $5(36)$ & $7(50)$ & $4.5(4-5)$ \\
\hline & 6 & & & $2(17)$ & $2(17)$ & $8(66)$ & $5(4-5)$ \\
\hline
\end{tabular}

Continua 


\begin{tabular}{|c|c|c|c|c|c|c|c|}
\hline Itens Avaliados & Fase & $\begin{array}{c}\text { Discordo } \\
\text { Totalmente } \\
\text { (1) }\end{array}$ & $\begin{array}{l}\text { Discordo } \\
\text { (2) }\end{array}$ & $\begin{array}{l}\text { Indiferente } \\
\text { (3) }\end{array}$ & $\begin{array}{c}\text { Concordo } \\
\text { (4) }\end{array}$ & $\begin{array}{c}\text { Concordo } \\
\text { Totalmente } \\
\text { (5) }\end{array}$ & $\begin{array}{c}\text { Mediana } \\
\text { (Intervalo } \\
\text { IQ) }\end{array}$ \\
\hline \multicolumn{8}{|l|}{ 1. Serviço - continuação } \\
\hline \multirow{6}{*}{$\begin{array}{l}\text { 1.1.4 A organização e apresentação do } \\
\text { conteúdo funcional da guia (guia) } \\
\text { Achados Clínicos, atendem às } \\
\text { necessidades do serviço de genética. }\end{array}$} & 1 & & & $1(12.5)$ & $3(37.5)$ & $4(50)$ & $4.5(4-5)$ \\
\hline & 2 & & & & $6(75)$ & $2(25)$ & $4(4-4)$ \\
\hline & 3 & & & & $3(33)$ & $6(67)$ & $5(4-5)$ \\
\hline & 4 & & & & $5(45)$ & $6(55)$ & $5(4-5)$ \\
\hline & 5 & & & $1(7)$ & $6(43)$ & $7(50)$ & $4.5(4-5)$ \\
\hline & 6 & & & $2(17)$ & $4(33)$ & $6(60)$ & $5(4-5)$ \\
\hline \multirow{6}{*}{$\begin{array}{l}\text { 1.1.5 A organização e apresentação do } \\
\text { conteúdo funcional do guia (Evolução) } \\
\text { satisfazem as necessidades do serviço } \\
\text { de genética. }\end{array}$} & 1 & & & $1(12.5)$ & $3(37.5)$ & $4(50)$ & $4.5(4-5)$ \\
\hline & 2 & & & $1(12.5)$ & $6(75)$ & $1(12.5)$ & $4(4-4)$ \\
\hline & 3 & & & & $2(22)$ & $7(78)$ & $5(5-5)$ \\
\hline & 4 & & & $1(9)$ & $3(27)$ & $7(64)$ & $5(4-5)$ \\
\hline & 5 & & $1(7)$ & $1(7)$ & $6(44)$ & $6(44)$ & $4(4-5)$ \\
\hline & 6 & & & $2(17)$ & $3(25)$ & $7(58)$ & $5(4-5)$ \\
\hline \multirow{6}{*}{$\begin{array}{l}\text { 1.1.6 A organização e apresentação do } \\
\text { conteúdo funcional dos guias (guia) } \\
\text { dos exames atendem às necessidades } \\
\text { do serviço de genética. }\end{array}$} & 1 & & & $3(37.5)$ & $2(25)$ & $3(37.5)$ & $4(3-5)$ \\
\hline & 2 & & $2(25)$ & $1(12.5)$ & $2(25)$ & $3(37.5)$ & $4(3-5)$ \\
\hline & 3 & & $1(12)$ & $4(44)$ & & $4(44)$ & $3(3-5)$ \\
\hline & 4 & & $1(10)$ & & $5(45)$ & $5(45)$ & $4(4-5)$ \\
\hline & 5 & & & $3(23)$ & $3(23)$ & $7(54)$ & $5(4-5)$ \\
\hline & 6 & & & $3(25)$ & $2(17)$ & $7(58)$ & $5(4-5)$ \\
\hline \multirow{6}{*}{$\begin{array}{l}\text { 1.1.7 A organização e apresentação do } \\
\text { conteúdo funcional da guia } \\
\text { Diagnóstico (guia) satisfazem as } \\
\text { necessidades do serviço genético. }\end{array}$} & 1 & & & $2(25)$ & $2(25)$ & $4(50)$ & $4,5(4-5)$ \\
\hline & 2 & & & & $5(62.5)$ & $3(37.5)$ & $4(4-5)$ \\
\hline & 3 & & & $2(22)$ & $1(11)$ & $6(67)$ & $5(4-5)$ \\
\hline & 4 & & & & $6(55)$ & $5(45)$ & $4(4-5)$ \\
\hline & 5 & & & $2(14)$ & $7(50)$ & $5(36)$ & $4(4-5)$ \\
\hline & 6 & & & $2(17)$ & $4(33)$ & $6(50)$ & $4,5(4-5)$ \\
\hline \multirow{6}{*}{$\begin{array}{l}\text { 1.1.8 A organização e apresentação do } \\
\text { conteúdo funcional do protocolo da } \\
\text { guia (guia) atendem às necessidades do } \\
\text { serviço de genética. }\end{array}$} & 1 & & & & & & \\
\hline & 2 & & & & & & \\
\hline & 3 & & & & & & \\
\hline & 4 & $2(25)$ & & $4(50)$ & & $2(25)$ & $3(3-3)$ \\
\hline & 5 & $2(15)$ & $3(23)$ & $1(8)$ & $5(39)$ & $2(15)$ & $4(2-4)$ \\
\hline & 6 & & $2(18)$ & $5(45)$ & $1(9)$ & $3(28)$ & $3(3-5)$ \\
\hline
\end{tabular}

continua 


\begin{tabular}{|c|c|c|c|c|c|c|c|}
\hline Itens Avaliados & Fase & $\begin{array}{l}\text { Discordo } \\
\text { Totalmente } \\
\quad(1)\end{array}$ & $\begin{array}{l}\text { Discordo } \\
\text { (2) }\end{array}$ & $\begin{array}{l}\text { Indiferente } \\
\text { (3) }\end{array}$ & $\begin{array}{c}\text { Concordo } \\
\text { (4) }\end{array}$ & $\begin{array}{l}\text { Concordo } \\
\text { Totalmente } \\
\quad(5)\end{array}$ & $\begin{array}{c}\text { Mediana } \\
\text { (Intervalo } \\
\text { IQ) }\end{array}$ \\
\hline 1. Serviço - continuação & & & & & & & \\
\hline \multirow{6}{*}{$\begin{array}{l}\text { 1.1.9 A organização e apresentação do } \\
\text { conteúdo funcional das guias (guia) } \\
\text { Imagens atendem às necessidades do } \\
\text { serviço de genética. }\end{array}$} & 1 & $1(25)$ & & $1(25)$ & $2(50)$ & & $3,4(3-4)$ \\
\hline & 2 & $1(20)$ & $1(20)$ & $1(20)$ & $1(20)$ & $1(20)$ & $3(2-4)$ \\
\hline & 3 & $2(25)$ & & $2(25)$ & $2(25)$ & $2(25)$ & $4(3-4)$ \\
\hline & 4 & $2(25)$ & & $4(50)$ & & $2(25)$ & $3(3-3)$ \\
\hline & 5 & $1(8)$ & $1(8)$ & $6(46)$ & $3(23)$ & $2(15)$ & $3(3-4)$ \\
\hline & 6 & & $2(18)$ & $5(46)$ & $1(9)$ & $3(27)$ & $3(3-5)$ \\
\hline \multirow{6}{*}{$\begin{array}{l}\text { 1.1.10 A organização e apresentação } \\
\text { do conteúdo funcional da guia (guia) } \\
\text { Relatório satisfaz as necessidades do } \\
\text { serviço de genética. }\end{array}$} & 1 & & & & & & \\
\hline & 2 & & & & & & \\
\hline & 3 & $1(12.5)$ & & $3(37.5)$ & $2(25)$ & $2(25)$ & $3(3-4)$ \\
\hline & 4 & $2(25)$ & & $3(37.5)$ & $1(12.5)$ & $2(25)$ & $3(3-4)$ \\
\hline & 5 & & $3(23)$ & $5(38)$ & $4(31)$ & $1(8)$ & $3(3-4)$ \\
\hline & 6 & & $2(18)$ & $4(36)$ & $1(9)$ & $4(36)$ & $3(3-5)$ \\
\hline \multirow{6}{*}{$\begin{array}{l}\text { 1.1.11 A organização e apresentação } \\
\text { do conteúdo funcional da guia (guia) } \\
\text { Resumo Médico satisfaz as } \\
\text { necessidades do serviço de genética. }\end{array}$} & 1 & & & & & & \\
\hline & 2 & & & & & & \\
\hline & 3 & & & & & & \\
\hline & 4 & & & $3(37.5)$ & $1(12.5)$ & $4(50)$ & $4,5(3-5)$ \\
\hline & 5 & & $1(8)$ & $2(15)$ & $7(54)$ & $3(23)$ & $4(4-4)$ \\
\hline & 6 & & $2(17)$ & $4(33)$ & $3(25)$ & $3(25)$ & $3,4(3-4)$ \\
\hline \multirow{6}{*}{$\begin{array}{l}1.12 \text { A organização e apresentação do } \\
\text { conteúdo funcional da guia (guia) } \\
\text { Antecedentes Médicos, atendem às } \\
\text { necessidades do serviço de genética. }\end{array}$} & 1 & & & & & & \\
\hline & 2 & & & & & & \\
\hline & 3 & & & & & & \\
\hline & 4 & & & & & & \\
\hline & 5 & & & & & & \\
\hline & 6 & & & $2(17)$ & $4(33)$ & $6(50)$ & $4,5(4-5)$ \\
\hline \multirow{6}{*}{$\begin{array}{l}1.2 \text { - As funções do sistema PEG na } \\
\text { assistência médica atendem às } \\
\text { necessidades do serviço de genética. }\end{array}$} & 1 & & & $1(12.5)$ & $4(50)$ & $3(37.5)$ & $4(4-5)$ \\
\hline & 2 & & & & 7 (87.5) & $1(12.5)$ & $4(4-4)$ \\
\hline & 3 & & & & $3(33)$ & $6(67)$ & $5(4-5)$ \\
\hline & 4 & & $1(10)$ & & $5(45)$ & $5(45)$ & $4(4-5)$ \\
\hline & 5 & & & & $9(64)$ & $5(36)$ & $4(4-5)$ \\
\hline & 6 & & & $1(8)$ & $4(34)$ & $7(58)$ & $5(4-5)$ \\
\hline
\end{tabular}




\begin{tabular}{|c|c|c|c|c|c|c|c|}
\hline Itens Avaliados & Fase & $\begin{array}{l}\text { Discordo } \\
\text { Totalmente } \\
\quad(1)\end{array}$ & $\begin{array}{l}\text { Discordo } \\
\text { (2) }\end{array}$ & $\begin{array}{c}\text { Indiferente } \\
\text { (3) }\end{array}$ & $\begin{array}{c}\text { Concordo } \\
\text { (4) }\end{array}$ & $\begin{array}{l}\text { Concordo } \\
\text { Totalmente } \\
\quad(5)\end{array}$ & $\begin{array}{c}\text { Mediana } \\
\text { (Intervalo } \\
\text { IQ) }\end{array}$ \\
\hline 1. Serviço - continuação & & & & & & & \\
\hline \multirow{6}{*}{$\begin{array}{l}1.3 \text { - O uso do sistema permite maior } \\
\text { clareza na leitura do histórico do } \\
\text { paciente. }\end{array}$} & 1 & & & $1(12.5)$ & $3(37.5)$ & $4(50)$ & $4,5(4-5)$ \\
\hline & 2 & & & & $6(75)$ & $2(25)$ & $4(4-4)$ \\
\hline & 3 & & & $1(11)$ & $2(22)$ & $6(67)$ & $5(4-5)$ \\
\hline & 4 & & & & $5(45)$ & $6(55)$ & $5(4-5)$ \\
\hline & 5 & & & $1(7)$ & $6(43)$ & $7(50)$ & $4,5(4-5)$ \\
\hline & 6 & & & $1(8)$ & $3(25)$ & $8(67)$ & $5(4-5)$ \\
\hline \multirow{6}{*}{$\begin{array}{l}\text { 1.4 - A linguagem utilizada é natural, } \\
\text { os termos, frases, conceitos são } \\
\text { semelhantes aos utilizados no meu dia- } \\
\text { a-dia ou no ambiente de estudo. }\end{array}$} & 1 & & & & $4(50)$ & $4(50)$ & $4,5(4-5)$ \\
\hline & 2 & & & & $4(50)$ & $4(50)$ & $4,5(4-5)$ \\
\hline & 3 & & & & $3(33)$ & $6(67)$ & $5(4-5)$ \\
\hline & 4 & & & & $4(36)$ & $7(64)$ & $5(4-5)$ \\
\hline & 5 & & & & $6(43)$ & $8(57)$ & $5(4-5)$ \\
\hline & 6 & & & & $4(33)$ & $8(67)$ & $5(4-5)$ \\
\hline \multirow{6}{*}{$\begin{array}{l}1.5 \text { - O tempo para preencher o registro } \\
\text { clínico através do sistema é menor que } \\
\text { o preenchimento manual (em papel). }\end{array}$} & 1 & & & & $2(25)$ & $6(75)$ & $5(5-5)$ \\
\hline & 2 & & & $1(12.5)$ & $3(37.5)$ & $4(50)$ & $4,5(4-5)$ \\
\hline & 3 & & & & $3(33)$ & $6(67)$ & $5(4-5)$ \\
\hline & 4 & & $1(9)$ & & $2(18)$ & $8(73)$ & $5(4-5)$ \\
\hline & 5 & & $1(7)$ & & $3(21)$ & $10(72)$ & $5(4-5)$ \\
\hline & 6 & & & $2(17)$ & $1(8)$ & $9(75)$ & $5(5-5)$ \\
\hline \multirow{6}{*}{$\begin{array}{l}1.6 \text { - Na impossibilidade de incluir a } \\
\text { consulta agendada no sistema PEG, } \\
\text { devido a problemas de rede, posso } \\
\text { inserir a consulta manual em outro } \\
\text { momento. }\end{array}$} & 1 & & & $2(33.3)$ & $2(33.3)$ & $2(33.3)$ & $4(3-5)$ \\
\hline & 2 & $1(12.5)$ & & $3(37.5)$ & $3(37.5)$ & $1(12.5)$ & $3(3-4)$ \\
\hline & 3 & $1(11)$ & $1(11)$ & $3(33.5)$ & $1(11)$ & $3(33.5)$ & $3(3-5)$ \\
\hline & 4 & $1(10)$ & & $4(36)$ & $3(27)$ & $3(27)$ & $3(3-5)$ \\
\hline & 5 & $1(7)$ & $3(22)$ & $2(14)$ & $5(35)$ & $3(22)$ & $4(2-5)$ \\
\hline & 6 & $1(8)$ & & $2(17)$ & $3(25)$ & $6(50)$ & $4,5(3-5)$ \\
\hline \multirow{6}{*}{$\begin{array}{l}1.7 \text { - Houve uma diminuição de papéis } \\
\text { na sala de genética com o uso do } \\
\text { sistema PEG. }\end{array}$} & 1 & & & & $2(25)$ & $6(75)$ & $5(5-5)$ \\
\hline & 2 & & & & $2(25)$ & $6(75)$ & $5(5-5)$ \\
\hline & 3 & & $1(11)$ & $1(11)$ & $1(11)$ & $6(67)$ & $5(3-5)$ \\
\hline & 4 & & & & $4(36)$ & $7(64)$ & $5(4-5)$ \\
\hline & 5 & 1(7) & $1(7)$ & & $7(50)$ & $5(36)$ & $4(4-5)$ \\
\hline & 6 & & $1(8)$ & $2(17)$ & $3(25)$ & $6(50)$ & $4,5(4-5)$ \\
\hline
\end{tabular}




\begin{tabular}{|c|c|c|c|c|c|c|c|}
\hline Itens Avaliados & Fase & $\begin{array}{l}\text { Discordo } \\
\text { Totalmente } \\
\quad \text { (1) }\end{array}$ & $\begin{array}{l}\text { Discordo } \\
\quad(2)\end{array}$ & $\begin{array}{l}\text { Indiferente } \\
\quad(3)\end{array}$ & $\begin{array}{l}\text { Concordo } \\
\text { (4) }\end{array}$ & $\begin{array}{c}\text { Concordo } \\
\text { Totalmente } \\
\text { (5) }\end{array}$ & $\begin{array}{c}\text { Mediana } \\
\text { (Intervalo } \\
\text { IQ) }\end{array}$ \\
\hline 1. Serviço - continuação & & & & & & & \\
\hline \multirow{6}{*}{$\begin{array}{l}1.8 \text { - Realizo consultas no sistema, para } \\
\text { fins de atendimento ambulatorial. }\end{array}$} & 1 & & & & $2(25)$ & $6(75)$ & $5(5-5)$ \\
\hline & 2 & & & & $2(25)$ & $6(75)$ & $5(5-5)$ \\
\hline & 3 & & & & $2(22)$ & $7(78)$ & $5(5-5)$ \\
\hline & 4 & & & & $2(18)$ & $9(82)$ & $5(5-5)$ \\
\hline & 5 & & & & $5(36)$ & $9(64)$ & $5(4-5)$ \\
\hline & 6 & & & & $3(25)$ & $9(75)$ & $5(5-5)$ \\
\hline \multirow{6}{*}{$\begin{array}{l}1.9 \text { - Faço consultas no sistema, para } \\
\text { fins de pesquisa. }\end{array}$} & 1 & $2(25)$ & & $1(12.5)$ & $2(25)$ & $3(37.5)$ & $4(3-5)$ \\
\hline & 2 & $1(12.5)$ & & & $3(37.5)$ & $4(50)$ & $4,5(4-5)$ \\
\hline & 3 & $1(11)$ & & $2(22)$ & $1(11)$ & $5(56)$ & $5(3-5)$ \\
\hline & 4 & & $1(9)$ & $1(9)$ & $2(18)$ & $7(64)$ & $5(4-5)$ \\
\hline & 5 & 1(7) & $1(7)$ & $3(21)$ & $5(36)$ & $4(29)$ & $4(3-5)$ \\
\hline & 6 & & & $2(17)$ & $2(17)$ & $8(66)$ & $5(4-5)$ \\
\hline \multirow{6}{*}{ SUBTOTAL - Serviço } & 1 & $3(2)$ & $\mathbf{0}(\mathbf{0})$ & $15(12)$ & $45(35)$ & $67(51)$ & $5(4-5)$ \\
\hline & 2 & $3(2.5)$ & $3(2.5)$ & $7(5)$ & $65(49)$ & $55(41)$ & $4(4-5)$ \\
\hline & 3 & $5(3)$ & $3(2)$ & $21(13)$ & $34(21)$ & $97(61)$ & $5(4-5)$ \\
\hline & 4 & $7(3)$ & $4(2)$ & $21(10)$ & $65(31)$ & $111(54)$ & $5(4-5)$ \\
\hline & 5 & $6(2)$ & $15(6)$ & $31(11)$ & $111(40)$ & $112(41)$ & $4(4-5)$ \\
\hline & 6 & $1(1)$ & $9(4)$ & $41(17)$ & $63(25)$ & $135(54)$ & $5(4-5)$ \\
\hline 2. Funcionalidade & & & & & & & \\
\hline \multirow{6}{*}{$\begin{array}{l}2.1 \text { - O PEG é adequado para o } \\
\text { registro de dados do paciente. }\end{array}$} & 1 & & & & $2(25)$ & $6(75)$ & $5(5-5)$ \\
\hline & 2 & & & & $3(37.5)$ & $5(62.5)$ & $5(4-5)$ \\
\hline & 3 & & & & $2(22)$ & $7(78)$ & $5(5-5)$ \\
\hline & 4 & & & $1(9)$ & $3(27)$ & $7(64)$ & $5(4-5)$ \\
\hline & 5 & & & $1(7)$ & $4(29)$ & $9(64)$ & $5(4-5)$ \\
\hline & 6 & & & & $3(27)$ & $8(73)$ & $5(4-5)$ \\
\hline \multirow{6}{*}{$\begin{array}{l}2.2 \text { - Considerando que o objetivo é } \\
\text { substituir o registro do paciente antigo } \\
\text { (manuscrito) pelos eletrônicos, o PEG } \\
\text { faz isso corretamente. }\end{array}$} & 1 & & & & $3(37.5)$ & $5(62.5)$ & $5(4-5)$ \\
\hline & 2 & & & & $4(50)$ & $4(50)$ & $4,5(4-5)$ \\
\hline & 3 & & & & $3(33)$ & $6(67)$ & $5(4-5)$ \\
\hline & 4 & & & & $4(36)$ & $7(64)$ & $5(4-5)$ \\
\hline & 5 & & & & $5(36)$ & $9(64)$ & $5(4-5)$ \\
\hline & 6 & & & & $5(42)$ & $7(58)$ & $5(4-5)$ \\
\hline
\end{tabular}




\begin{tabular}{|c|c|c|c|c|c|c|c|}
\hline Itens Avaliados & Fase & $\begin{array}{l}\text { Discordo } \\
\text { Totalmente } \\
\quad(1)\end{array}$ & $\begin{array}{l}\text { Discordo } \\
\quad(2)\end{array}$ & $\begin{array}{l}\text { Indiferente } \\
\quad(3)\end{array}$ & $\begin{array}{l}\text { Concordo } \\
(4)\end{array}$ & $\begin{array}{c}\text { Concordo } \\
\text { Totalmente } \\
\text { (5) }\end{array}$ & $\begin{array}{c}\text { Mediana } \\
\text { (Intervalo } \\
\text { IQ) }\end{array}$ \\
\hline 2. Funcionalidade - continuação & & & & & & & \\
\hline \multirow{6}{*}{$\begin{array}{l}2.3 \text { - Interage com o sistema de agenda. } \\
\text { já existente. }\end{array}$} & 1 & & & & $3(37.5)$ & $5(62.5)$ & $5(4-5)$ \\
\hline & 2 & & $1(12.5)$ & $3(37.5)$ & $2(25)$ & $2(25)$ & $3(3-4)$ \\
\hline & 3 & & $1(11)$ & $2(22)$ & $3(33.5)$ & $3(33.5)$ & $3(3-5)$ \\
\hline & 4 & $1(9)$ & & $2(18)$ & $7(64)$ & $1(7)$ & $4(4-4)$ \\
\hline & 5 & & 1(7) & $4(29)$ & $5(35)$ & $4(29)$ & $4(3-5)$ \\
\hline & 6 & & & $1(8)$ & $4(33)$ & $7(59)$ & $5(4-5)$ \\
\hline \multirow{6}{*}{$\begin{array}{l}2.4 \text { - Impede o acesso não autorizado } \\
\text { aos dados. }\end{array}$} & 1 & $1(12.5)$ & & $2(25)$ & $2(25)$ & $3(37.5)$ & $4(3-5)$ \\
\hline & 2 & & $2(25)$ & $1(12.5)$ & $3(37.5)$ & $2(25)$ & $4(3-4)$ \\
\hline & 3 & $1(11)$ & & $1(11)$ & $2(22)$ & $5(56)$ & $5(4-5)$ \\
\hline & 4 & & $1(9)$ & $1(9)$ & $5(46)$ & $4(36)$ & $4(4-5)$ \\
\hline & 5 & & & $1(7)$ & $4(29)$ & $9(64)$ & $5(4-5)$ \\
\hline & 6 & & $1(8)$ & $1(8)$ & $3(26)$ & $7(58)$ & $5(4-5)$ \\
\hline \multirow{6}{*}{$\begin{array}{l}2.5 \text { - Eu uso uma senha de acesso para } \\
\text { usar o sistema PEG. }\end{array}$} & 1 & $1(12.5)$ & $1(12.5)$ & & $3(37.5)$ & $3(37.5)$ & $4(4-5)$ \\
\hline & 2 & & $1(12.5)$ & & $2(25)$ & $5(62.5)$ & $5(4-5)$ \\
\hline & 3 & & & & $1(11)$ & $8(89)$ & $5(5-5)$ \\
\hline & 4 & & $1(9)$ & & $2(18)$ & $8(73)$ & $5(5-5)$ \\
\hline & 5 & & & & $3(21)$ & $11(79)$ & $5(5-5)$ \\
\hline & 6 & & & & $2(17)$ & $10(83)$ & $5(5-5)$ \\
\hline \multirow{6}{*}{$\begin{array}{l}2.6 \text { - O sistema está em conformidade } \\
\text { com normas, leis, etc. (mantém a } \\
\text { impressão em papel, apesar de possuir } \\
\text { o formato eletrônico). }\end{array}$} & 1 & & & $2(25)$ & $3(37.5)$ & $3(37.5)$ & $4,5(4-5)$ \\
\hline & 2 & & & $1(12.5)$ & $2(25)$ & $5(62.5)$ & $5(4-5)$ \\
\hline & 3 & & & $4(44)$ & & $5(56)$ & $5(3-5)$ \\
\hline & 4 & & & $1(9)$ & $3(27)$ & $7(64)$ & $5(4-5)$ \\
\hline & 5 & & $1(7)$ & $1(7)$ & $3(22)$ & $9(64)$ & $5(4-5)$ \\
\hline & 6 & & & $1(8)$ & $3(25)$ & $8(67)$ & $5(4-5)$ \\
\hline \multirow{6}{*}{ SUBTOTAL - Funcionalidade } & 1 & $2(4)$ & $1(2)$ & $4(9)$ & $16(33)$ & $25(52)$ & $5(4-5)$ \\
\hline & 2 & $\mathbf{0}(\mathbf{0})$ & $4(9)$ & $5(10)$ & $16(33)$ & $23(48)$ & $4(4-5)$ \\
\hline & 3 & $1(2)$ & $1(2)$ & 7 (13) & $11(20)$ & $34(63)$ & $5(4-5)$ \\
\hline & 4 & $1(2)$ & $2(3)$ & $4(6)$ & $24(37)$ & $34(52)$ & $5(4-5)$ \\
\hline & 5 & 0 (0) & $2(2)$ & $7(8)$ & $24(29)$ & $51(61)$ & $5(4-5)$ \\
\hline & 6 & $\mathbf{0}(\mathbf{0})$ & $1(1)$ & $3(5)$ & $20(28)$ & $47(66)$ & $5(4-5)$ \\
\hline
\end{tabular}




\begin{tabular}{|c|c|c|c|c|c|c|c|}
\hline Itens Avaliados & Fase & $\begin{array}{l}\text { Discordo } \\
\text { Totalmente } \\
\quad(1)\end{array}$ & $\begin{array}{l}\text { Discordo } \\
\quad(2)\end{array}$ & $\begin{array}{l}\text { Indiferente } \\
\quad \text { (3) }\end{array}$ & $\begin{array}{l}\text { Concordo } \\
\text { (4) }\end{array}$ & $\begin{array}{c}\text { Concordo } \\
\text { Totalmente } \\
\quad(5)\end{array}$ & $\begin{array}{c}\text { Mediana } \\
\text { (Intervalo } \\
\text { IQ) }\end{array}$ \\
\hline \multicolumn{8}{|l|}{ 3. Usabilidade } \\
\hline \multirow{6}{*}{$\begin{array}{l}3.1 \text { - É fácil entender o conceito e } \\
\text { aplicação. }\end{array}$} & 1 & & & $1(12.5)$ & $2(25)$ & $\overline{5(62.5)}$ & $5(4-5)$ \\
\hline & 2 & & & & $5(62.5)$ & $3(37.5)$ & $4(4-5)$ \\
\hline & 3 & & & & $1(11)$ & $8(89)$ & $5(5-5)$ \\
\hline & 4 & & & & $4(36)$ & $7(64)$ & $5(4-5)$ \\
\hline & 5 & & & & $5(36)$ & $9(64)$ & $5(4-5)$ \\
\hline & 6 & & & $1(8)$ & $2(17)$ & $9(75)$ & $5(5-5)$ \\
\hline \multirow{6}{*}{3.2 - É fácil aprender a usar. } & 1 & & & $1(12.5)$ & $2(25)$ & $5(62.5)$ & $5(4-5)$ \\
\hline & 2 & & & & $6(75)$ & $2(25)$ & $4(4-4)$ \\
\hline & 3 & & & $1(11)$ & & $8(89)$ & $5(5-5)$ \\
\hline & 4 & & & & $4(36)$ & $7(64)$ & $5(4-5)$ \\
\hline & 5 & & & & $5(36)$ & $9(64)$ & $5(4-5)$ \\
\hline & 6 & & & & $3(25)$ & $9(75)$ & $5(5-5)$ \\
\hline \multirow{6}{*}{$\begin{array}{l}3.3 \text { - Estão disponíveis instruções sobre } \\
\text { como usar o sistema. }\end{array}$} & 1 & $1(12.5)$ & & $3(37.5)$ & $2(25)$ & $2(25)$ & $3(3-5)$ \\
\hline & 2 & & $1(12.5)$ & $4(50)$ & $2(25)$ & $1(12.5)$ & $3(3-4)$ \\
\hline & 3 & & & $3(33)$ & $4(45)$ & $2(22)$ & $4(3-4)$ \\
\hline & 4 & & $1(9)$ & $4(36)$ & $3(27.5)$ & $3(27.5)$ & $4(4-5)$ \\
\hline & 5 & & $1(7)$ & $4(29)$ & $3(21)$ & $6(43)$ & $4(3-5)$ \\
\hline & 6 & & & $2(18)$ & $1(9)$ & $8(73)$ & $5(4-5)$ \\
\hline \multirow{6}{*}{3.4 - É fácil de operar e controlar. } & 1 & & & $2(25)$ & $3(37.5)$ & $3(37.5)$ & $4(4-5)$ \\
\hline & 2 & & & & $5(62.5)$ & $3(37.5)$ & $4(4-5)$ \\
\hline & 3 & & & & $1(11)$ & $8(89)$ & $5(5-5)$ \\
\hline & 4 & & & & $5(45)$ & $6(55)$ & $5(4-5)$ \\
\hline & 5 & & & & $4(29)$ & $10(71)$ & $5(4-5)$ \\
\hline & 6 & & & $1(8)$ & $2(17)$ & $9(75)$ & $5(5-5)$ \\
\hline \multirow{6}{*}{3.5 - O sistema PEG é ágil. } & 1 & & & $1(12.5)$ & $3(37.5)$ & $4(50)$ & $4,5(4-5)$ \\
\hline & 2 & & & $1(12.5)$ & $4(50)$ & $3(37.5)$ & $4(4-5)$ \\
\hline & 3 & & & & $4(44)$ & $5(56)$ & $5(4-5)$ \\
\hline & 4 & & & $1(9)$ & $3(27)$ & $7(64)$ & $5(4-5)$ \\
\hline & 5 & 1(7) & $2(14)$ & $1(7)$ & $3(22)$ & $7(50)$ & $4,5(4-5)$ \\
\hline & 6 & & $1(8)$ & $1(8)$ & $4(33)$ & $6(50)$ & $4,5(4-5)$ \\
\hline
\end{tabular}




\begin{tabular}{|c|c|c|c|c|c|c|c|}
\hline Itens Avaliados & Fase & $\begin{array}{l}\text { Discordo } \\
\text { Totalmente } \\
\quad(1)\end{array}$ & $\begin{array}{l}\text { Discordo } \\
\quad \text { (2) }\end{array}$ & $\begin{array}{l}\text { Indiferente } \\
\text { (3) }\end{array}$ & $\begin{array}{l}\text { Concordo } \\
\text { (4) }\end{array}$ & $\begin{array}{c}\text { Concordo } \\
\text { Totalmente } \\
\text { (5) }\end{array}$ & $\begin{array}{c}\text { Mediana } \\
\text { (Intervalo } \\
\text { IQ) }\end{array}$ \\
\hline \multicolumn{8}{|l|}{ 3. Usabilidade - continuação } \\
\hline \multirow{6}{*}{$\begin{array}{l}3.6 \text { - O sistema PEG possui boa } \\
\text { navegabilidade. }\end{array}$} & 1 & & & & $4(50)$ & $4(50)$ & $4,5(4-5)$ \\
\hline & 2 & & & & $5(62.5)$ & $3(37.5)$ & $4(4-5)$ \\
\hline & 3 & & & & $5(56)$ & $4(44)$ & $4(4-5)$ \\
\hline & 4 & & & $1(9)$ & $4(36)$ & $6(55)$ & $5(4-5)$ \\
\hline & 5 & & 1(7) & $1(7)$ & $4(29)$ & $8(57)$ & $5(4-5)$ \\
\hline & 6 & & & $1(8)$ & $2(17)$ & $9(75)$ & $5(5-5)$ \\
\hline \multirow{6}{*}{ SUBTOTAL - Usabilidade } & 1 & $1(2)$ & $\mathbf{0}(\mathbf{0})$ & $8(17)$ & $16(33)$ & $23(48)$ & $4(4-5)$ \\
\hline & 2 & $\mathbf{0}(\mathbf{0})$ & $1(2)$ & $5(10)$ & $27(56)$ & $15(32)$ & $4(4-5)$ \\
\hline & 3 & $\mathbf{0}(\mathbf{0})$ & $\mathbf{0}(\mathbf{0})$ & $4(7)$ & $15(28)$ & $35(65)$ & $5(4-5)$ \\
\hline & 4 & $\mathbf{0}(\mathbf{0})$ & $1(2)$ & $6(9)$ & $23(35)$ & $36(54)$ & $5(4-5)$ \\
\hline & 5 & $1(1)$ & $4(5)$ & $6(7)$ & $24(29)$ & $49(58)$ & $5(4-5)$ \\
\hline & 6 & $\mathbf{0}(\mathbf{0})$ & $1(\mathbf{1})$ & $6(9)$ & $14(20)$ & $50(70)$ & $5(4-5)$ \\
\hline 4. Confiabilidade & & & & & & & \\
\hline \multirow{6}{*}{4.1 - Não falha com frequência. } & 1 & $1(12.5)$ & $3(37.5)$ & $3(37.5)$ & $1(12.5)$ & & $2.5(2-3)$ \\
\hline & 2 & & $2(25)$ & $3(37.5)$ & $3(37.5)$ & & $3(3-4)$ \\
\hline & 3 & & $3(33)$ & $2(22)$ & $4(45)$ & & $3(2-4)$ \\
\hline & 4 & & $1(9)$ & $3(27)$ & $7(64)$ & & $4(3-4)$ \\
\hline & 5 & & $2(14)$ & $3(22)$ & $7(50)$ & $2(14)$ & $4(3-4)$ \\
\hline & 6 & & $1(8)$ & & $7(58)$ & $4(33)$ & $4(4-5)$ \\
\hline \multirow{6}{*}{$\begin{array}{l}4.2 \text { - Na ocorrência de falhas, não há } \\
\text { perda de dados. }\end{array}$} & 1 & $1(12.5)$ & $2(25)$ & $4(50)$ & $1(12.5)$ & & $3(2-3)$ \\
\hline & 2 & & $2(25)$ & $3(37.5)$ & $2(25)$ & $1(12.5)$ & $3(3-4)$ \\
\hline & 3 & & $4(44.5)$ & $4(44.5)$ & $1(11)$ & & $3(2-3)$ \\
\hline & 4 & & $2(18)$ & $5(45)$ & $3(27)$ & $1(9)$ & $3(3-4)$ \\
\hline & 5 & & $4(28.5)$ & $4(28.5)$ & $5(36)$ & $1(7)$ & $3(2-4)$ \\
\hline & 6 & & $1(8)$ & $3(25)$ & $6(50)$ & $2(17)$ & $4(3-4)$ \\
\hline \multirow{6}{*}{$\begin{array}{l}4.3 \text { - É capaz de recuperar dados em } \\
\text { caso de falhas. }\end{array}$} & 1 & $1(12.5)$ & & $4(50)$ & $3(37.5)$ & & $3(3-4)$ \\
\hline & 2 & & $1(12.5)$ & $4(50)$ & $2(25)$ & $1(12.5)$ & $3(3-4)$ \\
\hline & 3 & & $2(22)$ & $7(78)$ & & & $3(3-3)$ \\
\hline & 4 & & & $5(45.5)$ & $5(45.5)$ & $1(9)$ & $3(3-4)$ \\
\hline & 5 & & $2(14)$ & $5(36)$ & $5(36)$ & $2(14)$ & $3.5(3-4)$ \\
\hline & 6 & & $1(8)$ & $4(33)$ & $5(42)$ & $2(17)$ & $4(3-4)$ \\
\hline
\end{tabular}




\begin{tabular}{|l|c|c|c|c|c|c|c|}
\hline \multicolumn{1}{|c|}{ Itens Avaliados } & Fase & $\begin{array}{c}\text { Discordo } \\
\text { Totalmente } \\
(1)\end{array}$ & $\begin{array}{c}\text { Discordo } \\
(2)\end{array}$ & $\begin{array}{c}\text { Indiferente } \\
(3)\end{array}$ & $\begin{array}{c}\text { Concordo } \\
(4)\end{array}$ & $\begin{array}{c}\text { Concordo } \\
\text { Totalmente } \\
(5)\end{array}$ & $\begin{array}{c}\text { Mediana } \\
\text { (Intervalo } \\
\text { IQ) }\end{array}$ \\
\hline Continuação & & & & & & & \\
\hline \multirow{5}{*}{ SUBTOTAL - Confiabilidade } & 1 & $\mathbf{3}(12)$ & $5(21)$ & $11(46)$ & $5(21)$ & $0(0)$ & $3(2-3)$ \\
\cline { 2 - 8 } & 2 & $0(0)$ & $5(21)$ & $10(42)$ & $7(29)$ & $2(8)$ & $3(3-4)$ \\
\cline { 2 - 8 } & 3 & $0(0)$ & $9(33)$ & $13(48)$ & $5(19)$ & $0(0)$ & $3(2-3)$ \\
\cline { 2 - 8 } & 4 & $0(0)$ & $3(9)$ & $13(39)$ & $15(46)$ & $2(6)$ & $3(3-4)$ \\
\cline { 2 - 8 } & 5 & $0(0)$ & $\mathbf{8}(19)$ & $12(29)$ & $17(40)$ & $5(12)$ & $4(3-4)$ \\
\cline { 2 - 8 } & 6 & $0(0)$ & $3(8)$ & $7(20)$ & $18(50)$ & $\mathbf{8}(22)$ & $4(3-4)$ \\
\hline
\end{tabular}

Nota: As células em cinza claro se referem aos itens incluídos após o início do período de avaliação. Eles foram incluídos apenas nas fases para as quais existem respostas. 
Tabela S2 - Distribuição das frequências absolutas e relativas das avaliações dos usuários [n (\%)] para os itens Serviço, Funcionalidade, Usabilidade e Confiabilidade do PEG- software, nas Fases 1 a 6, classificados como respostas negativas, neutras e positivas

\begin{tabular}{|c|c|c|c|c|c|}
\hline Itens Avaliados & Fase & $\begin{array}{l}\text { Avaliações } \\
\text { Negativas } \\
\quad \text { (1) }\end{array}$ & $\begin{array}{l}\text { Avaliações } \\
\text { Neutras } \\
\text { (2) }\end{array}$ & $\begin{array}{l}\text { Avaliações } \\
\text { Positivas } \\
\quad \text { (3) }\end{array}$ & $\begin{array}{l}\text { Mediana } \\
\text { (Intervalo } \\
\text { IQ) }\end{array}$ \\
\hline \multicolumn{6}{|l|}{$\begin{array}{ll}1 . & \text { Serviço }\end{array}$} \\
\hline \multirow{6}{*}{$\begin{array}{l}1.1 \text { - A organização e apresentação do conteúdo } \\
\text { funcional do Registro Genético Eletrônico (PEG), } \\
\text { conforme as guias: Identificação do Paciente, Pré- } \\
\text { natal e Parto, História Clínica, Achados Clínicos, } \\
\text { Evolução, Exame, Diagnóstico, Protocolo, } \\
\text { Imagens, Relatórios, Resumo Médico e } \\
\text { Antecedentes, satisfazem as necessidades do } \\
\text { serviço de genética. }\end{array}$} & 1 & & & $8(100)$ & $3(3-3)$ \\
\hline & 2 & & & $8(100)$ & $3(3-3)$ \\
\hline & 3 & & & $9(100)$ & $3(3-3)$ \\
\hline & 4 & & & $11(100)$ & $3(3-3)$ \\
\hline & 5 & & & $14(100)$ & $3(3-3)$ \\
\hline & 6 & & & $12(100)$ & $3(3-3)$ \\
\hline \multirow{6}{*}{$\begin{array}{l}\text { 1.1.1 A organização e apresentação do conteúdo } \\
\text { funcional da aba (guia) Identificação do Paciente, } \\
\text { satisfazem as necessidades do serviço de genética. }\end{array}$} & 1 & & $1(12.5)$ & $7(87.5)$ & $3(3-3)$ \\
\hline & 2 & & & $8(100)$ & $3(3-3)$ \\
\hline & 3 & & $1(11)$ & $8(89)$ & $3(3-3)$ \\
\hline & 4 & & & $11(100)$ & $3(3-3)$ \\
\hline & 5 & & $1(7)$ & $13(93)$ & $3(3-3)$ \\
\hline & 6 & & & $12(100)$ & $3(3-3)$ \\
\hline \multirow{6}{*}{$\begin{array}{l}\text { 1.1.2 A organização e apresentação do conteúdo } \\
\text { funcional da guia pré-natal e parto (guia) atendem } \\
\text { às necessidades do serviço genético. }\end{array}$} & 1 & & $1(12.5)$ & $7(87.5)$ & $3(3-3)$ \\
\hline & 2 & & & $8(100)$ & $3(3-3)$ \\
\hline & 3 & & & $9(100)$ & $3(3-3)$ \\
\hline & 4 & & & $11(100)$ & $3(3-3)$ \\
\hline & 5 & & 1 (7) & $13(93)$ & $3(3-3)$ \\
\hline & 6 & & & $12(100)$ & $3(3-3)$ \\
\hline \multirow{6}{*}{$\begin{array}{l}\text { 1.1.3 A organização e apresentação do conteúdo } \\
\text { funcional da guia (guia) } \\
\text { satisfazem as } \\
\text { genética. }\end{array}$} & 1 & & & $8(100)$ & $3(3-3)$ \\
\hline & 2 & & & $8(100)$ & $3(3-3)$ \\
\hline & 3 & & $2(22)$ & $7(78)$ & $3(3-3)$ \\
\hline & 4 & & $1(9)$ & $10(91)$ & $3(3-3)$ \\
\hline & 5 & & $2(14)$ & $12(86)$ & $3(3-3)$ \\
\hline & 6 & & $2(17)$ & $10(83)$ & $3(3-3)$ \\
\hline
\end{tabular}

Continua 


\begin{tabular}{|c|c|c|c|c|c|}
\hline Itens Avaliados & Fase & $\begin{array}{l}\text { Avaliações } \\
\text { Negativas } \\
\text { (1) }\end{array}$ & $\begin{array}{l}\text { Avaliações } \\
\text { Neutras } \\
\text { (2) }\end{array}$ & $\begin{array}{l}\text { Avaliações } \\
\text { Positivas } \\
\text { (3) }\end{array}$ & $\begin{array}{l}\text { Mediana } \\
\text { (Intervalo } \\
\text { IQ) }\end{array}$ \\
\hline \multicolumn{6}{|l|}{ 1. Serviço - continuação } \\
\hline \multirow{6}{*}{$\begin{array}{l}\text { 1.1.4 A organização e apresentação do conteúdo } \\
\text { funcional da guia (guia) Achados Clínicos, } \\
\text { atendem às necessidades do serviço de genética. }\end{array}$} & 1 & & $1(12.5)$ & $7(87.5)$ & $3(3-3)$ \\
\hline & 2 & & & $8(100)$ & $3(3-3)$ \\
\hline & 3 & & & $9(100)$ & $3(3-3)$ \\
\hline & 4 & & & $11(100)$ & $3(3-3)$ \\
\hline & 5 & & $1(7)$ & $13(93)$ & $3(3-3)$ \\
\hline & 6 & & $2(17)$ & $10(83)$ & $3(3-3)$ \\
\hline \multirow{6}{*}{$\begin{array}{l}\text { 1.1.5 A organização e apresentação do conteúdo } \\
\text { funcional do guia (Evolução) satisfazem as } \\
\text { necessidades do serviço de genética. }\end{array}$} & 1 & & $1(12.5)$ & $7(87.5)$ & $3(3-3)$ \\
\hline & 2 & & $1(12.5)$ & $7(87.5)$ & $3(3-3)$ \\
\hline & 3 & & & $9(100)$ & $3(3-3)$ \\
\hline & 4 & & $1(9)$ & $10(91)$ & $3(3-3)$ \\
\hline & 5 & $1(7)$ & $1(7)$ & $12(86)$ & $3(3-3)$ \\
\hline & 6 & & $2(17)$ & $10(83)$ & $3(3-3)$ \\
\hline \multirow{6}{*}{$\begin{array}{l}\text { 1.1.6 A organização e apresentação do conteúdo } \\
\text { funcional dos guias (guia) dos exames atendem às } \\
\text { necessidades do serviço de genética. }\end{array}$} & 1 & & $3(37.5)$ & $5(62.5)$ & $3(2-3)$ \\
\hline & 2 & $2(25)$ & $1(12.5)$ & $5(62.5)$ & $3(1-3)$ \\
\hline & 3 & $1(12)$ & $4(44)$ & $4(44)$ & $2(2-3)$ \\
\hline & 4 & $1(9)$ & & $10(91)$ & $3(3-3)$ \\
\hline & 5 & & $3(23)$ & $10(77)$ & $3(3-3)$ \\
\hline & 6 & & $3(25)$ & $9(75)$ & $3(2-3)$ \\
\hline \multirow{6}{*}{$\begin{array}{l}\text { 1.1.7 A organização e apresentação do conteúdo } \\
\text { funcional da guia Diagnóstico (guia) satisfazem as } \\
\text { necessidades do serviço genético. }\end{array}$} & 1 & & $2(25)$ & $6(75)$ & $3(2-3)$ \\
\hline & 2 & & & $8(100)$ & $3(3-3)$ \\
\hline & 3 & & $2(22)$ & $7(78)$ & $3(3-3)$ \\
\hline & 4 & & & $11(100)$ & $3(3-3)$ \\
\hline & 5 & & $2(14)$ & $12(86)$ & $3(3-3)$ \\
\hline & 6 & & $2(17)$ & $10(83)$ & $3(3-3)$ \\
\hline \multirow{6}{*}{$\begin{array}{l}\text { 1.1.8 A organização e apresentação do conteúdo } \\
\text { funcional do protocolo da guia (guia) atendem às } \\
\text { necessidades do serviço de genética. }\end{array}$} & 1 & & & & \\
\hline & 2 & & & & \\
\hline & 3 & & & & \\
\hline & 4 & $2(25)$ & $4(50)$ & $2(25)$ & $2(2-2)$ \\
\hline & 5 & $5(38)$ & $1(8)$ & $7(54)$ & $3(1-3)$ \\
\hline & 6 & $2(18)$ & $5(46)$ & $4(36)$ & $2(2-3)$ \\
\hline
\end{tabular}

Continua 


\begin{tabular}{|c|c|c|c|c|c|}
\hline Itens Avaliados & Fase & $\begin{array}{l}\text { Avaliações } \\
\text { Negativas } \\
\text { (1) }\end{array}$ & $\begin{array}{l}\text { Avaliações } \\
\text { Neutras } \\
\text { (2) }\end{array}$ & $\begin{array}{l}\text { Avaliações } \\
\text { Positivas } \\
\text { (3) }\end{array}$ & $\begin{array}{c}\text { Mediana } \\
\text { (Intervalo } \\
\text { IQ) }\end{array}$ \\
\hline 1. Serviço - continuação & & & & & \\
\hline \multirow{6}{*}{$\begin{array}{l}\text { 1.1.9 A organização e apresentação do conteúdo } \\
\text { funcional das guias (guia) Imagens atendem às } \\
\text { necessidades do serviço de genética. }\end{array}$} & $\mathbf{1}$ & $1(25)$ & $1(25)$ & $2(50)$ & $3(2-3)$ \\
\hline & 2 & $2(40)$ & $1(20)$ & $2(40)$ & $2(1-3)$ \\
\hline & 3 & $2(25)$ & $2(25)$ & $4(50)$ & $3(2-3)$ \\
\hline & 4 & $2(25)$ & $4(50)$ & $2(25)$ & $2(2-2)$ \\
\hline & 5 & $2(15)$ & $6(46)$ & $5(39)$ & $2(2-3)$ \\
\hline & 6 & $2(18)$ & $5(46)$ & $4(36)$ & $2(2-3)$ \\
\hline \multirow{6}{*}{$\begin{array}{l}\text { 1.1.10 A organização e apresentação do conteúdo } \\
\text { funcional da guia (guia) Relatório satisfaz as } \\
\text { necessidades do serviço de genética. }\end{array}$} & 1 & & & & \\
\hline & 2 & & & & \\
\hline & 3 & $1(12.5)$ & $3(37.5)$ & $4(50)$ & $3(2-3)$ \\
\hline & 4 & $2(25)$ & $3(37.5)$ & $3(37.5)$ & $2(2-3)$ \\
\hline & 5 & $3(23)$ & $5(38)$ & $5(39)$ & $2(2-3)$ \\
\hline & 6 & $2(18)$ & $4(36)$ & $5(46)$ & $2(2-3)$ \\
\hline \multirow{6}{*}{$\begin{array}{l}\text { 1.1.11 A organização e apresentação do conteúdo } \\
\text { funcional da guia (guia) Resumo Médico satisfaz } \\
\text { as necessidades do serviço de genética. }\end{array}$} & 1 & & & & \\
\hline & 2 & & & & \\
\hline & 3 & & & & \\
\hline & 4 & & $3(37.5)$ & $5(62.5)$ & $2(2-3)$ \\
\hline & 5 & $1(8)$ & $2(15)$ & $10(77)$ & $3(3-3)$ \\
\hline & 6 & $2(16)$ & $4(34)$ & $6(50)$ & $3(2-3)$ \\
\hline \multirow{6}{*}{$\begin{array}{l}1.12 \text { A organização e apresentação do conteúdo } \\
\text { funcional da guia (guia) Antecedentes Médicos, } \\
\text { atendem às necessidades do serviço de genética. }\end{array}$} & 1 & & & & \\
\hline & 2 & & & & \\
\hline & 3 & & & & \\
\hline & 4 & & & & \\
\hline & 5 & & & & \\
\hline & 6 & & $2(17)$ & $10(83)$ & $3(3-3)$ \\
\hline \multirow{6}{*}{$\begin{array}{l}1.2 \text { - As funções do sistema PEG na assistência } \\
\text { médica atendem às necessidades do serviço de } \\
\text { genética. }\end{array}$} & 1 & & $1(12.5)$ & $7(87.5)$ & $3(3-3)$ \\
\hline & 2 & & & $8(100)$ & $3(3-3)$ \\
\hline & 3 & & & $9(100)$ & $3(3-3)$ \\
\hline & 4 & $1(9)$ & & $10(91)$ & $3(3-3)$ \\
\hline & 5 & & & $14(100)$ & $3(3-3)$ \\
\hline & 6 & & $1(8)$ & $11(92)$ & $3(3-3)$ \\
\hline
\end{tabular}

Continua 


\begin{tabular}{|c|c|c|c|c|c|}
\hline Itens Avaliados & Fase & $\begin{array}{l}\text { Avaliações } \\
\text { Negativas } \\
\text { (1) }\end{array}$ & $\begin{array}{l}\text { Avaliações } \\
\text { Neutras } \\
\text { (2) }\end{array}$ & $\begin{array}{l}\text { Avaliações } \\
\text { Positivas } \\
\text { (3) }\end{array}$ & $\begin{array}{c}\text { Mediana } \\
\text { (Intervalo } \\
\text { IQ) }\end{array}$ \\
\hline 1. Serviço - continuação & & & & & \\
\hline \multirow{6}{*}{$\begin{array}{l}1.3 \text { - O uso do sistema permite maior clareza na } \\
\text { leitura do histórico do paciente. }\end{array}$} & 1 & & $1(12.5)$ & $7(87.5)$ & $3(3-3)$ \\
\hline & 2 & & & $8(100)$ & $3(3-3)$ \\
\hline & 3 & & $1(11)$ & $8(89)$ & $3(3-3)$ \\
\hline & 4 & & & $11(100)$ & $3(3-3)$ \\
\hline & 5 & & $1(7)$ & $13(93)$ & $3(3-3)$ \\
\hline & 6 & & $1(8)$ & $11(92)$ & $3(3-3)$ \\
\hline \multirow{6}{*}{$\begin{array}{l}1.4 \text { - A linguagem utilizada é natural, os termos, } \\
\text { frases, conceitos são semelhantes aos utilizados no } \\
\text { meu dia-a-dia ou no ambiente de estudo. }\end{array}$} & 1 & & & $8(100)$ & $3(3-3)$ \\
\hline & 2 & & & $8(100)$ & $3(3-3)$ \\
\hline & 3 & & & $9(100)$ & $3(3-3)$ \\
\hline & 4 & & & $11(100)$ & $3(3-3)$ \\
\hline & 5 & & & $14(100)$ & $3(3-3)$ \\
\hline & 6 & & & $12(100)$ & $3(3-3)$ \\
\hline \multirow{6}{*}{$\begin{array}{l}1.5 \text { - O tempo para preencher o registro clínico } \\
\text { através do sistema é menor que o preenchimento } \\
\text { manual (em papel). }\end{array}$} & 1 & & & $8(100)$ & $3(3-3)$ \\
\hline & 2 & & $1(12.5)$ & $7(87.5)$ & $3(3-3)$ \\
\hline & 3 & & & $9(100)$ & $3(3-3)$ \\
\hline & 4 & $1(9)$ & & $10(91)$ & $3(3-3)$ \\
\hline & 5 & $1(7)$ & & $13(93)$ & $3(3-3)$ \\
\hline & 6 & & $2(17)$ & $10(83)$ & $3(3-3)$ \\
\hline \multirow{6}{*}{$\begin{array}{l}1.6 \text { - Na impossibilidade de incluir a consulta } \\
\text { agendada no sistema PEG, devido a problemas de } \\
\text { rede, posso inserir a consulta manual em outro } \\
\text { momento. }\end{array}$} & 1 & & $2(33.3)$ & $4(66.7)$ & $3(2-3)$ \\
\hline & 2 & $1(12.5)$ & $3(37.5)$ & $4(50)$ & $3(2-3)$ \\
\hline & 3 & $2(22)$ & $3(33.5)$ & $4(44.5)$ & $2(2-3)$ \\
\hline & 4 & $1(9)$ & $4(36)$ & $6(55)$ & $3(2-3)$ \\
\hline & 5 & $4(29)$ & $2(14)$ & $8(57)$ & $3(1-3)$ \\
\hline & 6 & $1(8)$ & $2(17)$ & $9(75)$ & $3(3-3)$ \\
\hline \multirow{6}{*}{$\begin{array}{l}1.7 \text { - Houve uma diminuição de papéis na sala de } \\
\text { genética com o uso do sistema PEG. }\end{array}$} & 1 & & & $8(100)$ & $3(3-3)$ \\
\hline & 2 & & & $8(100)$ & $3(3-3)$ \\
\hline & 3 & $1(11)$ & $1(11)$ & $7(78)$ & $3(3-3)$ \\
\hline & 4 & & & $11(100)$ & $3(3-3)$ \\
\hline & 5 & $2(14)$ & & $12(86)$ & $3(3-3)$ \\
\hline & 6 & $1(8)$ & $2(17)$ & $9(75)$ & $3(3-3)$ \\
\hline
\end{tabular}

Continua 


\begin{tabular}{|c|c|c|c|c|c|}
\hline Itens Avaliados & Fase & $\begin{array}{c}\text { Avaliações } \\
\text { Negativas } \\
\text { (1) }\end{array}$ & $\begin{array}{c}\text { Avaliações } \\
\text { Neutras } \\
(2)\end{array}$ & $\begin{array}{c}\text { Avaliações } \\
\text { Positivas } \\
\text { (3) }\end{array}$ & $\begin{array}{l}\text { Mediana } \\
\text { (Intervalo } \\
\text { IQ) }\end{array}$ \\
\hline 1. Serviço - continuação & & & & & \\
\hline \multirow{6}{*}{$\begin{array}{l}1.8 \text { - Realizo consultas no sistema, para fins de } \\
\text { atendimento ambulatorial. }\end{array}$} & 1 & & & $8(100)$ & $3(3-3)$ \\
\hline & 2 & & & $8(100)$ & $3(3-3)$ \\
\hline & 3 & & & $9(100)$ & $3(3-3)$ \\
\hline & 4 & & & $11(100)$ & $3(3-3)$ \\
\hline & 5 & & & $14(100)$ & $3(3-3)$ \\
\hline & 6 & & & $12(100)$ & $3(3-3)$ \\
\hline \multirow{6}{*}{$\begin{array}{l}1.9 \text { - Faço consultas no sistema, para fins de } \\
\text { pesquisa. }\end{array}$} & 1 & $2(25)$ & $1(12.5)$ & $5(62.5)$ & $3(2-3)$ \\
\hline & 2 & $1(13)$ & & $7(88)$ & $3(3-3)$ \\
\hline & 3 & $1(11)$ & $2(22)$ & $6(67)$ & $3(2-3)$ \\
\hline & 4 & $1(9)$ & $1(9)$ & $9(82)$ & $3(3-3)$ \\
\hline & 5 & $2(14)$ & $3(21)$ & $9(65)$ & $3(2-3)$ \\
\hline & 6 & & $2(17)$ & $10(83)$ & $3(3-3)$ \\
\hline \multirow{6}{*}{ SUBTOTAL - Serviço } & 1 & $3(2)$ & $15(12)$ & $112(86)$ & $3(3-3)$ \\
\hline & 2 & $6(5)$ & $7(5)$ & $120(90)$ & $3(3-3)$ \\
\hline & 3 & $8(5)$ & $21(13)$ & $131(82)$ & $3(3-3)$ \\
\hline & 4 & $11(5)$ & $21(10)$ & $176(85)$ & $3(3-3)$ \\
\hline & 5 & $21(8)$ & $31(11)$ & $223(81)$ & $3(3-3)$ \\
\hline & 6 & $10(4)$ & $41(17)$ & $198(80)$ & $3(3-3)$ \\
\hline \multicolumn{6}{|l|}{ 2. Funcionalidade } \\
\hline \multirow{6}{*}{$\begin{array}{l}2.1 \text { - O PEG é adequado para o registro de dados } \\
\text { do paciente. }\end{array}$} & 1 & & & $8(100)$ & $3(3-3)$ \\
\hline & 2 & & & $8(100)$ & $3(3-3)$ \\
\hline & 3 & & & $9(100)$ & $3(3-3)$ \\
\hline & 4 & & $1(9)$ & $10(91)$ & $3(3-3)$ \\
\hline & 5 & & $1(7)$ & $13(93)$ & $3(3-3)$ \\
\hline & 6 & & & $11(100)$ & $3(3-3)$ \\
\hline \multirow{6}{*}{$\begin{array}{l}2.2 \text { - Considerando que o objetivo é substituir o } \\
\text { registro do paciente antigo (manuscrito) pelos } \\
\text { eletrônicos, o PEG faz isso corretamente. }\end{array}$} & 1 & & & $8(100)$ & $3(3-3)$ \\
\hline & 2 & & & $8(100)$ & $3(3-3)$ \\
\hline & 3 & & & $9(100)$ & $3(3-3)$ \\
\hline & 4 & & & $11(100)$ & $3(3-3)$ \\
\hline & 5 & & & $14(100)$ & $3(3-3)$ \\
\hline & 6 & & & $12(100)$ & $3(3-3)$ \\
\hline
\end{tabular}




\begin{tabular}{|c|c|c|c|c|c|}
\hline Itens Avaliados & Fase & $\begin{array}{c}\text { Avaliações } \\
\text { Negativas } \\
\text { (1) }\end{array}$ & $\begin{array}{c}\text { Avaliações } \\
\text { Neutras } \\
\text { (2) }\end{array}$ & $\begin{array}{c}\text { Avaliações } \\
\text { Positivas } \\
\text { (3) }\end{array}$ & $\begin{array}{l}\text { Mediana } \\
\text { (Intervalo } \\
\text { IQ) }\end{array}$ \\
\hline 2. Funcionalidade - continuação & & & & & \\
\hline \multirow{6}{*}{$\begin{array}{l}2.3 \text { - Interage com o sistema de agenda. já } \\
\text { existente. }\end{array}$} & 1 & & & $8(100)$ & $3(3-3)$ \\
\hline & 2 & $1(13)$ & $3(38)$ & $4(50)$ & $3(2-3)$ \\
\hline & 3 & $1(11)$ & $2(22)$ & $6(67)$ & $3(2-3)$ \\
\hline & 4 & $1(09)$ & $2(18)$ & $8(73)$ & $3(2-3)$ \\
\hline & 5 & $1(7)$ & $4(29)$ & $9(64)$ & $3(2-3)$ \\
\hline & 6 & & $1(8)$ & $11(92)$ & $3(3-3)$ \\
\hline \multirow{6}{*}{2.4 - Impede o acesso não autorizado aos dados. } & 1 & $1(13)$ & $2(25)$ & $5(63)$ & $3(2-3)$ \\
\hline & 2 & $2(25)$ & $1(12.5)$ & $5(62.5)$ & $3(2-3)$ \\
\hline & 3 & $1(11)$ & $1(11)$ & $7(78)$ & $3(3-3)$ \\
\hline & 4 & $1(9)$ & $1(9)$ & $9(82)$ & $3(3-3)$ \\
\hline & 5 & & $1(7)$ & $13(93)$ & $3(3-3)$ \\
\hline & 6 & $1(8)$ & $1(8)$ & $10(84)$ & $3(3-3)$ \\
\hline \multirow{6}{*}{$\begin{array}{l}2.5 \text { - Eu uso uma senha de acesso para usar o } \\
\text { sistema PEG. }\end{array}$} & 1 & $2(25)$ & & $6(75)$ & $3(3-3)$ \\
\hline & 2 & $1(12.5)$ & & $7(87.5)$ & $3(3-3)$ \\
\hline & 3 & & & $9(100)$ & $3(3-3)$ \\
\hline & 4 & $1(9)$ & & $10(91)$ & $3(3-3)$ \\
\hline & 5 & & & $14(100)$ & $3(3-3)$ \\
\hline & 6 & & & $12(100)$ & $3(3-3)$ \\
\hline \multirow{6}{*}{$\begin{array}{l}2.6 \text { - O sistema está em conformidade com } \\
\text { normas, leis, etc. (mantém a impressão em papel, } \\
\text { apesar de possuir o formato eletrônico). }\end{array}$} & 1 & & $2(25)$ & $6(75)$ & $3(3-3)$ \\
\hline & 2 & & $1(12.5)$ & $7(87.5)$ & $3(3-3)$ \\
\hline & 3 & & $4(44)$ & $5(56)$ & $3(2-3)$ \\
\hline & 4 & & $1(9)$ & $10(91)$ & $3(3-3)$ \\
\hline & 5 & $1(7)$ & $1(7)$ & $12(86)$ & $3(3-3)$ \\
\hline & 6 & & $1(8)$ & $11(92)$ & $3(3-3)$ \\
\hline \multirow{6}{*}{ SUBTOTAL - Funcionalidade } & 1 & $3(6)$ & $4(9)$ & $41(85)$ & $3(3-3)$ \\
\hline & 2 & $4(9)$ & $5(10)$ & $39(81)$ & $3(3-3)$ \\
\hline & 3 & $2(4)$ & 7 (13) & $45(83)$ & $3(3-3)$ \\
\hline & 4 & $3(5)$ & $4(6)$ & $58(89)$ & $3(3-3)$ \\
\hline & 5 & $2(2)$ & $7(8)$ & $75(90)$ & $3(3-3)$ \\
\hline & 6 & $1(1)$ & $3(5)$ & $67(94)$ & $3(3-3)$ \\
\hline
\end{tabular}




\begin{tabular}{|c|c|c|c|c|c|}
\hline Itens Avaliados & Fase & $\begin{array}{c}\text { Avaliações } \\
\text { Negativas } \\
\text { (1) }\end{array}$ & $\begin{array}{c}\text { Avaliações } \\
\text { Neutras } \\
\text { (2) }\end{array}$ & $\begin{array}{l}\text { Avaliações } \\
\text { Positivas } \\
\text { (3) }\end{array}$ & $\begin{array}{c}\text { Mediana } \\
\text { (Intervalo } \\
\text { IQ) }\end{array}$ \\
\hline \multicolumn{6}{|l|}{ 3. Usabilidade - continuação } \\
\hline \multirow{6}{*}{3.1 - É fácil entender o conceito e aplicação. } & 1 & & $1(12.5)$ & $7(87.5)$ & $3(3-3)$ \\
\hline & 2 & & & $8(100)$ & $3(3-3)$ \\
\hline & 3 & & & $9(100)$ & $3(3-3)$ \\
\hline & 4 & & & $11(100)$ & $3(3-3)$ \\
\hline & 5 & & & $14(100)$ & $3(3-3)$ \\
\hline & 6 & & $1(8)$ & $11(92)$ & $3(3-3)$ \\
\hline \multirow{6}{*}{3.2 - É fácil aprender a usar. } & 1 & & $1(12.5)$ & $7(87.5)$ & $3(3-3)$ \\
\hline & 2 & & & $8(100)$ & $3(3-3)$ \\
\hline & 3 & & $1(11)$ & $8(89)$ & $3(3-3)$ \\
\hline & 4 & & & $11(100)$ & $3(3-3)$ \\
\hline & 5 & & & $14(100)$ & $3(3-3)$ \\
\hline & 6 & & & $12(100)$ & $3(3-3)$ \\
\hline \multirow{6}{*}{$\begin{array}{l}3.3 \text { - Estão disponíveis instruções sobre como usar } \\
\text { o sistema. }\end{array}$} & 1 & $1(12.5)$ & $3(37.5)$ & $4(50)$ & $3(2-3)$ \\
\hline & 2 & $1(13)$ & $4(50)$ & $3(38)$ & $2(2-3)$ \\
\hline & 3 & & $3(33)$ & $6(67)$ & $3(2-3)$ \\
\hline & 4 & $1(9)$ & $4(36)$ & $6(55)$ & $3(2-3)$ \\
\hline & 5 & $1(7)$ & $4(29)$ & $9(64)$ & $3(2-3)$ \\
\hline & 6 & & $2(18)$ & $9(82)$ & $3(3-3)$ \\
\hline \multirow{6}{*}{3.4 - É fácil de operar e controlar. } & 1 & & $2(25)$ & $6(75)$ & $3(3-3)$ \\
\hline & 2 & & & $8(100)$ & $3(3-3)$ \\
\hline & 3 & & & $9(100)$ & $3(3-3)$ \\
\hline & 4 & & & $11(100)$ & $3(3-3)$ \\
\hline & 5 & & & $14(100)$ & $3(3-3)$ \\
\hline & 6 & & $1(8)$ & $11(92)$ & $3(3-3)$ \\
\hline \multirow{6}{*}{3.5 - O sistema PEG é ágil. } & 1 & & $1(12.5)$ & $7(87.5)$ & $3(3-3)$ \\
\hline & 2 & & $1(12.5)$ & $7(87.5)$ & $3(3-3)$ \\
\hline & 3 & & & $9(100)$ & $3(3-3)$ \\
\hline & 4 & & $1(9)$ & $10(91)$ & $3(3-3)$ \\
\hline & 5 & $3(21)$ & $1(7)$ & $10(72)$ & $3(2-3)$ \\
\hline & 6 & $1(8)$ & $1(8)$ & $10(84)$ & $3(3-3)$ \\
\hline
\end{tabular}




\begin{tabular}{|c|c|c|c|c|c|}
\hline Itens Avaliados & Fase & $\begin{array}{c}\text { Avaliações } \\
\text { Negativas } \\
\text { (1) }\end{array}$ & $\begin{array}{c}\text { Avaliações } \\
\text { Neutras } \\
\text { (2) }\end{array}$ & $\begin{array}{l}\text { Avaliações } \\
\text { Positivas } \\
\text { (3) }\end{array}$ & $\begin{array}{c}\text { Mediana } \\
\text { (Intervalo } \\
\text { IQ) }\end{array}$ \\
\hline 3. Usabilidade - continuação & & & & & \\
\hline \multirow{6}{*}{3.6 - O sistema PEG possui boa navegabilidade. } & 1 & & & $8(100)$ & $3(3-3)$ \\
\hline & 2 & & & $8(100)$ & $3(3-3)$ \\
\hline & 3 & & & $9(100)$ & $3(3-3)$ \\
\hline & 4 & & $1(9)$ & $10(91)$ & $3(3-3)$ \\
\hline & 5 & $1(7)$ & $1(7)$ & $12(86)$ & $3(3-3)$ \\
\hline & 6 & & $1(8)$ & $11(92)$ & $3(3-3)$ \\
\hline \multirow{6}{*}{ SUBTOTAL - Usabilidade } & 1 & $1(2)$ & $8(17)$ & $39(81)$ & $3(3-3)$ \\
\hline & 2 & $1(2)$ & $5(10)$ & $42(88)$ & $3(3-3)$ \\
\hline & 3 & $\mathbf{0}(\mathbf{0})$ & $4(7)$ & $50(93)$ & $3(3-3)$ \\
\hline & 4 & $1(2)$ & $6(9)$ & $59(89)$ & $3(3-3)$ \\
\hline & 5 & $5(6)$ & $6(7)$ & $73(87)$ & $3(3-3)$ \\
\hline & 6 & $1(1)$ & $6(9)$ & $64(90)$ & $3(3-3)$ \\
\hline 4. $\quad$ Confiabilidade & & & & & \\
\hline \multirow{6}{*}{4.1 - Não falha com frequência. } & 1 & $4(50)$ & $3(37.5)$ & $1(12.5)$ & $2(1-2)$ \\
\hline & 2 & $2(25)$ & $3(37.5)$ & $3(37.5)$ & $2(2-3)$ \\
\hline & 3 & $3(33)$ & $2(22)$ & $4(44)$ & $2(1-3)$ \\
\hline & 4 & $1(09)$ & $3(27)$ & $7(64)$ & $3(2-3)$ \\
\hline & 5 & $2(14)$ & $3(22)$ & $9(64)$ & $3(2-3)$ \\
\hline & 6 & $1(8)$ & & $11(92)$ & $3(3-3)$ \\
\hline \multirow{6}{*}{$\begin{array}{l}4.2 \text { - Na ocorrência de falhas, não há perda de } \\
\text { dados. }\end{array}$} & 1 & $3(37.5)$ & $4(50)$ & $1(12.5)$ & $2(2-2)$ \\
\hline & 2 & $2(25)$ & $3(37.5)$ & $3(37.5)$ & $2(2-3)$ \\
\hline & 3 & $4(44.5)$ & $4(44.5)$ & $1(11)$ & $2(1-2)$ \\
\hline & 4 & $2(18)$ & $5(45)$ & $4(36)$ & $2(2-3)$ \\
\hline & 5 & $4(28.5)$ & $4(28.5)$ & $6(43)$ & $2(1-3)$ \\
\hline & 6 & $1(8)$ & $3(25)$ & $8(67)$ & $3(2-3)$ \\
\hline \multirow{6}{*}{$\begin{array}{l}4.3 \text { - É capaz de recuperar dados em caso de } \\
\text { falhas. }\end{array}$} & 1 & $1(12.5)$ & $4(50)$ & $3(37.5)$ & $2(2-3)$ \\
\hline & 2 & $1(12.5)$ & $4(50)$ & $3(37.5)$ & $2(2-3)$ \\
\hline & 3 & $2(22)$ & $7(78)$ & & $2(2-2)$ \\
\hline & 4 & & $5(45)$ & $6(55)$ & $3(2-3)$ \\
\hline & 5 & $2(14)$ & $5(36)$ & $7(50)$ & $3(2-3)$ \\
\hline & 6 & $1(8)$ & $4(33)$ & 7 (59) & $3(2-3)$ \\
\hline
\end{tabular}




\begin{tabular}{|c|c|c|c|c|c|}
\hline Itens Avaliados & Fase & $\begin{array}{c}\text { Avaliações } \\
\text { Negativas } \\
\text { (1) }\end{array}$ & $\begin{array}{c}\text { Avaliações } \\
\text { Neutras } \\
\text { (2) }\end{array}$ & $\begin{array}{c}\text { Avaliações } \\
\text { Positivas } \\
\text { (3) }\end{array}$ & $\begin{array}{c}\text { Mediana } \\
\text { (Intervalo } \\
\text { IQ) }\end{array}$ \\
\hline \multicolumn{6}{|l|}{ Continuação } \\
\hline \multirow{6}{*}{ SUBTOTAL - Confiabilidade } & 1 & $8(33)$ & $11(46)$ & $5(21)$ & $2(1-3)$ \\
\hline & 2 & $5(21)$ & $10(42)$ & $9(37)$ & $2(2-3)$ \\
\hline & 3 & $9(33)$ & $13(48)$ & $5(19)$ & $2(1-3)$ \\
\hline & 4 & $3(9)$ & $13(39)$ & $17(52)$ & $2(2-3)$ \\
\hline & 5 & $8(19)$ & $12(29)$ & $22(52)$ & $3(2-3)$ \\
\hline & 6 & $3(8)$ & $7(20)$ & $26(72)$ & $3(2-3)$ \\
\hline
\end{tabular}

Nota: As células em cinza claro se referem aos itens incluídos após o início do período de avaliação. Eles foram incluídos apenas nas fases para as quais existem respostas. 


\section{REFERÊNCIAS}

Associação Brasileira de Normas Técnicas. NBR ISO/IEC/IEEE 29119-1, Engenharia de software e sistemas - Teste de software - Parte 1: Conceitos e definições, Rio de Janeiro: ABNT, 2014.

Associação Brasileira de Normas Técnicas. ISO/TR 20514:2008. Informática em Saúde - Registro Eletrônico de Saúde - Definição, Escopo e Contexto. Rio de Janeiro: ABNT, 2008a.

Associação Brasileira de Normas Técnicas. NBR - ISO/IEC 14598-6:2004. Information Technology - Software Engineering - Product Evaluation - Part 6: Documentation of Evaluation Modules. Rio de Janeiro: ABNT, 2010.

Associação Brasileira de Normas Técnicas. NBR - ISO/IEC 2500:2008. Engenharia de software - Requisitos e avaliação da qualidade de produtos de software (SQuaRe) - Guia do SQuaRe. Rio de Janeiro: ABNT, 2008c.

Associação Brasileira de Normas Técnicas. NBR - ISO/IEC 25030:2008. Software Engineering - Software product Quality Requirements and Evaluation (SQuaRE) - Quality Requirements. Rio de Janeiro: ABNT, 2008b.

Associação Brasileira de Normas Técnicas. NBR - ISO/IEC 9126-1:2001. Information Technology - Software Engineering - Product Quality - Part 1: Quality model. Rio de Janeiro: ABNT, 2003.

Associação Brasileira de Normas Técnicas. NBR ISO 18308: 2013. Informática em Saúde - Requisitos para uma Arquitetura de Registro Eletrônico de Saúde. Rio de Janeiro: ABNT, 2013. 
Associação Brasileira de Normas Técnicas. NBR ISO 31000: 2009. Gestão de riscos - Princípios e diretrizes. Rio de Janeiro: ABNT, 2009.

Brasil. Ministério da Saúde, Secretaria Executiva. Reforço à Reorganização do Sistema Único de Saúde - REFORSUS. Avaliação tecnológica em saúde: subsidiando a melhoria da qualidade e eficiência do SUS. Brasília (DF);1998.

Brasil. Ministério da Saúde. DECIT - Departamento de Ciência e Tecnologia, Secretaria de Ciência e Tecnologia e Insumos Estratégicos do Ministério da Saúde. Avaliação de Tecnologias em Saúde: institucionalização das ações no Ministério da Saúde. Informes Técnicos Institucionais. Revista de Saúde Pública vol.40 no.4 São Paulo Aug. 2006.

Brasil. Ministério da Saúde. Política Nacional de Genética Clinica - PORTARIA № 81, DE 20 DE JANEIRO DE 2009.

Chen, Cheng-Mei; Hsu, Chien-Yeh; Worley, James Andrew. Evaluation Systems of the Electronic Medical Records: A Comparative Study. IEEE 4th International Conference on Software Engineering and Service Science. Beijing, China, 2013. 558-64. IEEE. DOI 978-1-4673-5000-6/13.

Chillarege, Ram; Bhandari, Inderpal S.; Chaar, Jarir K.; Halliday, Michael J.; Moebus, Diane S.; Ray, Bonnie K.; Wong, Man-Yuen. Orthogonal Defect Classification - A Concept For In-Process Measurements. IBM Thomas J. Watson Research Center, 1992. Acessado em 20/11/2017. Disponível em: http://www.chillarege.com/articles/odc-concept.html

Conselho Federal de Medicina. Resolução - CFM no 1.639/2002. http://www.portalmedico.org.br/resolucoes/CFM/2002/1639_2002.pdf. Acessado em: 31/07/2014. (2002b). 
Conselho Federal de Medicina. Resolução CFM no 1.638/2002. http://www.portalmedico.org.br/resolucoes/CFM/2002/1638_2002.pdf. Acessado em: 14/12/2015. (2002a).

Conselho Federal de Medicina. Resolução CFM no 1.821/2007. http://www.portalmedico.org.br/resolucoes/CFM/2007/1821_2007.pdf. Acessado em: 11/11/2019.

Costa, Ivanir. Qualidade em tecnologia da informação: conceitos de qualidade nos processos, produtos, normas, modelos e testes de software no apoio às estratégias empresariais. São Paulo: Atlas, 2013.

Duarte, J. G.; Azevedo, R. S.. Electronic health record in the internal medicine clinic of a Brazilian university hospital: Expectations and satisfaction of physicians and patients. International Journal of Medical Informatics 102 (2017) 80-86.

Farkas, Edward B. A Guide to the Project Management Body of Knowledge (PMBOK GUIDE). Newton Square, PA: Project Management Institute, 2017.

Flores, Cecilia D.; Barros, Paulo; Cazella, Sílvio; Bez, Marta Rosecler. Leveraging the Learning Process in Health through Clinical Cases Simulator. IEEE 2nd International Conference on Serious Games and Applications for Health (SeGAH). Algarve, Portugal, 2013. IEEE. DOI: 10.1109/SeGAH.2013.6665303.

Friedman, Charles P.; Wyatt, Jeremy C. Evaluation of Biomedical and Health Information Resources. In Shortliffe, Edward H. e Cimino, James J. (Eds). Biomedical Informatics: Applications in Health Care and Biomedicine. 4a. Ed. London: Springer, 2014. DOI 10.1007/978-1-4471-4474-8_27 
Gil, Antonio de Loureiro; Arima, Carlos Hideo. Auditoria do Negócio com TI Gestão e Operação - São Paulo: Editora Saraiva, 2019.

Grady, Robert B., Caswell, Deborah L.. Software Metrics: Establishing a Company - Wide Program. New Jersey: Prentice-Hall, 1987.

Grady, Robert B.. Practical Software Metrics for Project Management and Process Improvement. Hewlett-Packard Professional Books. New Jersey: Prentice-Hall, 1992.

Horovitz, Dafne D. G.; Cardoso, Maria Helena C. de Almeida; Llerena Junior, Juan C.; Mattos, Ruben Araújo de. Atenção aos Defeitos Congênitos no Brasil: características do atendimento e propostas para formulação de políticas públicas em genética clínica. Cad. Saúde Pública vol.22 no.12 Rio de Janeiro Dec. 2006. ISSN 1678-4464. Consultado em: 04/03/2015. Disponível em: $\quad$ http://www.scielo.br/scielo.php?script=sci_arttext\&pid=S0102$311 \times 2006001200010$

Hutcheson, Marnie L. Software Testing Fundamentals: Methods and Metrics. Indianapolis: Wiley Publishing, Inc. 2003. pp 187.

IBM. Orthogonal Defect Classification v 5.2 for Software Design and Code. IBM Research, 2013. Acessado em: 20/11/2017. Disponível em: https://researcher.watson.ibm.com/researcher/files/us-pasanth/ODC-5-2.pdf

Instituto da Criança. Conheça o Instituto. Acessado em: 24/08/2017. http://icr.usp.br/interna.aspx?portalid=@LDJUPRN\&areaid=EJLHQJUK\&pagid= JNDKNQQL\&navid=-1\&menu\&navid=66\&menuid=48. (2017b).

Instituto da Criança. Unidades Médicas. Genética. http://www.icr.usp.br/INTERNA.ASPX?PORTALID=@LDIQLWN\&AREAID=EJG 
FNNUN\&PAGID=GLMCORUQ\&NAVID=-1\&MENUID=\&navid=67. Acessado em: 24/08/2017a. (2017a).

International Organization of Standardization/International Electrotechnical Commission. ISO/IEC 25010. Systems and software engineering - Systems and software Quality Requirements and Evaluation (SQuaRE) - System and software quality models. Switzerland, Genebra: International Organization for Standardization - ISO, 2011.

International Organization of Standardization/International Electrotechnical Commission. ISO/IEC 25040. System and Software Engineering - System and Software Quality Requiriments and Evaluation (SQuaRe) - Evaluation Process. Switzerland, Genebra: ISO, 2011.

Kim, Chong Ae; Bertola, Débora Romeo; Albano, Lilian Maria José. Genética na Prática Pediátrica - Coleção Pediatria do Instituto da Criança HC - FMUSP. São Paulo: Manole, 2010.

Likert, Rensis. A Technique for the Measurement of Attitudes. Archives of Psychology, 1932 - 140: 1-55.

Marin, Heimar de F.; Massad, Eduardo; Azevedo Neto, Raymundo S.. Prontuário Eletrônico do Paciente: Definições e Conceito. In Massad, Eduardo; Marin, Heimar de Fátima; Azevedo Neto, Raymundo S. (Eds). O Prontuário Eletrônico do Paciente na Assistência, Informação e Conhecimento Médico. São Paulo: FMUSP/UNIFESP/OPAS, 1-20, 2003.

Mcinnes, Roderick R. ; Nussbaum, Robert L.; Willard, Huntington F. Thompson \& Thompson Genética Médica. Rio de Janeiro: ELSEVIER, 2008.

Möller, K. H., Paulish, D. J.. Software Metrics A practitioner's guide to improved product development. London: Chapman \& Hall, 1993. 
Nguyen, Lemai; Bellucci, Emilia; Nguyen, Linh Thuy. Electronic health records implementation: An evaluation of information system impact and contingency factors. International Journal of Medical Informatics. 83 (2014) 779-796.

Novaes, Hillegonda Maria D. Da produção à avaliação de tecnologias dos sistemas de saúde: desafios do século XXI. Rev Saúde Pública, 2006; 40(N Esp): 133-40.

Novaes, Hillegonda Maria D. Avaliação de programas, serviços e tecnologias em saúde. Revista de Saúde Pública 2000; 34(5): 547-59.

Office of the National Coordinator for Health Information Technology. Survey says: EHR Incentive Program is on track. Health IT Buzz Blog. http://www.healthit.gov/buzz-blog/from-the-onc-desk/survey-ehr-incentiveprogram. Publicado em 17 de Janeiro de 2014. Acessado em: 26/10/2017.

Oliveira, Neurilene B.; Peres, Heloisa Helena C.. Avaliação do Desempenho Funcional e Qualidade Técnica de um Sistema de Documentação Eletrônica do Processo de Enfermagem. Revista Latino-Americana de Enfermagem. MarçoAbril, 2015.

Oliveira, Neurilene Batista de. Avaliação de qualidade do registro eletrônico do processo de enfermagem. Dissertação de Mestrado. Escola de Enfermagem da Universidade de São Paulo. São Paulo, 2012.

Pereira, Irene Mari; Fugulin, Fernanda Maria T.; Gaidzinski, Raquel R.. Metodologia de Avaliação do Software Dimensionamento Informatizado dos Profissionais de Enfermagem. Journal of Health Informatics- Dezembro, 2012. 4 (Número Especial - SIIENF 2012): 205-8.

Pereira, Irene Mari; Gaidzinski, Raquel R.; Fugulin, Fernanda Maria T.; Peres, Heloisa Helena C.; Lima, Antonio F. C.; Castilho, Valéria et al. Computerized 
Nursing Staffing: a Software Evaluation. Revista da Escola de Enfermagem da USP - vol.45 (no spe) São Paulo Dec. 2011. ISSN 0080-6234.

Pereira, Júlio Cesar R.. Análise de Dados Qualitativos: Estratégias Metodológicas para as Ciências da Saúde, Humanas e Sociais. São Paulo: EdUSP, 2001.

Pressman, Roger S.. Engenharia de Software. São Paulo: MacGraw-Hill, 2011. pp $213-486$.

Rangel, Alexandre L.; Évora, Yolanda Dora Martinez; Oliveira, Márcio Mattos Borges de. O Processo de Avaliação do Software de Geração Automática de Escala de Trabalho da Enfermagem e da Escala por ele Gerada. Journal of Health Informatics, 2012 - Dezembro; 4 (Número Especial - SIIENF 2012):2004.

Rudin, Robert S; Tang, Paul C.; and Bates, David W.. Health Information Technology Policy. In Shortliffe, Edward H. e Cimino, James J. (Eds). Biomedical Informatics: Applications in Health Care and Biomedicine. 4a. Ed. London: Springer, 2014. DOI 10.1007/978-1-4471-4474-8_27

Silva, Gustavo Bacelar; Correia, Ricardo Cruz. As Bases do OpenEHR. Editora: Porto, Portugal, 2015 DOI: 1013140.

Sociedade Brasileira de Informática em Saúde. Manual de Requisitos de Segurança, Conteúdo e Funcionalidades para Sistemas de Registro Eletrônico em Saúde (RES). Acessado em 31/07/2014. Disponível em: http://www.sbis.org.br/GTCERT_20040219_RT_V2.1.pdf

Sommerville, lan. Engenharia de Software. São Paulo: Pearson AddisonWesley, 2007. pp 530. 
Sperandio, DJ. A tecnologia computacional móvel na sistematização da assistência de enfermagem: avaliação de um software-protótipo. Escola de Enfermagem de Ribeirão Preto da Universidade de São Paulo; Ribeirão Preto: 2008. Acessado em 11/08/2015. Disponível em: http://www.teses.usp.br/teses/ disponiveis/22/22132/tde-11092008-165036/publico/

DirceleneJussaraSperandio.pdf

Thurston, Janet. Meaningful Use of Electronic Health Records, CNM, FNP - The Journal for Nurse Practitioners - JNP Volume 10, Issue 7, July/August, 2014.

Wazlawick, Raul Sidnei. Engenharia de Software - Conceitos e Práticas. Rio de Janeiro: Elsevier, 2013. pp 491.

Wilcox, Adam B.; Narus, Scott P.; Vawdrey, David K.. Software Engineering for Health Care and Biomedicine. In Shortliffe, Edward H. e Cimino, James J. (Eds). Biomedical Informatics: Applications in Health Care and Biomedicine. 4a. Ed. London: Springer, 2014. 185-210. DOI 10.1007/978-1-4471-4474-8_27. 